\title{
Standardization of Bariatric Metabolic Procedures: World Consensus Meeting Statement
}

\author{
Mohit Bhandari ${ }^{1}$ • M. A. L. Fobi ${ }^{1}$ • Jane N. Buchwald ${ }^{2}$ • \\ and the Bariatric Metabolic Surgery Standardization (BMSS) Working Group:
}

\begin{abstract}
Alaa Abbass, Barham K. Abu Dayyeh, Munir Alamo, Mohammed Al-Jarallah, Luigi Angrisani, Estuardo J. Behrens, Aparna G. Bhasker, Camilo Boza, Henry Buchwald, Jean-Marc Chevallier, Pradeep Chowbey, David E. Cummings, Jerome Dargent, Maurizio De Luca, Eric J. DeMaria, Aureo DePaula, John Dixon, Karin Dolezalova, Martin Fried, Michel Gagner, Manoel Galvao Neto, Ramen Goel, Jan W. Greve, Miguel F. Herrera, Jacques Himpens, Chih-Kun Huang, Nelson R. Huerta, Nicolae N. Iordache, Gurvinder S. Jammu, Kazunori Kasama, Rajesh Khullar, Shanu N. Kothari, Lilian Kow, Muffazal Lakdawala, Andriy S. Lavryk, Kamal Mahawar, Tarek Mahdy, Samer Mattar, John Melissas, Vinod Menon, Mohammed K. Mirza Gari, Mahendra Narwaria, Abdelrahman Nimeri, Paul E. O'Brien, Oral B. Ospanov, Arun Prasad, Aurora D. Pryor, Almino C. Ramos, Rui Ribeiro, Raul Rosenthal, Sergio Santoro, Nicola Scopinaro, Shelby Sullivan, Mohammad Talebpour, Jayasshree Todkar, Antonio Torres, Surendra Ugale, Rudolf A. Weiner, Alan C. Wittgrove, Natan Zundel
\end{abstract}

Published online: 11 July 2019

(C) The Author(s) 2019

\begin{abstract}
Background Standardization of the key measurements of a procedure's finished anatomic configuration strengthens surgical practice, research, and patient outcomes. A consensus meeting was organized to define standard versions of 25 bariatric metabolic procedures. Methods A panel of experts in bariatric metabolic surgery from multiple continents was invited to present technique descriptions and outcomes for 4 classic, or conventional, and 21 variant and emerging procedures. Expert panel and audience discussion was followed by electronic voting on proposed standard dimensions and volumes for each procedure's key anatomic alterations. Consensus was defined as $\geq 70 \%$ agreement.

Results The Bariatric Metabolic Surgery Standardization World Consensus Meeting (BMSS-WOCOM) was convened March 22-24, 2018, in New Delhi, India. Discussion confirmed heterogeneity in procedure measurements in the literature. A set of anatomic measurements to serve as the standard version of each procedure was proposed. After two voting rounds, 22/25 (88.0\%) configurations posed for consideration as procedure standards achieved voting consensus by the expert panel, 1 did not attain consensus, and 2 were not voted on. All configurations were voted on by $\geq 50 \%$ of 50 expert panelists. The Consensus Statement was developed from scientific evidence collated from presenters' slides and a separate literature review, meeting video, and transcripts. Review and input was provided by consensus panel members.

Conclusions Standard versions of the finished anatomic configurations of 22 surgical procedures were established by expert consensus. The BMSS process was undertaken as a first step in developing evidence-based standard bariatric metabolic surgical procedures with the aim of improving consistency in surgery, data collection, comparison of procedures, and outcome reporting.
\end{abstract}

March 22-24, 2018, World Consensus Meeting on Standardization of Bariatric Metabolic Procedures, Taj Mahal Hotel, New Delhi, India

Mohit Bhandari

drmohitbhandari@gmail.com
2 Division of Scientific Research Writing, Medwrite Medical Communications, Maiden Rock, WI, USA

1 Department of Surgery, Sri Aurobindo Medical College and Postgraduate Institution, Mohak Bariatric and Robotic Surgery Centre, Indore, MP, India 
Keywords Bariatric surgery $\cdot$ Metabolic surgery $\cdot$ Standardization $\cdot$ Surgical technique $\cdot$ Anatomic $\cdot$ Gastric bypass $\cdot$ Sleeve gastrectomy $\cdot$ Type 2 diabetes

\section{Introduction}

The work of the scientist is essentially to measure. -A. Szent-Györgyi, 1937 Nobel Prize in Physiology or Medicine

We are metabolic surgeons working in an era of evidencebased medicine. As physicians, we must perform the exact technical procedure we agreed to perform for each patient; as surgical scientists, we must report a consistent technique in the international research literature to facilitate reproducibility and comparison of results. Establishing agreed standard measurements for the primary anatomic alterations performed in an operation ensures a level of scientific uniformity that strengthens surgical practice, research, and patient outcomes.

While the historic procedure of a surgical innovator is honored, and a surgical mentor's unique approach admired, neither technique is sacrosanct. The best technique is the most effective and safe approach at a given time. It can only be learned from the evidence of formal research, which depends on collection of precise, reliable data. Bariatric metabolic procedures are complex and, thus, especially require that exact intraoperative measurements of the final anatomic configurations be agreed upon and consistently employed. In the absence of uniform measurements, or use of those taken on different versions of a procedure, verifiable data cannot be collected, nor accurate results aggregated and refined through systematic review and meta-analysis [1]. The result is a weakening of the quality and utility of the evidence base that impairs our ability to improve patient care.

In working toward consistency, every aspect of a surgical procedure cannot, and likely should not, be standardized and will vary by a surgeon's clinical experience and resources. There will be differences in the choice of sutures, staples, reinforcement of staple lines, methods of hemostasis (e.g., sutures, clips, electrocautery, glue), use of drains and nasogastric tubes, and techniques of port insertion and retraction. While these variables may affect the incidence of complications, typically, they do not directly alter a procedure's lasting metabolic effectiveness. The primary characteristics of procedures most likely to influence bariatric metabolic outcomes are the dimensions and volumes of the final anatomy created (e.g., limb lengths, orifice outlets). It was in order to provide our profession with these important standard measurements of anatomic dimensions and volumes that the Bariatric Metabolic Surgery Standardization World Consensus Meeting (BMSS-WOCOM) was organized.

The aim of the BMSS meeting was to begin an important conversation about how to harmonize disparate versions of bariatric metabolic procedures toward a single standard version of each. This Statement is an independent report that reflects experienced, expert surgeon consensus on the key technical aspects of bariatric metabolic procedures based on knowledge available in the field. The longer-term aim of the BMSS Working Group is to attain widespread adoption of the consensus-based measurements so that new procedure data may be compiled using harmonized standards. In time, application of the standards will improve accuracy and comparability of outcomes across the evidence base.

\section{Metabolic and Bariatric Surgery}

Metabolic surgery was first formally defined by Drs. Buchwald and Varco in their 1978 book, Metabolic Surgery, as the "operative manipulation of a normal organ or organ system to achieve a biological result for a potential health gain" [2]. Examples of metabolic surgery date at least to the early 1900s and include reduction of breast cancer metastases by removal of normal ovaries, splenectomy to treat idiopathic thrombocytopenia purpura, pancreas transplant for type 1 diabetes, partial ileal bypass for hyperlipidemia, and resection of sections of normal stomach and division of vagus nerve branches to cure gastric ulcer disease. Today, bariatric surgery is the standard bearer for metabolic surgery. Recent metabolic procedures include duodenal stimulation for type 2 diabetes mellitus (T2DM), electronic vagal nerve stimulation for T2DM, carotid body procedures directed at hypertension, and treatment of epilepsy by central nervous system stimulation [3]. Metabolic surgery seeks to recognize impaired, often weight-independent, regulatory mechanisms within the neurohormonal network and microbiome and treat them with actions on, or reconfigurations of, essentially normal organs.

Bariatric surgery, the most extensively developed application of metabolic surgery, has evolved continuously in response to the escalating prevalence and social and economic burden of obesity and the metabolic syndrome $[4,5]$. In 2015, a total of 603.7 million adults and 107.7 million children were obese in the world [6]. Obesity is both a serious disease and a symptom of other metabolic diseases and one of the top 3 health burdens created by human beings after smoking and violence [5]. More than 50 distinct operations have been implemented by bariatric surgeons to manage the critical global threat of obesity and the metabolic syndrome [3, 7]. By recent count, 579,517 bariatric metabolic operations and 14,725 endoluminal procedures are performed annually worldwide [8]. These operations reduce body weight and improve or resolve a wide range of comorbid diseases. Currently, bariatric surgery is the only effective, safe, and durable therapeutic option for most patients with obesity [9-11]. In addition, bariatric surgery research has produced a vast body of scientific evidence that is revealing consequential insights into metabolic diseases. 
There is no single operation appropriate to the treatment of all patients in bariatric surgery - the diversity of procedures characterizes the imagination of its practitioners and vitality of the discipline. Four primary procedures have passed the twin tests of time and trial, remaining in currency for $>10$, and in some cases, 30 years. In order of current global use, they are as follows: sleeve gastrectomy (SG, 45.9\%), Roux-en-Y gastric bypass (RYGBP, 39.6\%), laparoscopic adjustable gastric banding (LAGB, 7.4\%), and biliopancreatic diversion/ duodenal switch (BPD/DS, 1.1\%) [8], each of which is associated with long-term, high evidence level and observational evidence. These operations have inspired numerous variants, endoluminal procedures, and emerging or novel techniques currently only associated with short-term evidence.

\section{Consensus Focus}

The 1991 National Institutes of Health (NIH) Consensus Development Conference Panel broad guidelines for the use of bariatric surgery [12] were the initial consensus milestone in the field. In 1997, obesity was recognized as an epidemic by the World Health Organization (WHO) [13] but only acknowledged as a disease by consensus resolution 16 years later, in 2013, by the American Medical Association (AMA) [14]. The publication of this landmark AMA declaration in medicine not only distinguished obesity as a medical illness with genetic and epigenetic origins, but as a constellation of metabolically related diseases including heart, renal, and gall bladder disease; type 2 diabetes; dyslipidemias; nonalcoholic steatohepatitis; sleep apnea; infertility; and cancers. At least 31 consensus statements from multiple countries that relate to treatment of diseases comorbid with obesity have been issued, featuring topics such as indications for bariatric metabolic surgery, bariatric endoscopy, robotic bariatric surgery, bariatric nutrition, childhood obesity, and quality of life. Consensus statements and guidelines for individual bariatric procedures have been published by independent surgical working groups [15-20], country-specific consensus alliances [21, 22], and professional surgical societies, e.g., the International Federation for the Surgery of Obesity and Metabolic Disorders (IFSO) [23], the American Society for Metabolic and Bariatric Surgery (ASMBS) [24], and the European Association for Endoscopic Surgery (EAES) [25], often in conjunction with nonsurgical societies.

\section{Consensus Meeting and Statement}

Observational and high-quality (levels 1-2 [26]) evidence comparing procedures is available for established bariatric operations proven safe and effective in many hands over the long term; however, these operations remain unstandardized in terms of their application and reporting. Guidance documents suggest best practices for the sequence of operative techniques involved in performing a bariatric procedure, yet no professional organization or field journal has issued a set of standard requirements for reporting the final anatomic configuration of a named procedure. Most new procedures are not yet associated with any high-quality evidence, and some lack a body of observational study evidence. Thus, by defining the set of key measurements that identify a procedure's finished anatomic configuration, precision can be added that will improve procedure safety, weight-loss efficacy, and our understanding of the metabolic changes induced surgically.

The BMSS meeting was conceived to review this gap in procedure definition and produce a preliminary consensus of uniform procedure standard definitions. This work is offered as a potential aid to further precision in reporting research on the procedures, and also as an encouragement to uniform collection of much-needed additional research data on the emerging procedures. To our knowledge, this Consensus Statement of the BMSS Working Group provides the first set of expert opinion-based standards to define the anatomic alterations performed in the majority of currently available bariatric metabolic procedures. Anatomic measurement standards were delineated for 25 procedures, including SG and 10 variants, RYGBP and 4 variants, the AGB, BPD and its DS variant, and 6 additional emerging procedures.

The recommendations for standardization of the procedures described in this statement do not constitute scientific approval, endorsement, or confirmation by professional surgical organizations of the safety and efficacy of the procedures. Of the procedures reviewed, only the SG, RYGBP, LAGB, and BPD/DS are currently endorsed by both IFSO and ASMBS. Guidelines for use of a procedure are established by each country in which the procedure is performed. This statement was not designed to approve, disapprove, or advocate any procedures, nor to set standard practice, nor to be a position paper or guidelines document.

\section{Methods}

\section{Meeting Design and Voting Process}

In preparation for the meeting, the chairmen (Drs. Bhandari and Fobi) conferred with international expert surgeons to characterize the final anatomic composition of each of the 25 bariatric metabolic procedures under consideration. The organizing committee in Indore, India, prepared a set of artistic drawings depicting the standard configurations for proposal to participants at the meeting. Use of uniform line and color in the illustrations imbued the basic GI anatomy with a standardized appearance on which the unique elements of each configuration were drawn. 
A consensus panel of expert bariatric metabolic surgeons and several bariatric endocrinologists and primary medicine researchers from multiple continents was invited to present technique descriptions and outcomes for the 4 historic/ conventional and 21 current variant and emerging procedures. The consensus expert panel was comprised of procedure innovators, renowned proponents of procedures, and bariatric metabolic surgery subject experts drawn from representative geographic areas. All national bariatric society presidents were invited, and those that attended were included in the expert voting panel. Most panel members serve on the editorial boards of peer-reviewed journals. A second voting group, comprised of bariatric metabolic surgeon attendees, was also invited in order to discern whether their responses differed from those of the expert panel.

The expert presenters were instructed to prepare presentations describing a designated procedure's origin and outcomes based on current scientific evidence and observations from their extensive procedure series and clinical experience. Presenters were asked to conclude their presentations with the proposed configuration of the finalized procedure anatomy for consideration as the standard version. A different consensus panel discussant was appointed to comment on and challenge each presentation. Comment and debate by audience members was to follow, culminating in an anonymous electronic vote taken serially by the two groups separately.

All participants were instructed to vote "yes" to agree and "no" to disagree as to whether the dimensions and volumes depicted in the anatomic drawing of the procedure displayed on the meeting screen should constitute the standardized, replicable characteristics of the operation. Voting agreement using a binary definition of consensus vs no consensus was reported for each configuration. The threshold for consensus was set at $\geq 70 \%$ agreement ("yes" votes). There was no designation of "levels" of consensus.

\section{Consensus Phases}

Two voting phases were scheduled within the two meeting days. A first vote and consensus tally was scheduled immediately following each expert panelist's presentation, discussant comments, and discussion interaction with attendees. After each vote, the distribution of the group's electronically submitted yes/no responses was to be immediately visible to panelists and attendees on the meeting screen. The second consensus voting phase was scheduled in the final session of the meeting to address issues associated with procedure standards, and reconsider configurations that had not attained consensus in the first vote. Participants were asked to vote on every proposed configuration during the first and second voting. In the second voting phase, only the vote of the expert panel was called and registered.

\section{Manuscript Development}

The Consensus Statement was developed from the proceedings of the meeting recorded in presenters' slides, meeting video, and meeting transcripts. The aim of the current study was to introduce, not statistically or clinically assess, each of the 25 procedures; thus, a systematic review of the literature for each operation was not undertaken. However, a structured comprehensive search, retrieval, and review of the scientific literature for every procedure under study was performed. Evidence was summarized to offer salient background and recent outcomes for each procedure using RCTs, systematic reviews, and meta-analyses, where available. Emphasis was placed on providing a fair balance of outcome data, particularly because evidence for many emerging procedures is lacking at this time and procedure comparison and judgment were not the study objectives. The BMSS Consensus Statement draft manuscript was submitted to panel members for review and eventual approval for peer-review submission.

\section{Statistical Analysis}

Voting group and consensus-level data were summarized using basic descriptive statistics (simple counts and percentages).

\section{Results}

\section{Procedure Consensus Outcomes}

For a given vote on a standard configuration, the total number of voters present in the meeting ranged from 30 to 60 in group A and 15 to 40 in group B, with some attendees abstaining from specific voting rounds. Summarized tallies reflect the percentage of attendees who voted on a given standard. The final number of anatomic configurations that attained expert panel consensus as the standardized version of a procedure was $22 / 25$ $(88.0 \%)$. Table 1 displays the outcomes for proposed procedure standards and indicates the figures that depict their agreed anatomic dimensions.

During the second voting phase, 13/25 procedure configurations that did not achieve consensus in the first phase were reconsidered in focused discussion followed by a revote. The floor was open to all participants to review in detail the anatomic dimensions and volumes of procedures in question. Debate produced slightly altered configuration specifications for several procedures, on which the second vote was taken. Voting consensus on 10 of the 13 outstanding configurations was achieved (finalized anatomic dimensions shown in Figs. $1,5,6,7,8,9,10,11$, and 12), and 8 of these configurations 
Table 1 Consensus outcomes of voting for standardized anatomic procedure configurations. Group A: Experienced bariatric surgeon attendee voters; Group B: Expert bariatric surgical consensus panel voters

\begin{tabular}{|c|c|c|c|c|c|c|c|}
\hline \multirow{2}{*}{$\begin{array}{l}\text { Figure no. depicting } \\
\text { anatomic } \\
\text { configuration }\end{array}$} & \multirow{2}{*}{ Procedure } & \multirow{2}{*}{$\begin{array}{l}\text { Voting } \\
\text { group }\end{array}$} & \multicolumn{2}{|c|}{ Vote $1(\%)$} & \multicolumn{2}{|c|}{ Vote $2(\%)$} & \multirow{2}{*}{$\begin{array}{l}\text { Final } \\
\text { consensus } \\
(\text { yes } \geq 70 \% \text { ) }\end{array}$} \\
\hline & & & Yes & $\begin{array}{l}\text { Consensus } \\
(\sqrt{ } \geq 70 \%)\end{array}$ & Yes & $\begin{array}{l}\text { Consensus } \\
(\sqrt{ } \geq 70 \%)\end{array}$ & \\
\hline
\end{tabular}

Sleeve gastrectomy and variants

\begin{tabular}{|c|c|c|c|c|c|c|c|}
\hline \multirow[t]{2}{*}{1} & \multirow[t]{2}{*}{ Standard sleeve gastrectomy (SG) } & A & \multicolumn{4}{|c|}{$71.7 \sqrt{ }$} & \multirow{2}{*}{$\begin{array}{l}\text { Yes } \\
\text { Yes }\end{array}$} \\
\hline & & B & 59.0 & No & 70.2 & $\sqrt{ }$ & \\
\hline \multirow[t]{2}{*}{2} & \multirow[t]{2}{*}{ Banded sleeve gastrectomy (BSG) } & A & 80.0 & $\sqrt{ }$ & & & Yes \\
\hline & & B & 92.9 & $\sqrt{ }$ & & & Yes \\
\hline \multirow[t]{2}{*}{3} & \multirow{2}{*}{$\begin{array}{l}\text { Sleeve gastrectomy with } \\
\text { jejunojejunostomy/enteral bypass } \\
\text { (SG-JJEB) }\end{array}$} & A & 65.9 & No & & & No \\
\hline & & B & 70.0 & $\sqrt{ }$ & & & Yes \\
\hline \multirow[t]{2}{*}{4} & \multirow{2}{*}{$\begin{array}{l}\text { Single-anastomosis duodenoileal bypass with } \\
\text { sleeve gastrectomy (SAD-I) }\end{array}$} & A & 80.0 & $\sqrt{ }$ & & & Yes \\
\hline & & B & 84.1 & $\sqrt{ }$ & & & Yes \\
\hline \multirow[t]{2}{*}{5} & \multirow{2}{*}{$\begin{array}{l}\text { Sleeve gastrectomy with jejunoileostomy } \\
\text { anastomosis (SG-JIA) }\end{array}$} & A & 58.2 & No & & & No \\
\hline & & B & 69.2 & No & 85.7 & $\sqrt{ }$ & Yes \\
\hline \multirow[t]{2}{*}{6} & \multirow{2}{*}{$\begin{array}{l}\text { Sleeve gastrectomy with duodenojejunal } \\
\text { bypass (SG-DJB) }\end{array}$} & A & 69.2 & No & & & No \\
\hline & & B & 59.4 & No & 79.6 & $\sqrt{ }$ & Yes \\
\hline \multirow[t]{2}{*}{7} & \multirow{2}{*}{$\begin{array}{l}\text { Sleeve gastrectomy with loop duodenojejunal } \\
\text { bypass (SG-LDJB) }\end{array}$} & A & 82.9 & $\sqrt{ }$ & & & Yes \\
\hline & & B & 69.0 & No & 84.2 & $\sqrt{ }$ & Yes \\
\hline \multirow[t]{2}{*}{8} & \multirow{2}{*}{$\begin{array}{l}\text { Sleeve gastrectomy with transit bipartition } \\
\text { (SG-TB) }\end{array}$} & A & 68.0 & No & & & No \\
\hline & & B & 41.0 & No & 78.7 & $\sqrt{ }$ & Yes \\
\hline \multirow[t]{2}{*}{9} & \multirow{2}{*}{$\begin{array}{l}\text { Sleeve gastrectomy with jejunoileal } \\
\text { interposition (SG-JII) and duodenal ileal in- } \\
\text { terposition (SG-DII) }\end{array}$} & A & 79.2 & $\sqrt{ }$ & & & Yes \\
\hline & & B & 59.3 & No & 71.4 & $\sqrt{ }$ & Yes \\
\hline \multirow[t]{2}{*}{10} & \multirow{2}{*}{$\begin{array}{l}\text { Single-anastomosis sleeve with ileal bypass } \\
\text { (SASI) }\end{array}$} & $\mathrm{A}$ & 65.9 & No & & & No \\
\hline & & B & 51.6 & No & 77.8 & $\sqrt{ }$ & Yes \\
\hline \multirow[t]{2}{*}{11} & \multirow[t]{2}{*}{ Endoscopic sleeve gastroplasty (E-SG) } & A & 63.6 & No & & & No \\
\hline & & $\mathrm{B}$ & 64.0 & No & 79.1 & $\sqrt{ }$ & Yes \\
\hline
\end{tabular}

Roux-en-Y gastric bypass and variants
Roux-en-Y gastric bypass (RYGBP)

13

Banded gastric bypass (BGBP)

$\begin{array}{lll}\text { A } & 62.5 & \text { N } \\ \text { B } & 37.5 & \text { N } \\ \text { A } & 82.0 & \sqrt{ } \\ \text { B } & 82.0 & \sqrt{ }\end{array}$

.

Yes

14 One-anastomosis gastric bypass or mini gastric $A$ bypass (OAGB/MGB)

15 Diverted one-anastomosis gastric bypass or mini gastric bypass (D-OAGB/D-MGB)

$\begin{array}{lll}\text { A } & 75.8 & \sqrt{ } \\ \text { B } & 72.0 & \sqrt{ } \\ \text { A } & 38.9 & \text { No } \\ \text { B } & 36.8 \text { No }\end{array}$

16

$\begin{array}{llll}\text { Single-anastomosis gastroileal bypass (SAG-I) } & \text { A } & 59.3 & \text { No } \\ & \text { B } & 46.9 & \text { No }\end{array}$

B $\quad 46.9$ No

Laparoscopic adjustable band

$17 \quad$ Laparoscopic adjustable gastric band (LAGB)

$\begin{array}{lrll}\text { A } & 87.5 & V & \text { Yes } \\ \text { B } & 93.5 & V & \text { Yes }\end{array}$

Biliopancreatic diversion and variant

\begin{tabular}{|c|c|c|c|}
\hline \multirow[t]{2}{*}{18} & \multirow[t]{2}{*}{ Biliopancreatic diversion (BPD) } & $81.6 \sqrt{ }$ & Yes \\
\hline & & $81.3 \sqrt{ }$ & Yes \\
\hline \multirow[t]{2}{*}{19} & \multirow{2}{*}{$\begin{array}{l}\text { Biliopancreatic diversion with duodenal switch } \\
\text { (BPD/DS) }\end{array}$} & $86.1 \sqrt{ }$ & Yes \\
\hline & & $85.0 \sqrt{ }$ & Yes \\
\hline
\end{tabular}


Table 1 (continued)

\begin{tabular}{|c|c|c|c|c|c|c|c|}
\hline \multirow{2}{*}{$\begin{array}{l}\text { Figure no. depicting } \\
\text { anatomic } \\
\text { configuration }\end{array}$} & \multirow{2}{*}{ Procedure } & \multirow{2}{*}{$\begin{array}{l}\text { Voting } \\
\text { group }\end{array}$} & \multicolumn{2}{|c|}{ Vote $1(\%)$} & \multicolumn{2}{|c|}{ Vote $2(\%)$} & \multirow{2}{*}{$\begin{array}{l}\text { Final } \\
\text { consensus } \\
(\text { yes } \geq 70 \%)\end{array}$} \\
\hline & & & Yes & $\begin{array}{l}\text { Consensus } \\
(\sqrt{ } \geq 70 \%)\end{array}$ & Yes & $\begin{array}{l}\text { Consensus } \\
(\sqrt{ } \geq 70 \%)\end{array}$ & \\
\hline \multicolumn{8}{|c|}{ Emerging and experimental procedures/techniques } \\
\hline \multirow[t]{2}{*}{20} & \multirow[t]{2}{*}{ Intragastric balloon (IGB) } & A & 79.4 & $\sqrt{ }$ & & & Yes \\
\hline & & B & 85.7 & $\sqrt{ }$ & & & Yes \\
\hline \multirow[t]{2}{*}{21} & \multirow[t]{2}{*}{ vBloc } & A & 80.0 & $\sqrt{ }$ & & & Yes \\
\hline & & B & 86.7 & $\sqrt{ }$ & & & Yes \\
\hline \multirow[t]{2}{*}{22} & \multirow[t]{2}{*}{ Gastric plication (GP) } & A & 71.4 & $\sqrt{ }$ & & & Yes \\
\hline & & B & 73.3 & $\sqrt{ }$ & & & Yes \\
\hline \multirow[t]{2}{*}{23} & \multirow[t]{2}{*}{ Adjustable banded gastric plication (BGP) } & A & 65.2 & No & & & No \\
\hline & & B & 57.7 & No & 61.4 & & No \\
\hline \multirow[t]{2}{*}{24} & \multirow[t]{2}{*}{ EndoBarrier } & A & 69.0 & No & & & No \\
\hline & & B & 62.5 & No & 100.0 & $\sqrt{ }$ & Yes \\
\hline \multirow[t]{2}{*}{25} & \multirow[t]{2}{*}{ AspireAssist } & A & 71.0 & $\sqrt{ }$ & & & Yes \\
\hline & & B & 82.9 & $\sqrt{ }$ & & & Yes \\
\hline
\end{tabular}

were revised. Procedures that involve devices (Figs. 17, 20, 21,24 , and 25) are not accompanied by configuration measurements taken by the surgeon; rather, their use is standardized by reference to the manufacturer's instructions for use (IFU).

It was agreed that there were two types of SGs, one standalone, mainly restrictive, and the other, an SG combined with a hypoabsorptive component. The standalone SG uses a 32-40 Fr bougie to size. The sleeve is transected $1-2 \mathrm{~cm}$ from the GE angle. Antrectomy is completed 2-
$6 \mathrm{~cm}$ from the pylorus (i.e., sleeve gastrectomy with duodenojejunal bypass [SG-DJB], sleeve gastrectomy with loop duodenojejunal bypass [SG-LDJB], and sleeve gastrectomy with jejunoileal interposition and duodenal ileal interposition [SG-II-DII], with an estimated volume of 75$150 \mathrm{cc}$ ). Other SGs with a hypoabsorptive component use a 50-60 Fr bougie for sizing. The sleeve is transected 3$4 \mathrm{~cm}$ from the GE angle. Antrectomy is completed 2$6 \mathrm{~cm}$ from the pylorus (i.e., BPD-DS, SAD-I, singleanastomosis sleeve with ileal bypass [SASI], sleeve

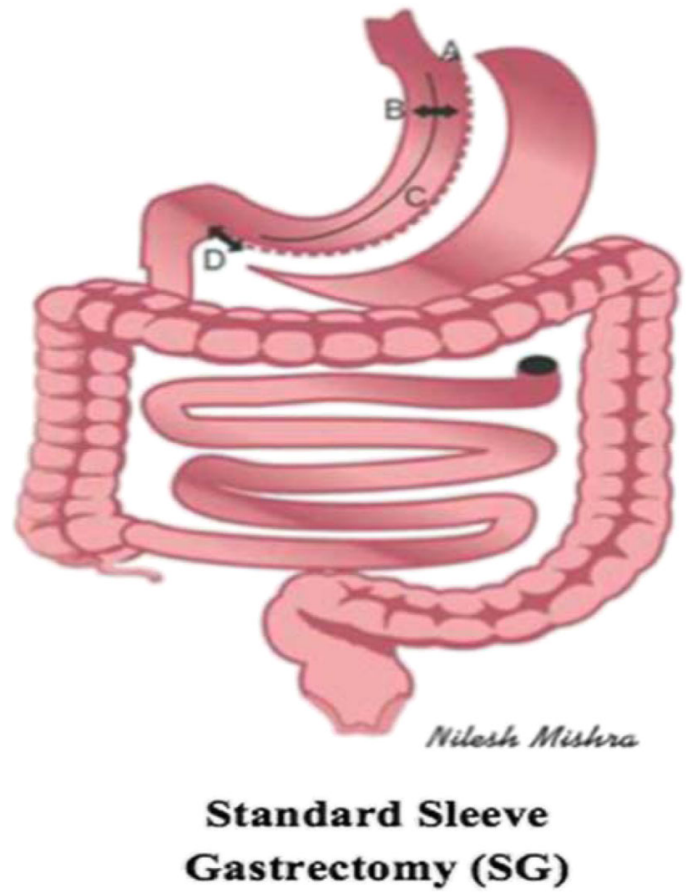
$\mathrm{A}=1-2 \mathrm{~cm}$
Distance of sleeve transection from esophagogastric junction
$\mathrm{B}=2.5-3 \mathrm{~cm} \quad$ Use $32-40 \mathrm{Fr}$ bougie to size sleeve width
$\mathrm{C}=\mathrm{As}$ is Length of the sleeve
$\mathrm{D}=2-6 \mathrm{~cm}$ Antrectomy distance from the pylorus
$\mathrm{V}=75-150 \mathrm{cc}$ Volume of sleeve

Fig. 1 Standard sleeve gastrectomy (SG) 
gastrectomy with transit bipartition [SG-TB], sleeve gastrectomy with jejunojejunostomy/enteral bypass [SGJJEB], and sleeve gastrectomy with jejunoileostomy anastomosis [SG-JIA], with an estimated volume of 150 $250 \mathrm{cc})$.

In the second voting, as in the first, the adjustable banded gastric plication (BGP) did not achieve consensus standardization. Due to disagreement about the composition of the anatomic configuration and its similarity to another procedure being voted on, two additional proposed procedure standards that did not achieve consensus on the first vote (the single-anastomosis gastroileal bypass [SAG-I] and the diverted one-anastomosis gastric bypass, or mini gastric bypass [D-OAGB/D-MGB]) were invalidated as candidates for revoting in phase 2 due to insufficient and/ or conflicting information.

\section{Procedure Background Summaries}

The following overviews of procedure origins and outcomes are presented solely as background: the meeting's actual results are strictly those that address the targeted aims, shown in the table and figures that detail the standardization voting outcomes. Inclusion and discussion of emerging procedures in this review, and voting on their standard end-procedure anatomic configurations, does not constitute a scientific validation or approval of that procedure.

\section{Standard Sleeve Gastrectomy (Fig. 1)—First of the Four Conventional Procedures Described}

Origin, Advantages Laparoscopic sleeve gastrectomy was initially introduced as the first step of both a BPD/DS and later an RYGBP, popularized as a standalone procedure by Gagner et al. in the early 2000s [19, 27]. Currently, it is the most performed bariatric procedure worldwide (45.9\%) [8]. The technical straightforwardness (not simplicity) of SG combined with its safety and very good short- and long-term outcomes compared with RYGBP is primarily responsible for its rapid attainment of popularity [28].

Indications/Contraindications, Weight Loss, Diabetes Resolution Indications for SG include patients considered at high risk, including morbidly obese patients with metabolic syndrome, liver and kidney transplant patients, and patients with BMI $30-35 \mathrm{~kg} / \mathrm{m}^{2}$ with comorbidities [29]. Primary relative contraindications are the presence of severe gastroesophageal reflux disease (GERD) and/or Barrett's esophagus and hiatal hernias $[19,30]$. In a 2017 systematic review, weight loss with SG at the 5-year point (20 included studies, $n=$ 1626 at 5 years) was $58.4 \%$ [31]. For patients with T2DM, $\mathrm{SG}$ is an effective long-term metabolic surgery. Five-year outcomes for 402 T2DM patients reported in a 2016 systematic review (11 included studies, $n=1354$ ) showed T2DM resolved in $60.8 \%$, mean fasting plasma glucose (FPG) levels

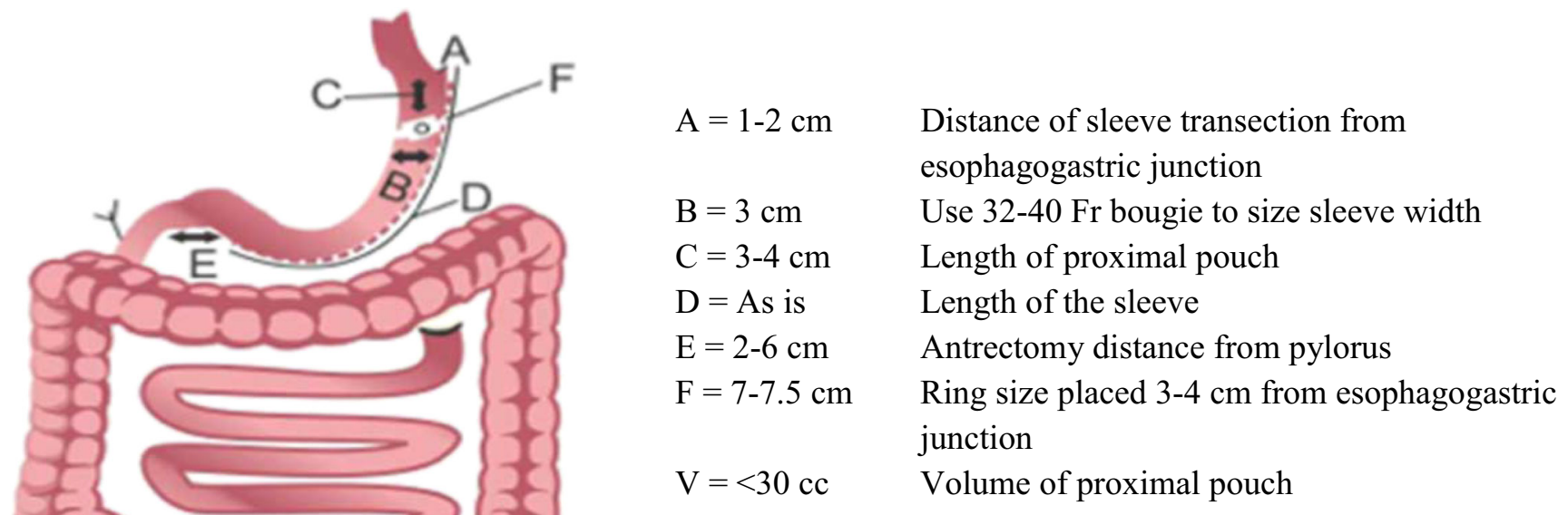

Wilests Misho

\section{Banded Sleeve Gastrectomy (BSG)}

Fig. 2 Banded sleeve gastrectomy (BSG) 
and $\mathrm{HbA}_{1 \mathrm{C}}$ values decreased from 170.3 to $112.0 \mathrm{mg} / \mathrm{dL}$ and 8.3 to $6.7 \%$, respectively [32].

Perioperative Mortality/Morbidity, Postoperative Complications, Reversal/Revision In a study comparing 25 hospitals and 62 bariatric surgeons, the incidence of lifethreatening perioperative morbidity with SG was $2.2 \%(95 \%$ CI, 1.2-3.2), with $0.0 \%$ mortality [33]. In a consensus study, in the short term, stricture or stenosis was the complication seen most frequently (mean $2.1 \pm 8.4 \%$, range $0-76$ ), and leak was the complication associated with the greatest mortality (mean 2.4 $\pm 7.6 \%$, range 1-54) [19]. In the long term, intractable GERD is the main complication [34], most commonly treated with proton pump inhibitors after ruling out a mechanical obstruction, and an emerging incidence of de novo Barrett's esophagus. Depending on the nature of its failure, SG can be converted, revised, or used in a staged procedure. If severe symptoms of aspiration (e.g., night cough, recurrent pneumonias) persist, RYGBP is the favored procedure for conversion [35]. In a consensus study, mean conversion rate was $4.7 \pm 8.3 \%$ (range $0-50$ ) [19].

\section{Banded Sleeve Gastrectomy (Fig. 2)}

Origin, Advantages Banding of the SG was initially reported in 2009-2011 by Karcz et al., Agrawal et al., and Alexander et al. as a response to medium-term issues with weight regain in SG [36-38]. In a study of long-term outcomes representative of many SG reports, mean percentage excess weight loss (EWL) of $72.8 \%$ at 3 years dropped to $57.3 \%$ at $\geq 6$-year follow-up [39]. De novo, likely multifactorial weight regain and GERD often become significant problems with SG between postoperative years 3 and $6[39,40]$. The sleeve reservoir has been shown to dilate with time [41], in one study, necessitating revision of $88 / 937$ patients at $\geq 6$-year follow-up [42]. Some studies also demonstrate that weight regain is accompanied by recurrence of comorbidities [43]. The effect of banding the sleeve in banded sleeve gastrectomy (BSG) occurs after the second year, when the reservoir typically expands. As shown radiologically, when a ring or band is added loosely around the sleeve, reservoir size appears to stabilize, maintaining restriction and providing a sense of satiety that aids in weight-loss maintenance [44].

Indications/Contraindications, Weight Loss, Diabetes Resolution BSG is indicated for obese patients with clear contraindications against RYGBP or BPD and for those on medication who need reliable intestinal resorption [36]. In a comparative long-term study of SG $(n=51)$ and BSG $(n=96)$ in obese and super-obese patients, EWL increased at each point through longer-term follow-up from $77.4 \%$ at year 1 to $86.7 \%$ EWL at 5 years. No weight regain was seen in $>97 \%$ of the BSG group vs $80 \%$ of the SG group, and the SG group had < $50 \%$ weight loss in $35.2 \%$ of patients at 5 -year follow-up [45].

Operative Mortality/Morbidity, Postoperative Complications, Reversal/Revision Complications include band erosion, typically directly related to contamination or infection, kinking or slippage, and solid food intolerance. Regurgitation was significantly higher in the BSG vs SG group at 3-year follow-up [46]. Complications of band erosion are treated by outpatient endoscopic band removal, as with the banded gastric bypass

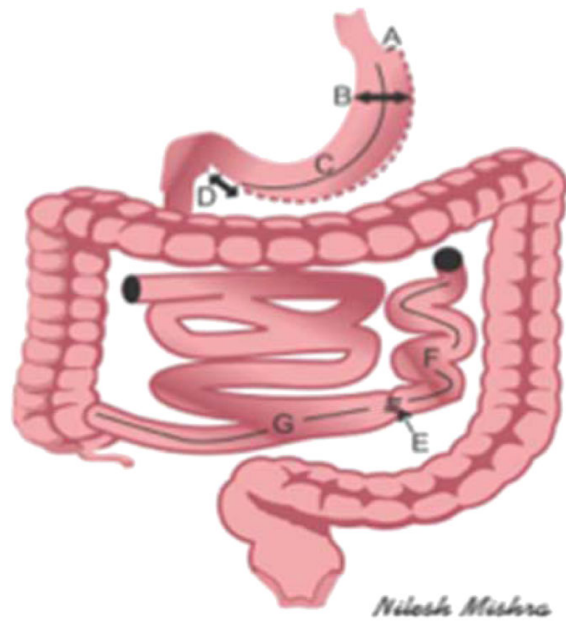

\section{Sleeve Gastrectomy with Jejuno- Jejunostomy/Enteral Bypass (SG-JJEB)}

Fig. 3 Sleeve gastrectomy with jejunojejunostomy/enteral bypass (SG-JJEB)

\author{
$\mathrm{A}=2-3 \mathrm{~cm}$ \\ $\mathrm{B}=3-4 \mathrm{~cm}$ \\ $\mathrm{C}=\mathrm{As}$ is \\ $\mathrm{D}=2-6 \mathrm{~cm}$ \\ $\mathrm{E}=3 \mathrm{~cm}$ \\ $\mathrm{F}=100 \mathrm{~cm}$ \\ $\mathrm{G}=200 \mathrm{~cm}$ \\ $\mathrm{V}=150-250 \mathrm{cc}$ \\ Distance of sleeve transection from esophagogastric \\ junction \\ Use approx. 50-60 Fr bougie to size sleeve width \\ Length of the sleeve \\ Antrectomy distance from pylorus \\ Jejuno-ileal anastomosis \\ Length of jejunal limb \\ Length of ileal limb \\ Volume of sleeve (approx.)
}


(BGBP). Solid food intolerance is treated by either band/ring removal or revision to RYGBP. As with BGBP, the absence of an FDA-approved ring device has limited the use of the operation in the USA.

\section{Sleeve Gastrectomy with Jejunojejunostomy/Enteral Bypass} (Fig. 3)

Origin, Advantages The SG-JJEB is an emerging operation first described by Alamo et al. in 2006 [47] and advanced by de Menezes Ettinger and colleagues [48]. Described by Alamo, in 2018, approximately 2000 cases have been performed worldwide. SG-JJEB is technically more straightforward than RYGBP. Patients benefit from restriction and ghrelin secretion reduction resulting from the SG element and the hindgut mechanism of ileal stimulation. Alamo et al., who have 14 years of follow-up in $>1000$ patients with the SGJJEB, and Huang et al. [49] emphasize the differences between the historic JIB (abandoned around 1980 after experience with a high number of JIB complications necessitating conversion or reversal) and the SG-JJEB, in which, in their series, there has been no evidence of bacterial overgrowth with blind-loop syndrome.

Indications/Contraindications, Weight Loss, Diabetes Resolution Weight loss and T2DM resolution appear to be better with SG-JJEB than with SG and similar to RYGBP [50]. In a 2012 study of 49 SG-JJEB patients with BMI < $35 \mathrm{~kg} / \mathrm{m}^{2}$, mean BMI at 18 months was $24.0 \mathrm{~kg} / \mathrm{m}^{2}$. Complete remission of T2DM was seen in 40/41 (97.5\%) patients

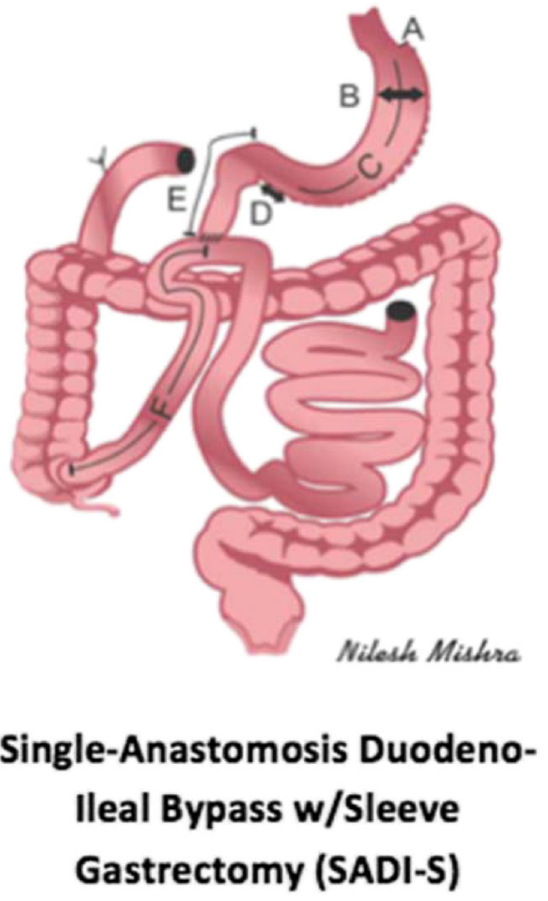

receiving oral hypoglycemic agents (OHGA), and partial remission in $8 / 8(100.0 \%)$ receiving insulin [51].

Operative Mortality/Morbidity, Postoperative Complications, Reversal/Revision In their 2012 study of 49 patients with BMI $<35 \mathrm{~kg} / \mathrm{m}^{2}$, Alamo et al. found no mortality, one $(2.1 \%)$ gastrointestinal (GI) bleed, and no hemoperitoneum, gastric tube leak or stenosis, anastomotic leak, or internal hernia. Also, no anemia, dumping, blind-loop syndrome or bacterial overgrowth, or portal thrombosis was reported. Liver function as well as albumin and calcium levels was normal [51]. With SGJJEB, in the long term, internal hernias may be a concern. Detailed micronutrient studies and incidence of bypass enteritis (SIBO = small intestinal bacterial overgrowth) and subsequent liver failure after SG-JJEB are unknown. Bowel anatomy of the JJEB is reversible [49].

\section{Single-Anastomosis Duodenoileal Bypass with Sleeve Gastrectomy (Fig. 4)}

Origin, advantages In 2007, the single-anastomosis duodenoileal bypass with sleeve gastrectomy (SADI-S) procedure was first described and popularized by SánchezPernaute et al. [52]. The operation is increasingly popular in the USA and is performed in many institutions. An SG with a duodenoileostomy $250 \mathrm{~cm}$ from the ileocecal junction, it is akin to and almost as effective as the BPD/DS in the short term and with a lower incidence of diarrhea and protein malnutrition. The hypothesis for the procedure is that a one-loop DS would be a simpler surgical technique with one fewer

$\begin{array}{ll}A=2-3 \mathrm{~cm} & \text { Distance of sleeve transection from esophagogastric junction } \\ \mathrm{B}=3-4 \mathrm{~cm} & \text { Use } 50-60 \text { Fr bougie to size sleeve width } \\ \mathrm{C}=\text { As is } & \text { Length of sleeve } \\ \mathrm{D}=2-6 \mathrm{~cm} & \text { Antrectomy distance from pylorus } \\ \mathrm{E}=3-4 \mathrm{~cm} & \text { Length of transected duodenum from pylorus } \\ \mathrm{F}=250 \mathrm{~cm} & \text { Length of duodeno-ileal limb } \\ \mathrm{V}=150-250 \mathrm{cc} & \text { Volume of sleeve }\end{array}$

$A=2-3 \mathrm{~cm} \quad$ Distance of sleeve transection from esophagogastric junction

Fig. 4 Single-anastomosis duodenoileal bypass with sleeve gastrectomy (SAD-I) 
anastomosis that might decrease complications while preserving long-term weight loss and metabolic outcomes [53, 54]. SADI-S/OADS is the classification recommended for this procedure by the 2018 IFSO Position Statement [54].

Indications/Contraindications, Weight Loss, Diabetes Resolution SADI-S is indicated primarily for obese patients when greater weight loss or T2DM/metabolic syndrome control is indicated, or with weight regain after a procedure [53]. Mean 12-month EWL has been reported in a few case series ranging from 61.6 to $95.0 \%$. Most series report 12- or 24month weight-loss outcomes, with one report of 5-year results (total body weight loss [TBWL] 38\%, $n=24$ patients, $66.7 \%$ follow-up) $[54,55]$. Resolution of T2DM with SAD-I is similar to that of BPD-DS, which is associated with the highest T2DM resolution reported for any bariatric operation, including OAGB or MGB. SADI-S appears to reduce glucose variability and T2DM remission at 5 years after surgery $[56,57]$.

Operative Mortality/Morbidity, Postoperative Complications, Reversal/Revision In most studies, early complications were few, including nausea, bleeding, and anastomotic leaks. Longer-term complications included nutritional hypoalbuminemia and iron deficiency, and also GERD [54]. A longer-term benefit of the one-loop reconstruction in the Sanchez-Pernaute et al. study is that very few patients have been submitted to reoperation for intestinal obstruction or internal hernia [55]. Concerns with SADI-S long term may be intestinal adaptation, possible weight regain, gas bloat, enteritis (SIBO), and uncertain optimal limb lengths [52]. SADI-S has been converted to a Roux-en-Y DS and RYGBP [24].

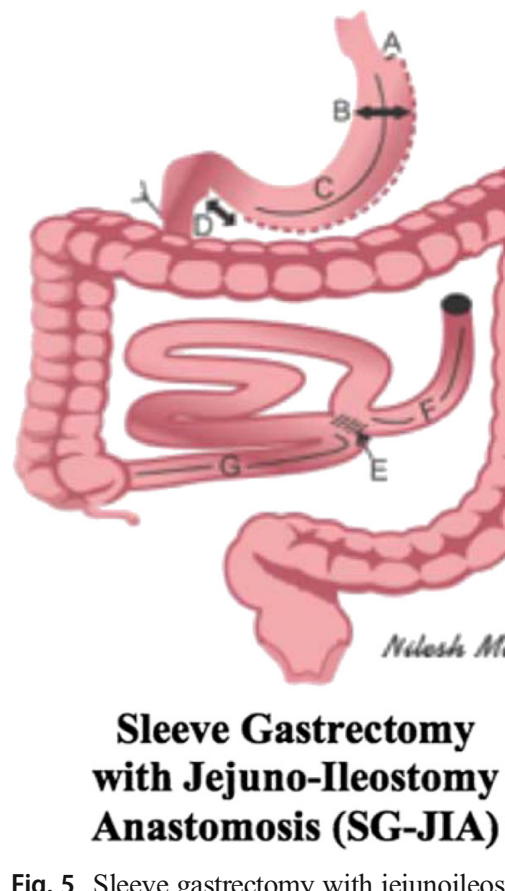

Fig. 5 Sleeve gastrectomy with jejunoileostomy anastomosis (SG-JIA)

$\mathrm{C}=\mathrm{As}$ is

$\mathrm{E}=3 \mathrm{~cm}$

\section{Sleeve Gastrectomy with Jejunoileostomy Anastomosis}

(Fig. 5)

Origin, Advantages The emerging SG variant, SG-JIA, developed by Melissas et al., offers the benefits of SG combined with enhanced neuroendocrine response. It is thought that faster gastric emptying and reduced ghrelin combine with the shorter duodenum-to-cecum transit time to enhance incretin effect [56, 57].

Indications/Contraindications, Weight Loss, Diabetes Resolution Currently considered indications are morbid obesity with weight-loss failure following SG after 12 years to allow the stomach to dilate and contain more food and, also, nonmorbidly obese patients with BMI 28$32 \mathrm{~kg} / \mathrm{m}^{2}$. The temporary one to two postoperative months of malnutrition and the possible effects on hepatic function may contraindicate patients with severe nonalcoholic fatty liver disease (NAFLD) or nonalcoholic steatohepatitis (NASH) for the SG-JIA procedure. In terms of weight loss, in a dual-center study (Crete and Istanbul), SG-JIA patients ( $n=100$, mean BMI 46.8, Crete and Istanbul) were compared with 360 comparable patients who underwent SG (Crete only). Results showed statistically significant greater mean EWL improvement in SG-JIA vs SG patients at 6and 12 -month follow-up (59.9 vs $50.0 \%, 77.3$ vs $61.4 \%$, respectively). At 6 months, the SG-JIA group vs SG alone had statistically significant greater mean resolution of T2DM ( 85.8 vs $50.0 \%)$, hypertension ( 100.0 vs $33.3 \%$ ), and dyslipidemia (100.0 vs $44.4 \%$ ). These results suggest that SG-JIA may be suitable as a procedure to target

$A=2-3 \mathrm{~cm} \quad$ Distance of sleeve transection from esophagogastric junction

$\mathrm{B}=3-4 \mathrm{~cm} \quad$ Use 50-60 Fr bougie to size sleeve width

$\mathrm{D}=2-6 \mathrm{~cm}$

Length of sleeve

Distance from pylorus

$\mathrm{F}=100 \mathrm{~cm}$

Width of jejuno-ileal anastomosis

$\mathrm{G}=200 \mathrm{~cm}-$

Length of jejunal limb

Length of ileal limb

$\mathrm{V}=150-250 \mathrm{cc}$ Volume of sleeve (approx.) 
obesity with comorbid T2DM or T2DM in low-BMI patients $[56,57]$.

Operative Mortality/Morbidity, Postoperative Complications, Reversal/Revision In the Melissas et al. SG-JIA study, there were no deaths and no major perioperative complications. Late complications may be gallstones, which can be treated with cholecystectomy, and bowel obstruction from torsion of the jejunoileal anastomosis around its longitudinal axis, which can be treated by suturing proximal and distal to the anastomosis. Melissas et al. experienced a single case of a patient with more than $100.0 \%$ EWL and frequent nausea and vomiting which on exploration was found to be an antiperistaltic jejunoileal anastomosis. Following this complication, the group has performed the jejunoileal anastomosis isoperistaltically. An unanswered question is the incidence of bypass enteritis (SIBO) and subsequent liver failure. Reversal of the SG-JIA is possible with the option to leave the SG portion intact $[56,57]$.

\section{Sleeve Gastrectomy with Duodenojejunal Bypass (Fig. 6)}

Origin, Advantages The SG-DJB was introduced by Kasama et al. in 2007 to treat obesity and metabolic disorders as an alternative to RYGBP [58]. In SG-DJB, the bypass of the duodenojejunal axis is believed to augment the metabolic effects of the SG. Compared with RYGBP, the preservation of the physiologic pylorus in SG-DJB reduces the frequency of anastomotic stenosis and dumping syndrome [59].

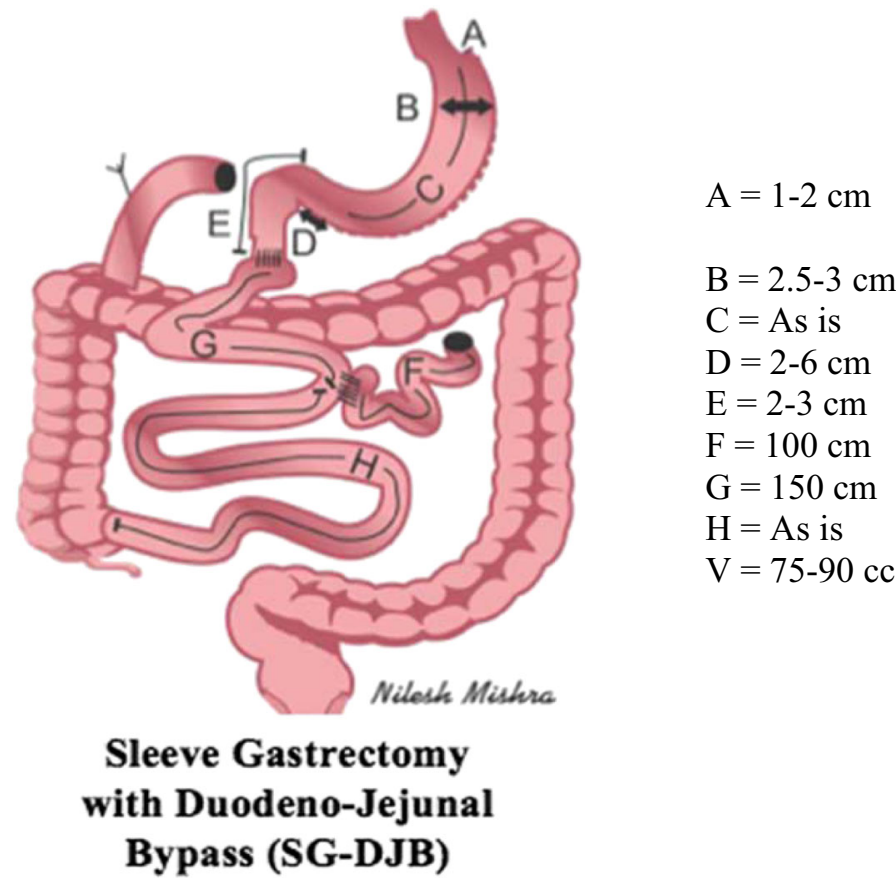

Indications/Contraindications, Weight Loss, Diabetes Resolution In addition to its indication for poorly controlled T2DM, SG-DJB is indicated for patients in areas with high incidence of gastric cancer (the highest prevalence of which is in Asia) because the duodenal-jejunal bypass is accessible to endoscopic evaluation, and relative to RYGBP, SG-DJB averts the risk of gastric cancer in the remnant stomach [60]. Weight loss in a long-term study by Seki and Kasama showed that mean preoperative BMI of $39.0 \mathrm{~kg} / \mathrm{m}^{2}$ was reduced to $28.0 \mathrm{~kg} / \mathrm{m}^{2}$ at 5 -year follow-up [59]. In a 2012 randomized trial by Praveen et al., SG-DJB weight loss was found to be approximately the same as with RYGBP at 1 year [61]. In another study of 1-year outcomes, Lee et al. found that adding DJB to SG may increase EWL by up to $20 \%$ (to $87.2 \%$ EWL) [60]. A 2018 multicenter comparison study by Naitoh and Kasama of obese diabetic patients showed that SG-DJB $(n=$ 121) was significantly more effective for weight loss than $S G$ $(n=177)(67.0 \pm 19.8$ vs $59.4 \pm 18.7 \%$ EWL, respectively $)$ at 1-year follow-up and more effective in T2DM resolution (86.0 vs $80.8 \%$ ). In addition, SG-DJB was found more effective in reducing T2DM in lower BMI patients $\left(27.5-34.9 \mathrm{~kg} / \mathrm{m}^{2}\right)$ [62].

Operative Mortality/Morbidity, Postoperative Complications, Reversal/Revision Adding a DJB to an SG adds operative complexity, time, and risk. A very low rate of major complications has been seen with SG-DJB, primarily postoperative bleeding and leak $(<1.0 \%)$ [61]. SG-DJD carries a higher rate of GERD than RYGBP, but a significantly lower incidence of marginal ulceration, stenosis, leakage, and dumping syndrome

Fig. 6 Sleeve gastrectomy with duodenojejunal bypass (SG-DJB)

Distance of sleeve transection from esophagogastric junction

Use 32-40 Fr bougie to size sleeve width

Length of sleeve

Distance from pylorus

Length of duodenum from pylorus

Length of biliopancreatic limb

Length of Roux-en-Y limb

Common limb

Volume of sleeve (approx.) 


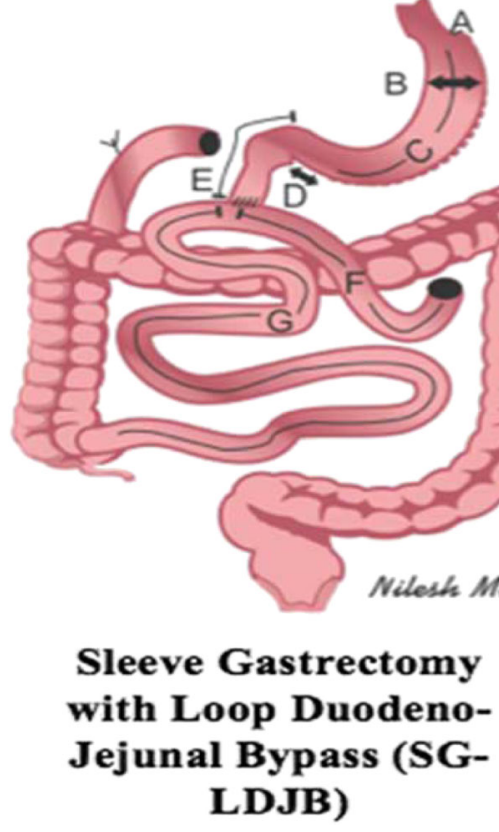

Fig. 7 Sleeve gastrectomy with loop duodenojejunal bypass (SG-LDJB)

than RYGBP and a similar incidence of nutrient deficiency, more pronounced in Asian patients [62]. SG-DJB is very difficult to revise, and nonreversible.

\section{Sleeve Gastrectomy with Loop Duodenojejunal Bypass (Fig. 7)}

Origin, Advantages SG-LDJB was introduced by Huang in 2011 with the objective of avoiding some of the complications of RYGBP by retaining the physiologic pylorus, and the incidence of marginal ulcer, dumping syndrome, and bile reflux is reduced [63]. The technique restricts caloric intake and is believed to engage the posited benefits of the foregut and hindgut hypotheses. SG-DJB also facilitates endoscopic surveillance of gastric cancer [63-65].

Indications/Contraindications, Weight Loss, Diabetes Resolution SG-LDJB is indicated for obesity and/or T2DM in patients with a BMI ranging from 30 to $40 \mathrm{~kg} / \mathrm{m}^{2}$ and in Asian patients with BMI from 27.5 to $37.5 \mathrm{~kg} / \mathrm{m}^{2}$ stratified by their number of comorbidities and level of glycemic control. The procedure is contraindicated for those with active psychiatric illness or drug/alcohol abuse. Relative contraindications include duodenal ulcer, T1DM, severe GERD, or Barrett's esophagus. In the initial report of Huang et al. of SG-LDJB, 22 low-BMI (mean $28.4 \mathrm{~kg} / \mathrm{m}^{2}$ ) patients with long-standing T2DM (mean onset duration, 8 years), at 6 months, 11 patients (50.0\%) experienced $\mathrm{T} 2 \mathrm{DM}$ remission $\left(\mathrm{HbA}_{1 \mathrm{C}}<6.0 \%\right)$ and 20 patients $(91.0 \%)$ achieved $\mathrm{HbA}_{1 \mathrm{C}}<7.0 \%$ off all medicines [63]. In their 2016 case-matched report, Huang et al. comparatively studied patients with mean BMI $<35 \mathrm{~kg} / \mathrm{m}^{2}$ and T2DM who underwent RYGBP $(n=30)$ or SG-SDJB $(n=$
Distance of sleeve transection from esophagogastric junction Use 32-40 Fr bougie to size sleeve width Length of sleeve Antrectomy distance from pylorus Length of transected duodenum from pylorus Length of biliopancreatic limb Common limb Volume of sleeve (approx.)
30). One-year results showed that all parameters were significantly improved from baseline and comorbidity resolution was similar, although there were no statistically significant differences between procedures in mean BMI, FPG, and $\mathrm{HbA}_{1 \mathrm{C}}[66]$.

Operative Mortality/Morbidity, Postoperative Complications, Reversal/Revision In the comparative study of Huang et al., there was no mortality. Late complications were higher but not statistically significant in the very small RYGBP vs SG-LDJB groups (12 vs $5, p=0.08$ ). Two patients in each group required reoperation. In these short-term results, weight loss, glycemic control, and resolution of comorbid disease, SGLDJB proved comparable to RYGB in low-BMI patients [66]. Endoluminal stenting for the management of leak after SG-JDJB has been described recently by Tsai et al. with some success in closing staple-line leaks, although stent migration and associated ulceration were common [67]. Unpublished data characterizing successful conversion of SG-LDJB to RYGB due to stricture, GERD, or leak at the duodenojejunal anastomosis was described by Dr. Huang regarding his ongoing series of $>316$ patients.

\section{Sleeve Gastrectomy with Transit Bipartition (Fig. 8)}

\section{Origin, Advantages}

SG-TB, a procedure introduced by Santoro in the early 2000 s [68], is described as safer and easier to perform than a DS while retaining its excellent weight loss and comorbidity resolution and reducing its adverse effects. The operation 


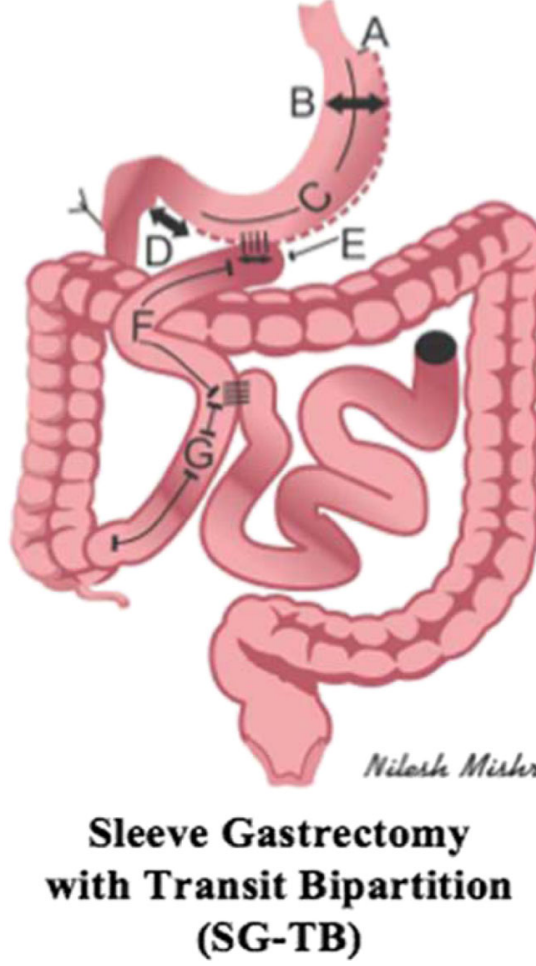

Fig. 8 Sleeve gastrectomy with transit bipartition (SG-TB)

combines an SG with a Roux-en-Y gastroileostomy from the gastric antrum at a point $250 \mathrm{~cm}$ from the ileocecal junction. The procedure has no narrow anastomoses, excluded segments, or prostheses $[68,69]$. SG-TB employs the principle of functional restriction, defined by Santoro et al. as a metabolically (rather than mechanically/ physically) driven rate of reduction in gastric emptying and intestinal transit [70].

Indications/Contraindications, Weight Loss, Diabetes Resolution SG-TB is indicated for obese patients with
T2DM. In a study by Santoro et al. of 1020 patients (mean BMI $41.0 \mathrm{~kg} / \mathrm{m}^{2}$ ) undergoing SG-TB, mean excess BMI loss (EBMIL) was $91.0 \%$ at 1 year and $74.0 \%$ at 5 years $(59.1 \%$ follow-up) [69]. SG-TB resolution of hypertension was $62.0 \%$, hypertriglyceridemia $85.0 \%$, and respiratory problems $91.0 \%$. T2DM was resolved in $86.0 \%$ of patients, a rate superior to that reported in a 2016 meta-analysis for RYGBP, $56.8 \%$ [71]. In a 2018, 24-month, parallel-group, randomized controlled trial (RCT) of the metabolic effects of SG-TB, 20 low-BMI patients with T2DM were randomized to SG-TB or
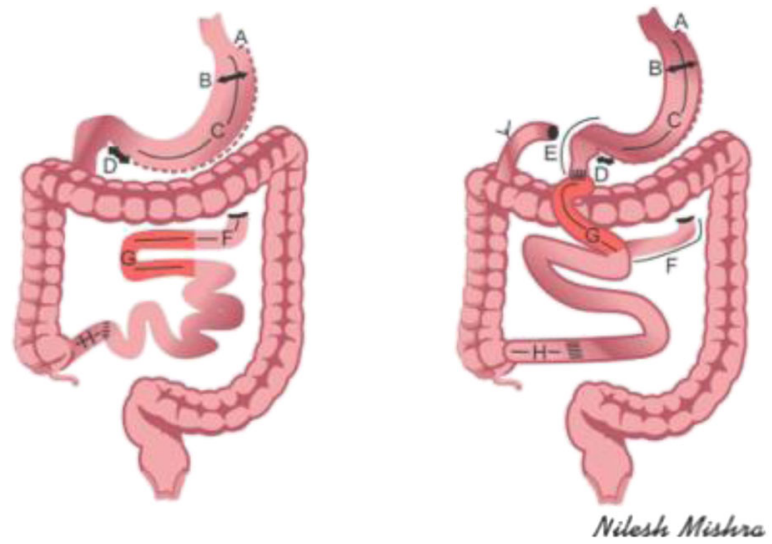

Sleeve Gastrectomy w/Jejunoileal Interposition (SG-II) \& Duodenal Ileal Interposition (SG-DII)

$\begin{array}{ll}A=1-2 \mathrm{~cm} & \begin{array}{l}\text { Distance of sleeve transection from esophagogastric } \\ \text { junction }\end{array} \\ \mathrm{B}=2.5-3 \mathrm{~cm} & \text { Use } 32-40 \text { Fr bougie to size sleeve width } \\ \mathrm{C}=\mathrm{As} \text { is } & \text { Length of sleeve } \\ \mathrm{D}=2-6 \mathrm{~cm} & \text { Antrectomy distance from pylorus } \\ \mathrm{E}=3-4 \mathrm{~cm} & \text { Length of duodenum from pylorus } \\ \mathrm{F}=50 \mathrm{~cm} & \text { Length of biliopancreatic limb } \\ \mathrm{G}=150-170 \mathrm{~cm} & \text { Length of ileal interposed limb } \\ \mathrm{H}=30 \mathrm{~cm} & \text { Distance of ileal transection from ileocecal junction } \\ \mathrm{V}=75-150 \mathrm{cc} & \text { Volume of sleeve }\end{array}$

$A=1-2 \mathrm{~cm} \quad$ Distance of sleeve transection from esophagogastric

$\mathrm{B}=2.5-3 \mathrm{~cm} \quad$ Use $32-40 \mathrm{Fr}$ bougie to size sleeve width

$\mathrm{C}=\mathrm{As}$ is $\quad$ Length of sleeve

$\mathrm{D}=2-6 \mathrm{~cm} \quad$ Antrectomy distance from pylorus

$\mathrm{E}=3-4 \mathrm{~cm} \quad$ Length of duodenum from pylorus

$\mathrm{F}=50 \mathrm{~cm} \quad$ Length of biliopancreatic limb

$\mathrm{G}=150-170 \mathrm{~cm}$ Length of ileal interposed limb

$\mathrm{V}=75-150 \mathrm{cc} \quad$ Volume of sleeve 
standard medical therapy. At 24 months, $\mathrm{HbA}_{1 \mathrm{C}}$ was statistically significantly reduced from baseline in the SG-TB group $(9.3 \pm 2.1$ vs $5.5 \pm 1.1 \%, p<0.05)$ relative to the medical therapy group $(8.0 \pm 1.5 \mathrm{vs} 8.3 \pm 1.1 \%, p=\mathrm{NS})$ [70].

Operative Mortality/Morbidity, Postoperative Complications, Reversal/Revision In the 2012 Santoro et al. study, there were two deaths $(0.2 \%)$ and surgical complications occurred in $6.0 \%$ of the patients [69]. With this procedure, nutrient deficiencies often associated with bypass of the duodenojejunal axis are minimized, and dumping syndrome and diarrhea are lessened. SG-TB can be reversed or converted.

\section{Sleeve Gastrectomy with Jejunoileal Interposition and Duodenal Ileal Interposition (Fig. 9)}

Origin, Advantages The concept of an isolated ileal transposition in rats was first published by Koopmans et al. in 1982 [72]. Combined with SG, Gagner reported it in humans in 2005 [73].

In 2006, de Paula introduced the SG-II in a pilot study in 19 severely obese adults. After the jejunum was divided $50 \mathrm{~cm}$ from the ligament of Treitz, a 100-150-cm segment of ileum was created $50 \mathrm{~cm}$ proximal to the ileocecal valve, peristaltically interposing it in the proximal jejunum [74]. The SG-JII is typically used in low-BMI patients, and the SG-DII version of the technique in obese patients. Animal studies show that SG-JII delayed the onset of diabetes, an effect possibly related to increased nutrient-stimulated secretion of PYY and GLP-17-36 and improvements of beta-cell function, insulin sensitivity, and lipid metabolism [75].
Indications/Contraindications, Weight Loss, Diabetes Resolution SG-JII is indicated for morbidly obese and lowBMI patients with T2DM [76, 77]. Mean BMI in low-BMI patients decreased from 29.7 to $23.5 \mathrm{~kg} / \mathrm{m}^{2}$ [77]. A 2017 systematic review of bariatric procedures for diabetes reported six studies of SG-JII ( $n=474$ patients, 381 with T2DM). Variable rates of T2DM remission (47.0-95.7\%) were reported. Defining remission as $\mathrm{HbA}_{1 \mathrm{C}}$ level $\geq 7$ with no medicines, the cumulative remission rate was $77.8 \%$ [73].

Operative Mortality/Morbidity, Postoperative Complications, Reversal/Revision Early mortality in low-BMI patients was $0.99 \%$ and late $1.0 \%$ as reported by de Paula et al. [77]. In the short term, the reported leak rate is $0.8 \%$. The most frequent long-term SG-II complication is intestinal obstruction, $2.5 \%$ reoperation rate [78], relative to that reported for RYGBP, $4.0 \%(0.6-10.4 \%)$ in a review of 3464 patients [79]. Although the crura are closed routinely in hiatal hernia and GERD patients, postoperative symptoms were seen in $13.4 \%$. New reflux symptoms were present in $5.1 \%$. Other major complications reported are fistulas requiring reoperation and GI bleed [77].

\section{Single-Anastomosis Sleeve with lleal Bypass (Fig. 10)}

Origin, Advantages The SASI bypass is a modification of the SG-TB of Santoro [68] popularized by Mahdy and colleagues [80]. It combines an SG and loop transit bipartition rather than Roux-en-Y gastroileostomy $300 \mathrm{~cm}$ from the ileocecal junction. Ghrelin secretion is decreased and the flow of food through the gastroileostomy instead of the pylorus is theorized to lessen foregut stimulation and augment hindgut

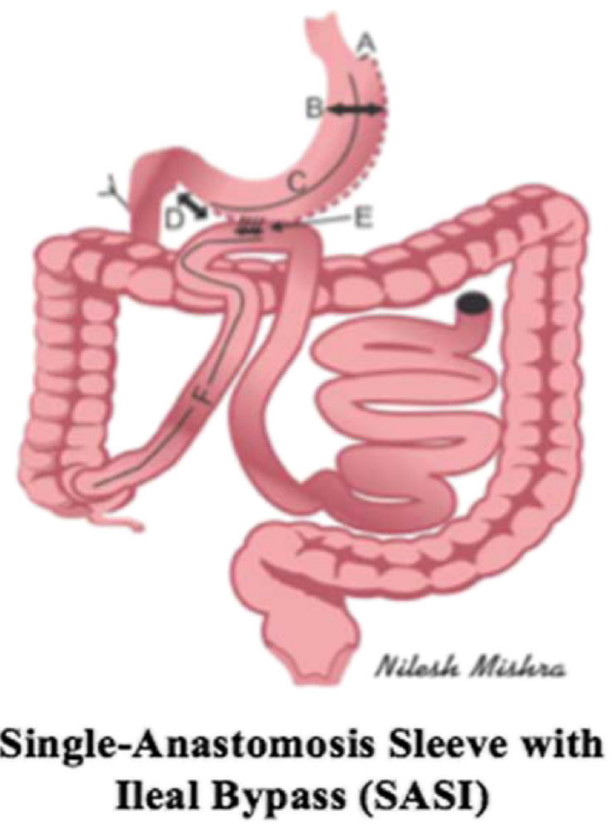

$\mathrm{A}=2-3 \mathrm{~cm}$

Distance of sleeve transection from esophagogastric junction

$\mathrm{B}=3-4 \mathrm{~cm} \quad$ Use 50-60 $\mathrm{Fr}$ bougie to size sleeve width

$\mathrm{C}=\mathrm{As}$ is

Length of sleeve

$\mathrm{D}=2-6 \mathrm{~cm}$

Distance from pylorus

$\mathrm{E}=3 \mathrm{~cm}$

Width of gastroileal anastomosis

$\mathrm{F}=300 \mathrm{~cm}$

Length of gastroileal limb

$\mathrm{V}=150-250 \mathrm{cc}$

Volume of sleeve (approx.)

Fig. 10 Single-anastomosis sleeve with ileal bypass (SASI) 
stimulation. Like the SG-TB, the SASI is described as safer and easier to perform than DS and carries the weight-loss benefits without the nutrient deficiencies and protein caloric malnutrition [80]. The duodenum and papilla are endoscopically accessible. SASI evidence is available for short-term follow-up only.

Indications/Contraindications, Weight Loss, Diabetes Resolution SASI bypass is indicated for obese patients with or without T2DM. At 1-year follow-up of 45 patients (mean BMI $43.2 \mathrm{~kg} / \mathrm{m}^{2}$ ) in a study by Salama et al., BMI had decreased to $29.1 \mathrm{~kg} / \mathrm{m}^{2}$. FPG, low-density lipoprotein (LDL), and insulin use were statistically significantly lessened, while high-density lipoprotein (HDL) was significantly increased [81]. In the single study by Mahdy et al., 50 included patients (mean BMI $48.7 \pm 7.6 \mathrm{~kg} / \mathrm{m}^{2}$ ) experienced significant mean weight loss of $90.0 \%$ EWL at 1 year, glucose was normalized in $100.0 \%$ of patients at 3 months, and all were off insulin and hypoglycemic drugs [80].

Operative Mortality/Morbidity, Postoperative Complications, Reversal/Revision There has been no mortality to date. SASI bypass results in minimal postoperative nutritional complications relative to other procedures. Incidence of dumping syndrome and diarrhea was reduced in the Salama et al. study [81]. Complications in the Mahdy et al. study included one complete obstruction at the gastroileal anastomosis, one bleed, one pulmonary embolism, and one leak in the biliary limb. At
6 months, one patient was diagnosed with a marginal ulcer; at 1 year, one patient was reoperated to avert potential excessive weight loss. Patency of the anastomosis and ulceration are potential long-term concerns [80]. SASI may potentially be revised or reversed.

\section{Endoscopic Sleeve Gastroplasty (Fig. 11)}

Origin, Advantages Endosuturing was first performed in 2004 to revise a RYGBP [82] and for primary weight loss in 2008 with an early generation endoscopic suturing device that employed a suction-based superficial thickness suturing mechanism [83]. Development of widely available fullthickness endoscopic suturing has made possible more effective, enduring procedures. OverStitch (Apollo Endosurgery, Austin, TX) is the device used in endoscopic sleeve gastroplasty (E-SG). It was initially tested in three phases by Kumar et al., during which stitch patterns and sequences were optimized for efficiency [84]. Surgical groups in numerous countries are trialing the E-SG although few RCTs have been performed. E-SG has a good safety profile (no reported mortality in 2-year follow-up) with 17.0-19.0\% TBWL.

Indications/Contraindications, Weight Loss, Diabetes Resolution E-SG may be indicated for low-BMI $(\leq 30 \mathrm{~kg} /$ $\mathrm{m}^{2}$ ) and obese patients. In terms of weight loss, in the third phase of the Kumar et al. study, 77 patients with a mean BMI of $36.1 \pm 0.6 \mathrm{~kg} / \mathrm{m}^{2}$ who underwent E-SG achieved TBWL of

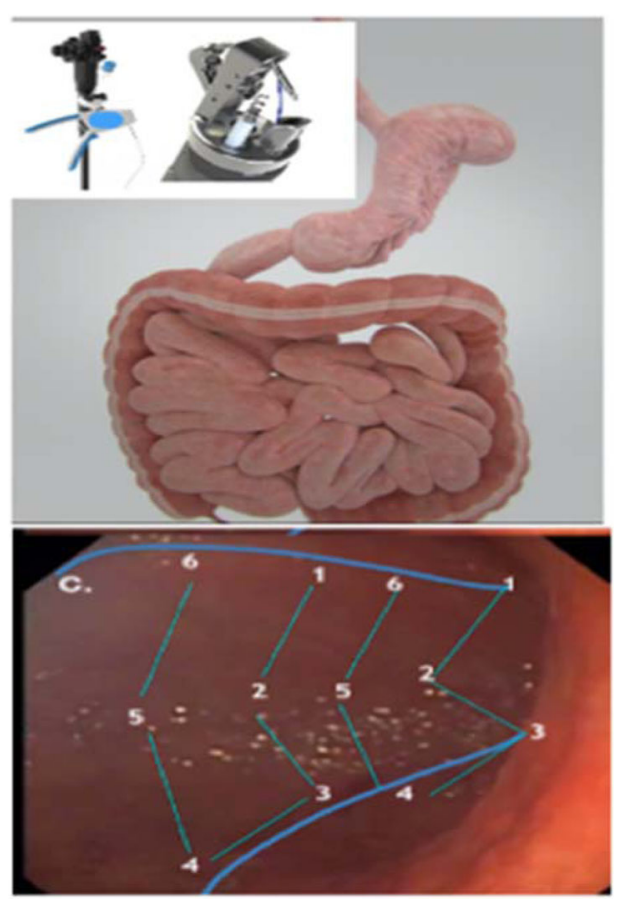

Endoscopic Sleeve Gastroplasty (E-SG )
No measurements that can be standardized. Technique summary:

- Double-channel endoscope and endosutring equipment used.

- Use of general anesthesia, an overtube $\mathrm{CO}_{2}$ insufflation, and prophylactic antibiotics

- Start suturing from proximal body in direction of the fundus including the greater curvature of the stomach

- Place sutures by sequentially catching the anterior wall, the greater curvature, and the posterior wall, returning to the anterior wall in a Ushape or crossing directly from the posterior wall to the anterior wall, ending on the posterior wall including the greater curvature

Fig. 11 Endoscopic sleeve gastroplasty (E-SG) 
$16.0 \pm 0.8 \%$ at 6 months and $17.4 \pm 1.2 \%$ at 12 months $(n=$ 44). In patients with BMI $35-40 \mathrm{~kg} / \mathrm{m}^{2}$, TBWL was $17.6 \pm$ $2.1 \%$; in BMI $<35 \mathrm{~kg} / \mathrm{m}^{2}$, TBWL was $15.2 \pm 1.9 \%$ [84]. In addition to three other primary studies of E-SG to date [85-87], several comparative studies relate E-SG to other procedures. In one such multicenter study by Garcia et al., 173 patients with a mean BMI of $39.5-40.2 \mathrm{~kg} / \mathrm{m}^{2}$ were compared: laparoscopic greater curvature plication (LGCP, $n=38$ ), E-SG $(n=69)$, and $\mathrm{SG}(n=66)$. At 12 months, their respective TBWL was 19.8, 25.3, and $24.4 \mathrm{~kg}$ [NS] and EWL, 60.6, 64.4 , and $76.1 \%$ [NS] [88].

Operative Mortality/Morbidity, Postoperative Complications, Reversal/Revision In the Kumar et al. study, no significant adverse events occurred intraoperatively or in the follow-up period, though nausea and epigastric pain were frequently reported in postoperative week 1 [84]. Serious adverse events with E-SG may include perigastric inflammatory serous fluid collection that resolves with percutaneous drainage, pulmonary embolism, and pneumoperitoneum and pneumothorax requiring chest tube placement. The procedure may be reversible.

\section{Roux-en-Y Gastric Bypass (Fig. 12)—Second of the Four Conventional Procedures Described}

Origin, Advantages The open GBP was developed by Mason and Ito in 1966 [89] and first performed laparoscopically by
Wittgrove and colleagues in 1993 [90]. In 1977, Griffen et al. added the Roux-en-Y gastrojejunostomy (instead of the Mason loop gastrojejunostomy), reducing tension on the loop, preventing bile reflux into the upper gastric pouch [91], and increasing weight loss [92]. RYGBP is one of the most reliable historic/conventional operations. In the majority of patients, RYGBP resolves or significantly improves hypertension, dyslipidemia, obstructive sleep apnea, arthritis, stress incontinence, headache, congestive heart failure, and depression [93]. It can be used as a revision or conversion option.

Indications/Contraindications, Weight Loss, Diabetes Resolution RYGBP is indicated for morbidly obese patients. Results of a 2017 network meta-analysis of comparative bariatric procedure outcomes showed mean EWL with RYGBP was $67.3 \%(n=294)$ at 1 -year follow-up [94], these findings are similar to yet exceed the RYGBP EWL reported by the 2004 original comparative meta-analysis by Buchwald et al. (56.7-66.5\% EWL within the first 2 years) [95]. Typically, the excellent initial weight loss nadir is followed by $5.0-20.0 \%$ EW regain; however, RYGBP weight loss $\geq 50.0 \%$ is typically maintained over the long term. In studies 10-year follow-up, T2DM resolves in 50.0-80.0\% of RYGBP patients, depending on the severity and duration of disease [96, 97], an undeniable attribute of bariatric surgery that caused the American Diabetes Association (ADA) to recommend it in their treatment algorithm [93]. Importantly, at 7 years post-RYGBP, Adams et al. found that all-cause mortality dropped

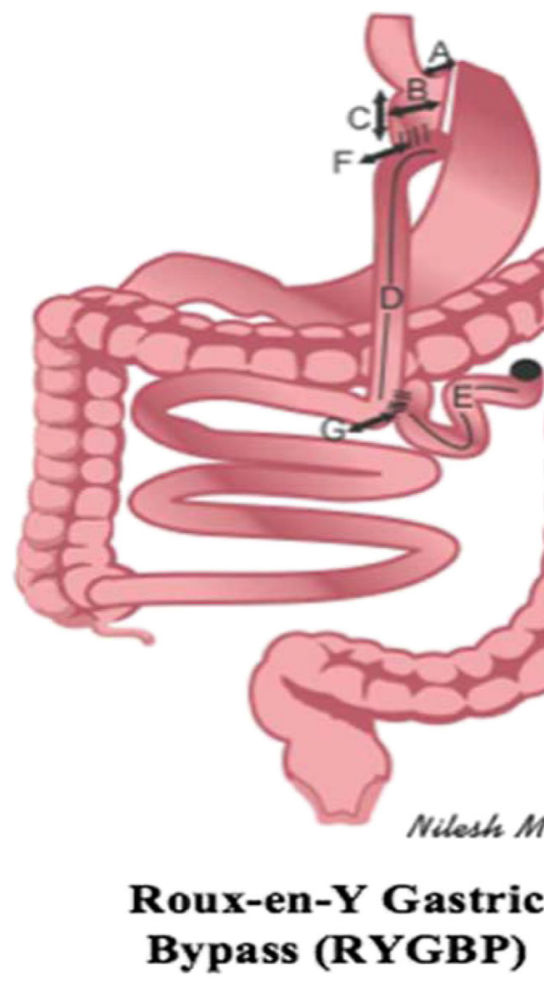

$\mathrm{A}=1-2 \mathrm{~cm}$

$\mathrm{B}=3 \mathrm{~cm}$

$\mathrm{C}=3-4 \mathrm{~cm}$

$\mathrm{D}=50-150 \mathrm{~cm}$

$\mathrm{E}=50-150 \mathrm{~cm}$

$\mathrm{D}+\mathrm{E}=200 \mathrm{~cm}$

$\mathrm{F}=1.2-1.5 \mathrm{~cm}$

$\mathrm{G}=3-4 \mathrm{~cm}$

$\mathrm{V}=<30 \mathrm{cc}$
Distance from esophagogastric junction

Width of created gastric pouch (approx.)

Length of created gastric pouch

Length of Roux-en-Y limb

Length of biliopancreatic limb

Width of gastroenterostomy

Width of enteroenterostomy

Volume of gastric pouch

Fig. 12 Roux-en-Y gastric bypass (RYGBP) 


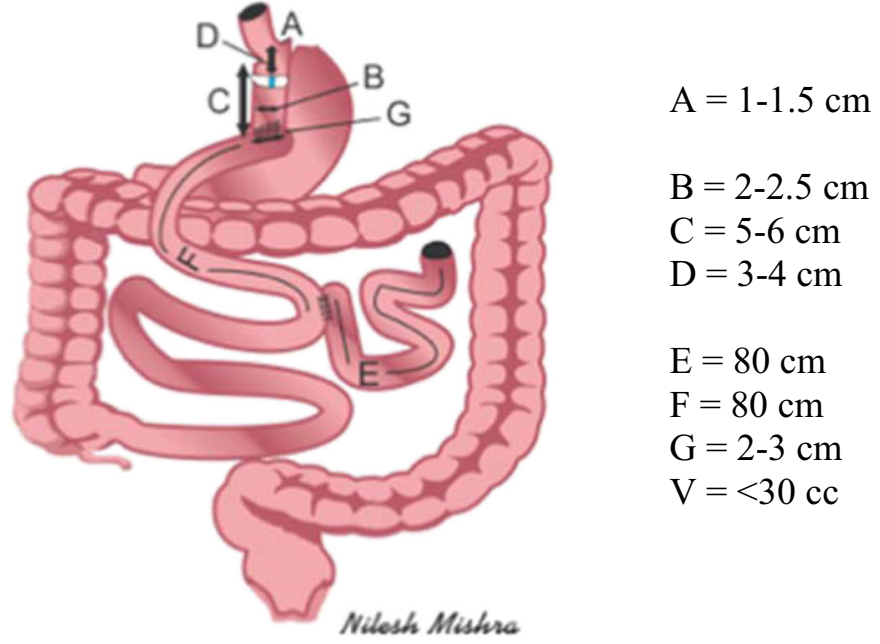

\section{Banded Gastric Bypass} (BGBP)

Fig. 13 Banded gastric bypass (BGBP)

significantly by $40.0 \%$, particularly deaths from heart disease, T2DM, and cancer [98].

Operative Mortality/Morbidity, Postoperative Complications, Reversal/Revision In a study of comparative complication rates by Birkmeyer et al., life-threatening perioperative morbidity with RYGBP was $3.6 \%$ (95\% CI, 3.2-4.0\%) and mortality, $0.14 \%$ (95\% CI, $0.08-0.25 \%$ ) [33]. A persistent question has been the relation to pouch size of longterm weight regain after RYGBP. "Out-eating" the operation, lack of exercise, etc are theorized contributors to an enlarged pouch that slows food passage and decreases incretin production, contributing to weight regain. Recently, Riccioppo et al. reported that smaller pouch size yielded faster gastric emptying, greater maintenance of weight loss, and better food tolerance [99]; yet, other studies suggest alternate or additive factors. RYGBP can be reversed or revised.

\section{Banded Gastric Bypass (Fig. 13)}

Origin, Advantages BGBP evolved from the observation that in a significant number of patients there is weight regain after RYGBP due typically to dilation of the gastroenterostomy. Linner and Drew addressed this by placing a Silastic $\AA$ ring around the gastroenterostomy to stabilize the stoma [100]. When a high rate of erosion occurred, they used fascia to stabilize the stoma [101]. Fobi et al. and others reported better weight loss and maintenance in patients with inadequate weight loss or regain after banded gastroplasty operations were revised to RYGBP with construction of the gastroenterostomy distal to the ring/band [102, 103], and they reported an erosion rate $<2.0 \%$. This gave rise to success with
Distance of transected pouch from esophagogastric junction

Width of pouch (approx.)

Length of pouch created

Distance of ring placement from esophagogastric junction

Length of biliopancreatic limb

Length of Roux-en-Y limb

Width of gastroenterostomy

Volume of functional proximal pouch (proximal to ring)
BGBP with band placement 5-6 cm from the GE junction, $\geq$ $1.5-2 \mathrm{~cm}$ proximal to the gastroenterostomy with a functional $15-25 \mathrm{cc}$ pouch.

Indications/Contraindications, Weight Loss, Diabetes Resolution BGBP is indicated for obese and super-obese patients. BGBP is as effective as BPD-DS for weight loss and maintenance [104]. Weight loss peaks around 18-24 months after the procedure with maintenance of 70.0-80.0\% EWL reported at 4-12 years of follow-up [97, 104, 105] and significant TBWL of $32.5 \%$ [106]. There is slightly better resolution of T2DM and hypertension with BGBP associated with its higher long-term weight loss and maintenance [105]. By meta-analysis, at 10-year follow-up, T2DM remitted in 80/95 $(84.2 \%)$ [104].

Operative Mortality/Morbidity, Postoperative Complications, Reversal/Revision The most common BGBP complication is food intolerance (5.0-15.0\%) and occasional postprandial emesis [107], mostly resolved with nutritional counseling or band removal in a small set of patients. By a recent Buchwald et al. meta-analysis, long-term rates of gastric outlet stenosis, band erosion, and band slippage were, respectively, 2.8, 2.3, and $1.5 \%$ [104]. Placing the band very loosely initially has markedly minimized the complications of food intolerance and migration of the band $[105,108]$. The perioperative complication of gastric outlet stenosis, common after standard RYGBP (6.0-23.0\%), is significantly less because the BGBP gastroenterostomy is made wider $(2.5-3 \mathrm{~cm})$ than in RYGBP $(1-2 \mathrm{~cm})$ [109]. There are four to five bands on the market, but no FDA-approved device for banding the RYGBP or SG yet; currently, BGBP is mostly performed in countries accepting the CE mark. 


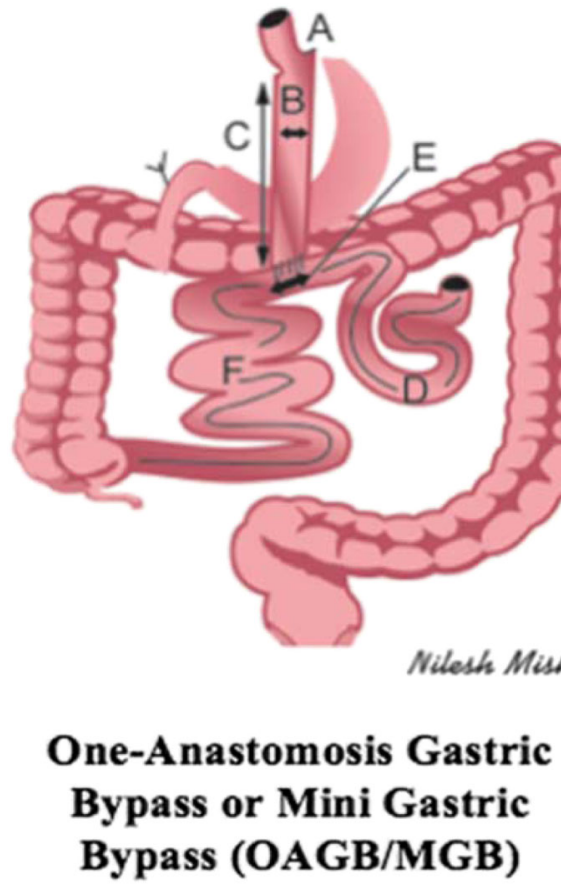

$\mathrm{A}=1-1.5 \mathrm{~cm} \quad$ Distance from esophagogastric junction

$\mathrm{B}=2.5-3 \mathrm{~cm} \quad$ Width of pouch

$\mathrm{C}=15 \mathrm{~cm} \quad$ Length of pouch $(12-19 \mathrm{~cm})$

$\mathrm{D}=200 \mathrm{~cm} \quad$ Length of biliopancreatic limb BMI $>50 \mathrm{~kg} / \mathrm{m}^{2}$

$\mathrm{D}=150 \mathrm{~cm}$

Length of biliopancreatic imb BMI $<50 \mathrm{~kg} / \mathrm{m}^{2}$

$\mathrm{E}=3-4 \mathrm{~cm} \quad$ Width of gastroenterostomy

$\mathrm{F}=\mathrm{As}$

Length of common channel

$\mathrm{V}=50-75 \mathrm{cc}$

Volume of pouch (approx.)

Fig. 14 One-anastomosis gastric bypass or mini gastric bypass (OAGB/MGB)

\section{One-Anastomosis Gastric Bypass Or Mini Gastric Bypass} (Fig. 14)

Origin, Advantages One-anastomosis gastric bypass (OAGB) or mini gastric bypass (MGB) was innovated by Robert Rutledge in 1997 [110]. In OAGB, a long tubular pouch is made on the gastric lesser curvature and connected by a wide, nonrestrictive anastomosis to a loop of jejunum $150-250 \mathrm{~cm}$ from the ligament of Treitz. Weight loss is excellent and more rapid than with RYGBP or BPD [111], mostly due to a longer biliopancreatic limb. Reduction of T2DM and hyperlipidemia are also comparable to that of BPD [112-114]. Early in its development, OAGB fell into disrepute due to its high incidence of bile reflux followed by sometimes fatal protein malnutrition and its high probability of Barrett's esophagus and malignancy $[115,116]$. Yet, in a 2018 systematic review by Parmar and Mahawar of 12,807 morbidly obese OAGB patients, the rate of reflux was $2.0 \%$ [114]. Although OAGB has not been approved by the ASMBS, it has become the fourth most common operation performed worldwide [8]. In mid 2018, there were 4 RCTs, 34 single-arm cohort studies, and 14 comparative studies of OAGB [117].

\section{Indications/Contraindications, Weight Loss, Diabetes} Resolution OAGB may be indicated for obese and superobese patients who are compliant with prescribed nutritional supplementation. In the long-term study of 1054 by Kular et al. in morbidly obese patients at 6-year follow-up, mean EWL was $85.0 \%$ (84\% follow-up) [112]. In a recent large review of 12,807 cases at a median of 2 years (range 6 months to 12 years), EWL was $75.65 \%$ at $\geq 5$ years. In the same review, T2DM resolution was $83.7 \%$ at median 2-year follow-up [114]. T2DM remission of $93.2 \%$ at 6 years postOAGB in the Kular et al. series [112] is similar to that seen in multiple other series ranging from 80.0 to $90.0 \%$ [118-122], suggesting that OAGB remission of T2DM is comparable to that of BPD.

\section{Operative Mortality/Morbidity, Postoperative Complications,} Reversal/Revision In a 7-year 2016 comparative study of 1107 patients by Jammu and Sharma of OAGB $(n=473)$, SG $(n=$ $339)$, and RYGBP $(n=295)$, respective mortality was $0.0,2.1$, and $0.3 \%$, and the respective leak rate was $0.0,1.5$, and $0.3 \%$. In the OAGB group, bile reflux was seen in $n<1.0 \%$, and there was $0.0 \%$ weight regain [123]. In the large series by Kular et al., there were 49 (4.6\%) early minor complications following OAGB, 14 (1.3\%) major complications, as well as 2 leaks $(0.2 \%) ; 5$ patients had marginal ulcers $(0.6 \%)$, and the most frequent late complication was anemia in 68 patients (7.6\%) [112]. In Parmar and Mahawar's review, 30-day mortality was $0.1 \%(0.0-0.5 \%)$, mean leak rate $0.96 \%(0.0$ $5.0 \%)$, marginal ulceration $2.7 \%(0.0-10.0 \%)$, and malnutrition $0.71 \%(0.0-3.8 \%)$ [114]. With OAGB, there has been concern about bile reflux, marginal ulceration, leak, protein malnutrition, nutritional deficiency, liver failure, and possible multiple organ failure. OAGB advocates suggest customization of the biliopancreatic limb to the weight and nutritional habits (vegetarian/nonvegetarian) of the patient [124], although compliance is frequently a challenge. OAGB is readily reversible to RYGBP [112]. 


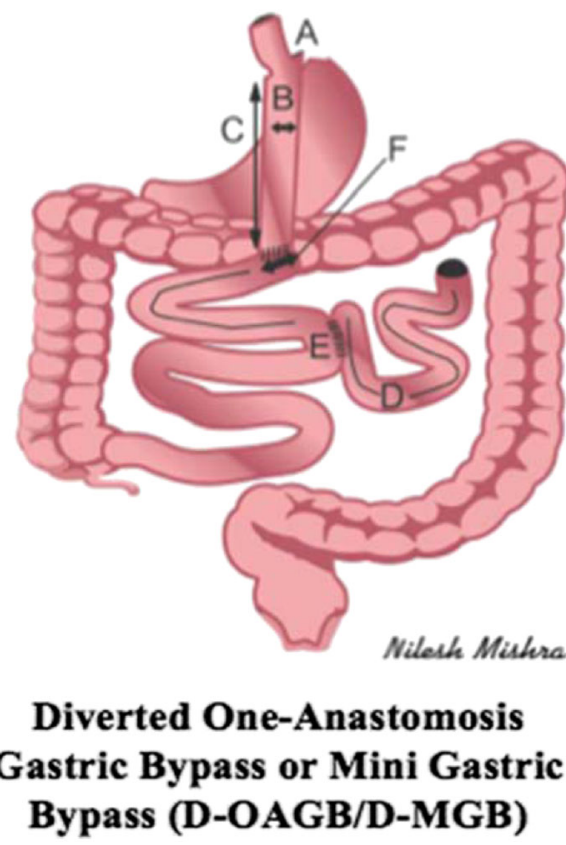

$\mathrm{A}=1-1.5 \mathrm{~cm} \quad$ Distance from esophagogastric junction

$\mathrm{B}=2.5-3 \mathrm{~cm} \quad$ Width of pouch

$\mathrm{C}=12-18 \mathrm{~cm} \quad$ Length of pouch

$\mathrm{D}=200 \mathrm{~cm}$

Length of biliopancreatic limb (tailored: $+50 \mathrm{~cm}$ in

diabetic and super-obese; $-50 \mathrm{~cm}$ in elderly)

$\mathrm{E}=100 \mathrm{~cm} \quad$ Length of Roux limb

$\mathrm{F}=3 \mathrm{~cm} \quad$ Width of gastroenterostomy

$\mathrm{V}=50-70 \mathrm{cc} \quad$ Volume of pouch

Always $>300 \mathrm{~cm}$ of common limb, shortening biliopancreatic limb to get it

Fig. 15 Diverted one-anastomosis gastric bypass or mini gastric bypass (D-OAGB/D-MGB)

\section{Diverted One-Anastomosis Gastric Bypass or Mini Gastric Bypass (Fig. 15)}

Origin, Advantages In this very new procedure, adding a Roux-en-Y diversion to an OAGB provides an effective solution to address complications of postoperative bile reflux and marginal ulcer seen with OAGB [125]. In 2013, this conversion of an OAGB was first used by Ribeiro et al. as a primary procedure - the D-OAGB - with the same effective outcomes as OAGB. The technique is more straightforward to perform than RYGBP as it avoids the need to bring the small bowel up to the GE junction, placing less tension on the anastomosis [125].

Indications/Contraindications, Weight Loss, Diabetes Resolution D-OAGB is indicated for obese patients at risk of GERD, Barrett's esophagus, or hiatal hernia. Weight loss in the first 300 patients of their series (169 primary cases) with mean 2-year follow-up has been described by Ribeiro et al. as the same as with OAGB [125]. They found $82.90 \%$ EBMIL at 4 years, 3 patients $(1.0 \%)$ had weight regain, and 0 excessive weight loss; $54.0 \%$ of patients experienced T2DM resolution and were off medications.

\section{Operative Mortality/Morbidity, Postoperative Complications,}

Reversal/Revision In the series of Ribeiro et al., there was no mortality and there were six intraoperative complications. The diverted version of the procedure is more challenging than OAGB. Due to an increased acid load from the larger gastric pouch, D-OAGB is associated with a higher incidence of marginal ulceration than OAGB (1.0\%). The procedure appears to offer a reduction in the rate of internal hernias from that OAGB and an almost nil rate of leaks, stenosis, and dumping syndrome. With D-OAGB, there are fewer bowel movements but with fatty stools. Intermesenteric spaces need to be closed, unlike OAGB. It is reversible and readily revised to reduce or elongate the length of the biliopancreatic limb [125]. Only one publication reports evidence on this procedure.

\section{Single-Anastomosis Gastroileal Bypass (Fig. 16)}

Origin, Advantages The SAG-I technique is primarily that of OAGB; however, to address possible insufficient absorption of the efferent intestinal limb, de Luca and colleagues modified the OAGB technique, constructing the GI anastomosis at a fixed distance (approximately $300 \mathrm{~cm}$ ) from the ileocecal valve. The novel variant makes endoscopic and laparoscopic management easier than with the SADI-S in the instance of leak and/or anastomotic hemorrhage. The innovators posit that the fixed length of the common channel may result in more consistent outcomes than with OAGB and prevent its serious complications, including hypoalbuminemia or malnutrition [126]. There is only one evidence publication to date on this procedure.

Indications/Contraindications, Weight Loss, Diabetes Resolution SAG-I is indicated for insufficient weight loss or regain after LAGB, OAGB, or SG, especially for patient noncompliance unrelated to gastric pouch dilation. It is also an indicated primary surgery for obese patients who are OAGB 


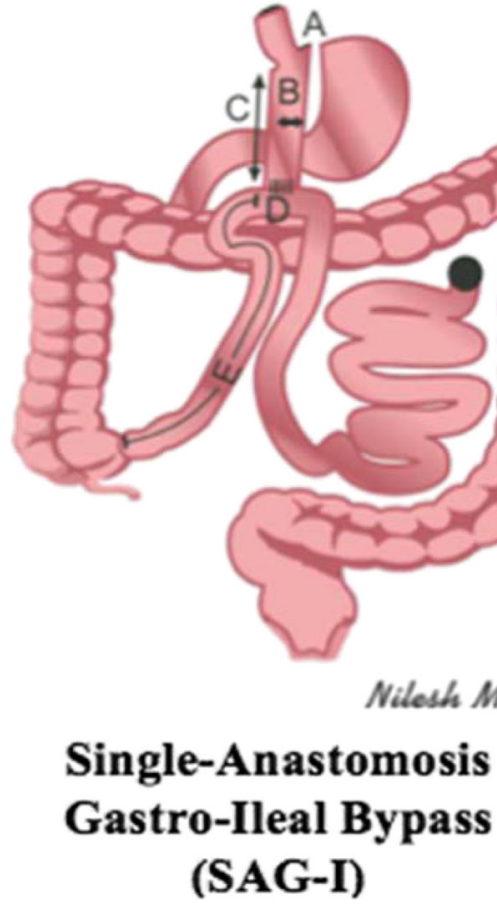

$\mathrm{A}=1-1.5 \mathrm{~cm}$
$\mathrm{~B}=2.5-3 \mathrm{~cm}$
$\mathrm{C}=12-18 \mathrm{~cm}$
$\mathrm{D}=3-4 \mathrm{~cm}$
$\mathrm{E}=300 \mathrm{~cm}$
$V=50-75 \mathrm{cc}$

Distance of sleeve transection from esophagogastric junction

Width of pouch (approx.)

Length of pouch

Width of gastroenterostomy

Length of gastrocecal limb

$\mathrm{V}=50-75 \mathrm{cc} \quad$ Volume of gastric pouch

Fig. 16 Single-anastomosis gastroileal bypass (SAG-I)

candidates but with short bowels. Outcomes are limited to a single-center experience (seven patients, mean BMI $42.1 \mathrm{~kg}$ / $\mathrm{m}^{2}$, three remedial, none diabetic). At 3-month follow-up, EWL was $55.1 \%(n=7)$, and 6-month follow-up $82.1 \%$ $(n=2)$.

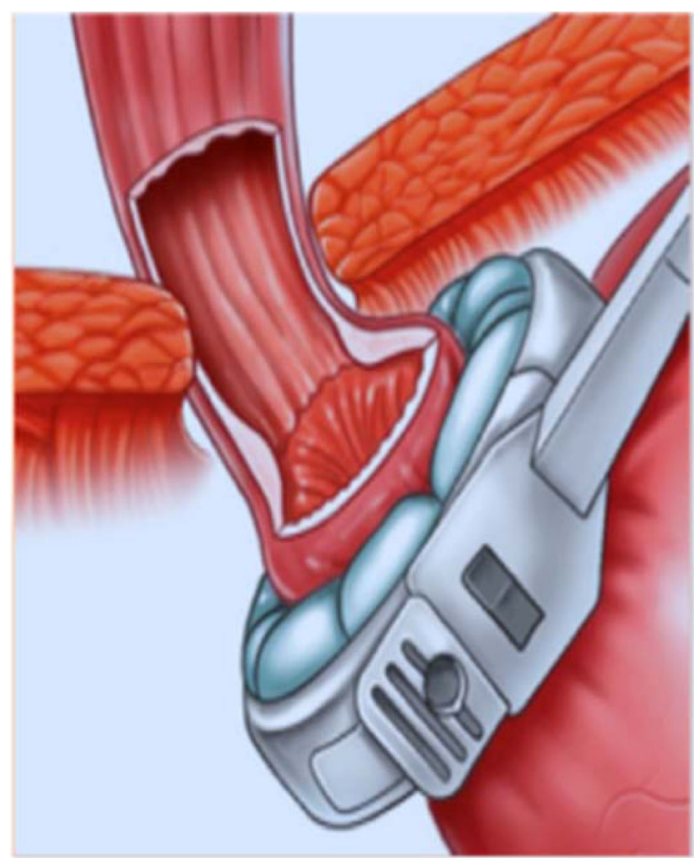

\section{Laparoscopic Adjustable Gastric Banding (LAGB)}

Fig. 17 Laparoscopic adjustable gastric band (LAGB)
Operative Mortality/Morbidity, Postoperative Complications, Reversal/Revision In the small initial cohort of de Luca et al., there were no intraoperative complications, and there was no perioperative or postoperative mortality, no reflux, anemia, or hypoproteinemia. At 6 months, a patient reporting reduced

The use is standardized by the manufacturer's instructions for use.

- The upper border of the band is $1 \mathrm{~cm}$ below esophagogastric junction - Virtual volume of proximal pouch $(\mathrm{Lx} \pi \mathrm{r} 2=1 \mathrm{~cm}$ X 3.14 X $1 \mathrm{~cm} \mathrm{X}$ $1 \mathrm{~cm}=3.14 \mathrm{cc}$ )

- There must be no fat interposed between the band and gastric wall

3. The band must be passed above the lesser sac posteriorly 4. The anterior gastric wall below the band must be fixed by sufficient sutures to prevent slippage

5. The access port must be accessible easily in the office

Essential aftercare elements

- Saline must be added to the band until satiety and early satiation are achieved (the green zone)

- There must be at least a 1-minute wait between bites

- Each bite must be small and chewed to mush

- Total calorie intake must be less than $1200 \mathrm{kcals}$ per day 
food intake had a low level of albumin concentration, $2.9 \mathrm{~g} / \mathrm{dL}$ (normal 3.5-5.5 g/L). SAG-I can be easily revised, reversed, or sleeved if necessary [126]. These are the results of a small cohort over the very short term, and more studies are needed for proper comparison and consideration of the procedure.

\section{Laparoscopic Adjustable Gastric Banding (Fig. 17)—Third of the Four Conventional Procedures Described}

Origin, Advantages Despite a marked decline in its use internationally, in 2014, LAGB was the third-most performed procedure worldwide (7.4\%) after SG (45.9\%) and RYGBP (39.6\%) [8]. Evidence suggests that it is a safe and effective procedure, reversible, and durable when patients are properly selected and supported [127]. In a recent multicountry systematic review of seven major studies with 10-year evidence (mean follow-up 84.0\%), LAGB EWL was 54.2\% (33.0$60.0 \%$ ) compared with RYGBP, 54.0\% EWL (27.0-68.0\%) [128]. Marked improvement in well-being and health is often reported with LAGB [129]. LAGB detractors cite its removal and revision rate of $8.0-60.0 \%[128,130]$; however, improvements in understanding of the procedure physiology, device design, and operative techniques have reduced LAGB revision rates [131]. Successful long-term LAGB practitioners advocate the use of their techniques to achieve low rates of reoperation [127], and also advocate careful patient selection, including those who are risk averse and wish to maintain their native anatomy, low-BMI patients, and young patients [132].

Indications/Contraindications, Weight Loss, Diabetes Resolution Indications for LAGB are BMI $>30 \mathrm{~kg} / \mathrm{m}^{2}$ with one or more obesity-related comorbidity, and in certain instances of multiple comorbidities and/or Asian descent, BMI
$27.5-35.0 \mathrm{~kg} / \mathrm{m}^{2}$. In a 2018 study of 2246 obese patients, weight loss at 5 and 8 years was durable, with $52.4 \pm 41.7$ and $57.1 \pm 28.6 \%$ mean EBMIL, respectively [133]. In a 2017 study of 89 morbidly obese patients, metabolic syndrome resolution occurred in $60 / 89$ patients $(67.0 \%)$ at 12 months following LAGB and in $60 / 75(80.0 \%)$ at 24 months [134]. In another 2018 study of patients with T2DM who underwent LAGB $(n=200$, BMI $52.8 \pm 9.2 \mathrm{~kg} /$ $\mathrm{m}^{2}$ ), at mean follow-up of $62.0 \pm 13.0$ months (18-84), $\mathrm{HbA}_{1 \mathrm{C}}$ was reduced by $1.4 \pm 2.0 \%$ from $7.9 \pm 1.9 \%$ and insulin use was reduced from 36.2 to $12.3 \%$ [135].

Operative Mortality/Morbidity, Postoperative Complications, Reversal/Revision LAGB is associated with an extremely low rate of mortality and minimal early and late complications that are generally less severe than with more invasive bariatric procedures [136]. In a comparative study of bariatric surgery morbidity in 25 hospitals, LAGB incidence of life-threatening perioperative morbidity was $0.9 \%$ (95\% CI, $0.6-1.1 \%)$, and mortality was $0.04 \%$ ( $95 \%$ CI, $0.001-0.13 \%$ ) [33]. Critiques of banding include the potential for the band to erode into the stomach, band slippage/migration, dilation of the esophagus, and insufficient weight loss. In the Giet et al. long-term study, overall rate of reoperation for LAGB complications was $4.2 \%$ over 9 years and explant rate was $1.5 \%$ [133]. However, in another long-term LAGB study with less favorable rates of band retention, 405 patients (BMI $44.3 \pm 6.0 \mathrm{~kg} / \mathrm{m}^{2}, 85.0 \%$ follow-up at a mean of 13.3 years [8-18]) saw $71.0 \%$ of patients undergo band removal. Of 343 with intact bands at $\geq 15$ year follow-up, 100 patients (29.0\%) had bands in place with a mean BMI of $35 \pm 7.0 \mathrm{~kg} / \mathrm{m}^{2}$ (EBMIL $48.0 \pm 27.0 \%$ ), with $15.0 \%$ reporting a good or excellent BAROS score outcome [137]. Proponents of the procedure advocate for its acceptable

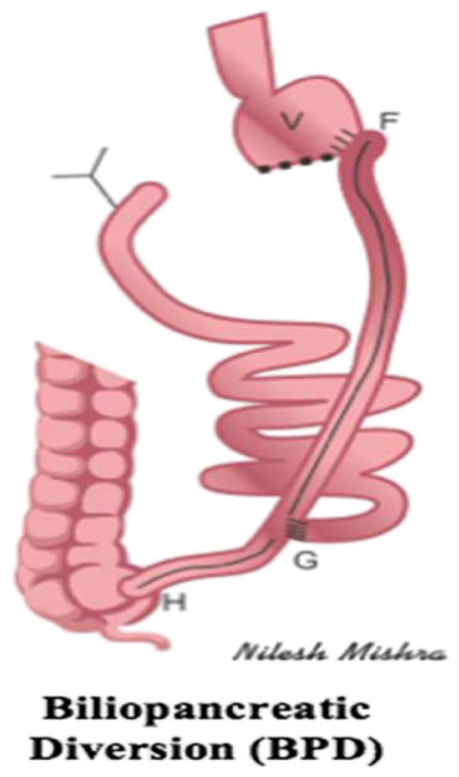

$\begin{array}{ll}V=400 \mathrm{cc} & \text { Volume gastric pouch } \\ \mathrm{F}-\mathrm{G}=250 \mathrm{~cm} & \text { Length of gastrocecal limb } \\ \mathrm{G}-\mathrm{H}=50 \mathrm{~cm} & \text { Length of common limb }\end{array}$

Fig. 18 Biliopancreatic diversion (BPD) 
complication rate and successful use in correctly selected and well-supported patients. LAGB can be safely revised [127].

\section{Biliopancreatic Diversion (Fig. 18)}

Origin, Advantages Scopinaro was the first to develop, perform (1976), and describe BPD (1979) [138]. The procedure yields exceptional weight loss, the best and most permanent of all of the conventional bariatric procedures. It also yields other metabolic effects, some of which appear partially or wholly weight independent, including normalization of serum cholesterol and T2DM remission in $\geq 95.0 \%$. BPD is a technically demanding procedure; despite its many benefits, it is performed in a limited number of patients, approximately $4000 /$ year, with $<3.0 \%$ of the estimated bariatric procedures performed annually in the world [8].

Indications/Contraindications, Weight Loss, Diabetes Resolution BPD is indicated in patients with BMI $\geq 35.0 \mathrm{~kg} /$ $\mathrm{m}^{2}$ with comorbidities [139]. Multiple uncontrolled series of BPD demonstrate long-term weight-loss outcomes (mean 10 years) with maintained EWL ranging from 61.0 to $85.0 \%$ $[140,141]$. Full resolution of T2DM and components of the metabolic syndrome after BPD persists over the long term. In a study of BPD by Scopinaro et al., the major elements of the metabolic syndrome were reversed in all but $2 / 312$ patients with T2DM, and resolution was maintained over 10 -year follow-up [142].

Operative Mortality/Morbidity, Postoperative Complications, Reversal/Revision Protein malnutrition may be an early serious complication of BPD. Other and later-term complications, which have a low incidence, include intestinal obstruction, anemia, marginal ulceration, bone demineralization, peripheral neuropathy, and stomal ulcer in cigarette smokers [143]. The main long-term BPD complication is related to noncompliance with the need for life-long nutritional supplementation, most importantly, liposoluble vitamins (especially A and $\mathrm{E}, \mathrm{Fe}$, and $\mathrm{Ca}$ ). Generally, the long-term surgical revision rate (elongation of the common limb) is $<1.0 \%$. BPD can be readily revised to control protein malnutrition or excessive side effects [144].

\section{Biliopancreatic Diversion with Duodenal Switch (Fig. 19) -Fourth of the Four Conventional Procedures Described}

Origin, Advantages Hess and Hess and Marceau et al. adapted the DeMeester duodenojejunostomy [145] to bariatric surgery as a DS, describing it in conjunction with a Scopinaro BPD [146-148]. The BPD-DS was first performed lapaproscopically by Gagner and colleagues in 1999 [149]. The DS, in which a vertical SG is added to duodenoenterostomy, preserves the gastric lesser curvature, antrum, pylorus, and first part of the duodenum, and the common channel is lengthened from 50 to $\geq 100 \mathrm{~cm}$. These alterations were designed to reduce BPD complications of vomiting, marginal ulceration, micronutrient deficiency, and dumping syndrome [141]. BPD/DS is a well-demonstrated, conventional bariatric operation, and it is the most effective weightloss operation practiced today [95], with the greatest resolution rate of comorbidities of obesity, principally T2DM (95.0\%) [150]. $\mathrm{BPD} / \mathrm{DS}$ is used in $<4.0 \%$ of bariatric procedures globally [8].

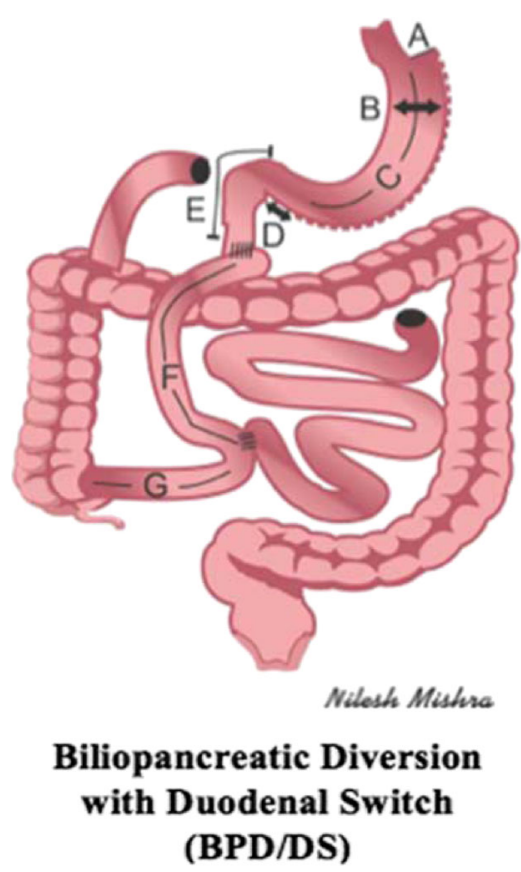

Fig. 19 Biliopancreatic diversion with duodenal switch (BPD/DS)

\author{
$\mathrm{A}=2-3 \mathrm{~cm}$ \\ $\mathrm{B}=3-4 \mathrm{~cm}$ \\ $\mathrm{C}=\mathrm{As}$ is \\ $\mathrm{D}=2-6 \mathrm{~cm}$ \\ $\mathrm{E}=3-4 \mathrm{~cm}$ \\ $\mathrm{F}+\mathrm{G}=250 \mathrm{~cm}$ \\ $\mathrm{G}=100 \mathrm{~cm}$ \\ $\mathrm{V}=150-250 \mathrm{cc}$ \\ Distance of sleeve transection from esophagogastric junction \\ Use 50-60 Fr bougie to size sleeve width \\ Length of sleeve (esophagogastric junction to pylorus) \\ Antrectomy distance from pylorus \\ Length of transected duodenum from pylorus \\ Length of alimentary limb \\ Length of common limb \\ Volume of sleeve created (approx.)
}


Indications/Contraindications, Weight Loss, Diabetes Resolution BPD/DS is indicated for obese and morbidly obese patients with comorbidities. Long-term maintenance of excellent weight loss (61.0-85.0\% EWL) with BPD/DS has been shown in multiple studies [140, 150, 151]. In the Marceau et al. 2015 large single-center study in 2615 open BPD/DS patients, a mean $71.0 \%$ EWL was maintained over 5-20 years [152]. In a meta-analysis of sustained long-term effects of bariatric surgery by Yu et al., 99.2\% (95\% CI, 97.0-99.8) of $400 \mathrm{BPD} / \mathrm{DS}$ patients experienced complete T2DM remission [153]. This outcome is similar to most of the other long-term studies of diabetes remission following BPD/DS.

Operative Mortality/Morbidity, Postoperative Complications, Reversal/Revision In BPD/DS, early mortality is most often associated with anastomotic leaks, pulmonary embolism, and respiratory failure, particularly in super-obesity [141]. In a meta-analysis of 85,048 patients (361 studies), BPD/DS had early mortality rates of $0.29-1.23 \%$ (open) and $0.0-2.7 \%$ (laparoscopic) [154]. In a study of 1000 patients by Biertho et al., the rate of major BPD/DS complications was $7.0 \%$, $6.0 \%$ requiring reoperation [155]; Hamoui et al. in a 10-year study of $701 \mathrm{BPD} / \mathrm{DS}$ patients found a $5.0 \%$ rate of complications requiring revision [156]. BPD/DS necessitates lifelong nutritional monitoring, particularly for nutritional complications [156]. BPD/DS is a time-honored standard procedure with known advantages and disadvantages. It is an operation not only for highly skilled and dedicated metabolic/ bariatric surgeons [157] but also for patients committed to life-long follow-up care. BPD/DS can be employed as a revisional procedure. The prevalence of standalone DS may rise as an option increasingly recommended for revision of failed SG.

\section{Intragastric Balloon (Fig. 20)}

Origin, Advantages Of those who qualify for bariatric surgery, $99.0 \%$ do not accept it or cannot access it, fearing its serious complications, challenges to access, and cost. In addition, there is a vast worldwide population of patients with lower BMIs who have failed conventional weight-loss therapies and seek minimally or noninvasive treatments. Intragastric balloons (IGBs), of which there have been 330,000 implanted worldwide, with 2000 active users, are more effective than lifestyle interventions alone, less costly, and less invasive and risky compared to bariatric surgery. IGBs can also be used for patients with severe obesity as a bridge to traditional bariatric or other surgery (e.g., orthopedic surgery, organ transplantation).

Early IGBs (e.g., Garren Edwards gastric bubble [158]) experienced high complication and failure rates due to structural and placement issues. Current IGBs have been extensively trialed with a focus on safety $[159,160]$. For single-fluidfilled IGBs (type studied most extensively), the device functions by decreasing gastric volume capacity and affecting satiety by means of altered gastric emptying, accommodation, and GI neurohormonal activity over the course of its implantation (6-12 months). With $\geq 10.0 \%$ TBWL, comorbidities improve as well. An abundance of peer-reviewed level-1 evidence describing IGB outcomes exists, including 21 RCTs, a meta-analysis with $n=6800$ from 68 studies [161], and a

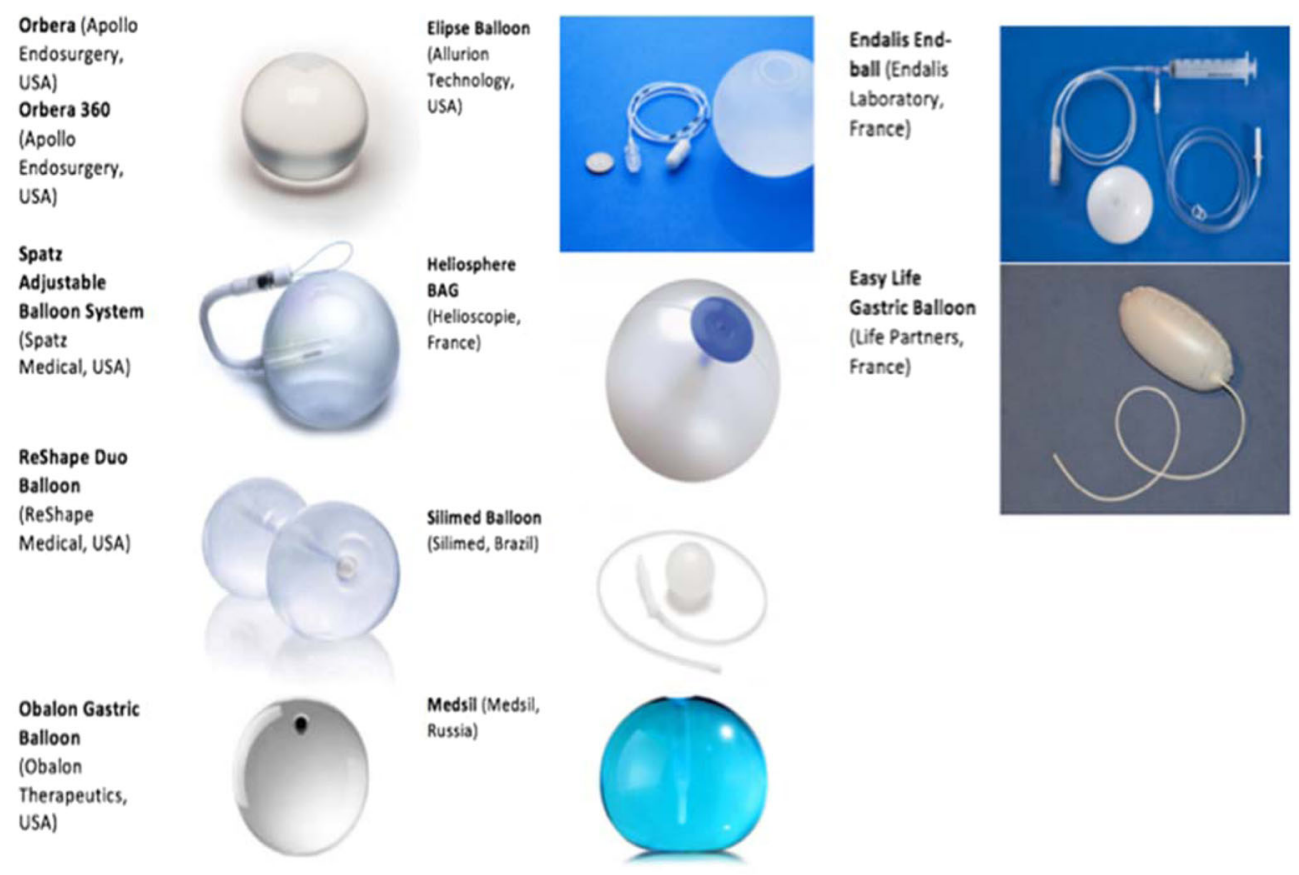

Use is standardized by the manufacturer's instructions.

Fig. 20 Intragastric balloon (IGB) 
Consensus Statement (Brazilian) with $n=41,863$ [22], as well as a report of a consecutive series of post-FDA patients [162].

Indications/Contraindications, Weight Loss, Diabetes Resolution IGBs are indicated for patients with mild to moderate obesity (BMI $30.0-40.0 \mathrm{~kg} / \mathrm{m}^{2}$ ) unsuccessful in maintaining weight loss with lifestyle interventions, or in patients with BMI $>40 \mathrm{~kg} / \mathrm{m}^{2}$ as a bridge to bariatric and other surgical procedures [163]. Contraindications include large hiatal hernia $(>5 \mathrm{~cm})$, prior gastric or esophageal surgery, active ulcer in the stomach, inflammatory bowel disease involving the stomach, etc. [164]. Most IGB weight loss happens within the first 3 months. Whether overweight or severely obese, patients tend to lose approximately $10.0-13.0 \%$ TBWL. A study of IGBs by Melissas et al. found $25.0 \%$ of patients retained $>90.0 \%$ of 6 -month BMI reduction at 1 year; however, $\leq 75.0 \%$ of IGB recipients had some weight regain within 6-30 months [165]. Significant weight loss may continue for 1 year after balloon removal [166]. Meta-analysis of 55 studies including 6645 Orbera IGBs resulted in a pooled estimate of $13.2 \%$ TBWL at 6 months (95\% CI, 12.4-13.95) [161]. In a US multicenter randomized nonblinded pivotal clinical trial of the Orbera IGB plus lifestyle intervention for 6 months $(n=116)$ vs lifestyle intervention alone $(n=135)$, Orbera completers at 6 months lost $10.7 \pm 6.8$ vs $4.7 \pm 5 \%$ TBWL in the control group [167]. In a pivotal US multicenter blinded RCT $(n=187)$ receiving the ReShape Duo IGB plus lifestyle intervention for 6 months compared to those receiving a sham procedure with lifestyle intervention $(n=139), 6$ month TBWL among completers was ReShape Duo group $(n=167) 7.6 \pm 5.5 \%$ vs control group $3.6 \pm 6.3 \% \quad(n=126)$ [168]. In a recent systematic review and meta-analysis by Popov et al., short-term data demonstrated a salutary impact of IGBs on FPG of $-12.7 \mathrm{mg} / \mathrm{dL}$ (95\% CI, - 21.5, - 4.0), triglycerides $-19 \mathrm{mg} / \mathrm{dL}(-42.0,3.5)$, and waist circumference $-4.1 \mathrm{~cm}(-6.9,-1.4)$ [169]. There are scant long-term data on IGB outcomes.

Operative Mortality/Morbidity, Postoperative Complications, Reversal/Revision In the collective results of 21 RCTs $(n=$ $877)$, mortality was $0.0 \%$, perforation $2(0.002 \%)$, bleeding $3(0.003 \%)$, migration $11(0.01 \%)$, obstruction $1(0.002 \%)$, aspiration $2(0.002 \%)$, and pancreatitis 0 . By the metaanalysis of Abu Dayyeh et al. ( $n=6800,68$ studies $)$, mortality was $0.08 \%$, migration $1.4 \%$, and perforation $0.1 \%$ (half in patients with prior surgery) [161]. In the recent Brazilian IGB Consensus Statement, in 41,863 IGB implants, there were 3 balloon-related deaths $(0.000024 \%)$ (gastric perforation, pulmonary aspiration, and pulmonary embolism) [22]. However, a review of the literature featuring eight recent (2006-present) RCTs reported a weighted mean incidence of serious adverse events of $10.5 \%$ in the IGB group across all eight studies. In a recent update from the FDA, new adverse events including acute pancreatitis and balloon hyperinflation were reported for the ReShape and Orbera IGBs [170].

IGB therapy can be used to prevent progression of overweight, manage primary obesity, or serve as a bridge to surgical therapy where weight loss is necessary for the success of that therapy. It is vital to build the expectation of the patient that following IGB removal, lifestyle management of their weight with multidisciplinary medical support and, possibly medication, will be required. IGB practitioners are considering the most effective plans of follow-up post-IGB removal to retain the weight lost and comorbidity improvement [161, 171]. Serious adverse events in a minimally or noninvasive treatment such as the IGB may continue to be a challenge to acceptance. Better clinical and physiologic patient selection tools will be required to maximize benefit and minimize risk associated with IGBs.

\section{vBloc (Fig. 21)}

Origin, Advantages Gastric electrical stimulation (GES) was first performed in 1992 and reported by Cigaina et al. in 1996 [172]. Shikora undertook the first large multicenter, doubleblind RCT of GES in 2000 in the USA in 103 morbidly obese patients [173], and multiple smaller trials followed. Based on the known role of the vagus nerve in weight regulation, an implantable GES therapy evolved, the vBloc System (ReShape Lifesciences, St. Paul, MN). vBloc successfully blocked vagal nerve signaling, emulating the action of surgical vagotomy as performed by Kral [174], but without its unwanted side effects and irreversibility [175]. Vagus nerve blockade using vBloc applies high-frequency electrical impulses directly to vagal nerve trunks to block existing neurophysiologic activities, increasing satiety. Approved by the FDA in January 2015, > 700 patients have been implanted with vBloc worldwide. vBloc effectiveness has been investigated in four feasibility studies, two pivotal trials, the EMPOWER study ( $n=294$, using vBloc RF system), and the RECHARGE study ( $n=239$, using vBloc RC1 system) [176-181]. The action of therapy is believed to delay gastric emptying, resulting in earlier fullness, less hunger, consumption of smaller portion sizes, and reduction of calories.

Indications/Contraindications, Weight Loss, Diabetes Resolution vBloc is indicated for patients with BMI of 35.0 $35.0 \mathrm{~kg} / \mathrm{m}^{2}$. The EMPOWER trial was a prospective, parallelgroup, double-blind RCT in 294 nondiabetic patients in 15 centers (13 USA, 2 Australia). Patients were randomized in a 2:1 allocation to the treatment group (activated device) or control group (nonactivated device). vBloc was shown to be safe in treating obesity, but without significantly different weight loss from the controls. Post-study analysis suggested that the electrical safety checks may have inappropriately 


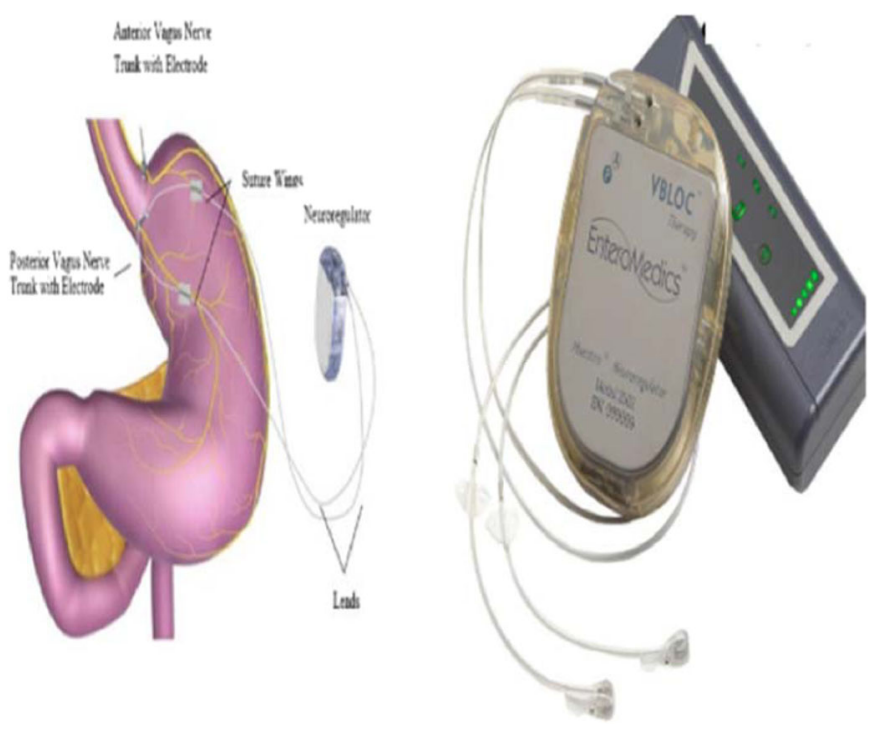

Use is standardized by the manufacturer's instructions.

Fig. 21 vBloc

blocked vagal trunks also contributing to weight loss among controls [176].

The ReCharge trial was a double-blind, sham-controlled, RCT in 239 patients (BMI $35.0-45.0 \mathrm{~kg} / \mathrm{m}^{2}$ ) across 10 centers (8 USA, 2 Australia). Sham/control group patients were implanted with subcutaneous neuroregulators without electrodes, and the sham operation involved the same number of incisions as the treatment group, however with no peritoneal penetration. Both groups received neuroregulators that could be programmed, and all devices were set to deliver charges for at least $12 \mathrm{~h}$ /day [177, 178, 180]. At 24-month follow-up, mean vBLoc treatment group EWL was $21.0 \%$ (95\% CI, 16.0-26.0\%) and mean TBWL was $8.0 \%$ (95\% CI, 6.0$10.0 \%$ ). Overall improvements from baseline in diastolic and systolic blood pressure and waist circumference were significant. Among all vBloc participants, 24-month improvements from baseline were statistically significant at 24 months for LDL and HDL cholesterol, triglycerides, and $\mathrm{HbA}_{1 \mathrm{C}}$. FPG was the only parameter not significantly changed. Fifty percent of patients remitted from metabolic syndrome at 12 months and $47.0 \%$ by 24 months. Among prediabetic patients, at 12 months, $57.0 \%$ had achieved normoglycemia, and at 24 months, 50.0\% [181]. vBloc therapy for intermittent vagal blocking is safe and produces meaningful weight loss through 2 years with sustained improvements in obesityrelated cardiovascular risk factors and healthy eating behaviors.

\section{Operative Mortality/Morbidity, Postoperative Complications,} Reversal/Revision vBloc therapy is associated with an excellent safety profile, and fewer serious adverse events are reported with vBloc than in almost all other bariatric procedures (e.g., mild to moderate heartburn or dyspepsia and abdominal pain) $[176,177]$. A large knowledge gap remains regarding its mechanisms of action, patient selection, optimum therapeutic targets, and efficacy markers (e.g., gastric distention, neuropeptides, electrocardiogram changes, etc). vBloc can be programmed to administer multiple pulse frequencies, voltages, currents, and total energy delivered. The parameters to achieve maximum weight loss and metabolic effectiveness remain to be determined. vBloc vagal nerve blocking is reversible and programmable, does not alter native anatomy, and can achieve durable benefits in weight loss and metabolic improvements. It is an option for patients who are not interested in, or are unable to have, standard bariatric surgery.

\section{Gastric Plication (Fig. 22)}

Origin, Advantages LGCP was first reported in the 1960s [182] and popularized by Talebpour et al. in Iran in 1999. It involves an SG that is formed by vertically plicating the gastric greater curvature using nonabsorbable sutures following transection of the omentum (with no bowel transection). Although originally thought to offer the advantage of ready reversibility, this characteristic is not universally the case, and the procedure is practiced particularly for its other advantages, including no need for resection, bypass, or an implantable device, and a low rate of complications [183]. The cost of LGCP was found to be less that of SG, RYGBP, and LAGB [184].

Indications/Contraindications, Weight Loss, Diabetes Resolution LGCP is indicated for patients with a BMI $\geq$ $40 \mathrm{~kg} / \mathrm{m}^{2}$. A relative contraindication is previous surgery that might limit a patient's ability to vomit [183]. LGCP is effective for weight loss and T2DM resolution (based on collective worldwide evidence of $>6000$ patients, 


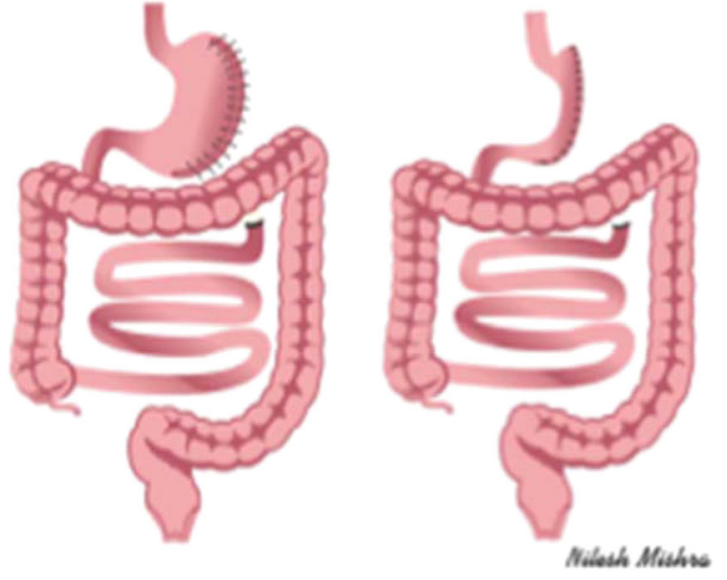

Gastric Plication (GP)
No measurements that can be standardized. Technique summary:

- Place gastric tube 32-36 as size guide for creation of sleeve

- Identify pylorus

- Take down omentum on greater curvature starting $3 \mathrm{~cm}$ from pylorus up to angle of His

- Perform 2-row plication from angle of His to $3 \mathrm{~cm}$ from pylorus (purse string interrupted nonabsorbable sutures)

- Perform $3^{\text {rd }}$ row of continuous nonabsorbable suturing for alignment

- Endoscopic evaluation of created sleeve

Fig. 22 Gastric plication (GP)

including 3500 patients in the experience of Dolezalova and Fried (> 200 of which have attained 5-year outcomes) [185]. In a systematic review of LGCP by Ji et al. (14 studies, 1450 patients), mean EWL of $74.4 \%$ EWL at 2 years was reported [186]. In the 2017 Dolezalova et al. study of LGCP patients with complete weight data at 5 years, mean respective EWL and EBMIL were 56.8 and $61.5 \%$ at 2 years and 52.6 and $56.9 \%$ at 5 years [185]. Their findings correspond with those of the 2012 study of Talebpour et al. of 800 LGCP patients who, at 5year follow-up, achieved 55.0\% EWL (28.0-100.0\%) [184]. In a 2015 report by Talebpour et al. in 60 LGCP patients who had achieved a maximum weight loss of $57 \mathrm{~kg}$ at 6 months, $95.0 \%$ of T2DM patients attained resolution at 1 year follow-up, and 2/55 patients who experienced weight regain also regained their T2DM [187]. In the Dolezalova et al. study, 58 patients $(27.4 \%)$ had T2DM at baseline; at 5 years, $65.5 \%$ of T2DM was resolved. The majority of LGCP patients with early improvement in T2DM retained these benefits despite varying weight regain (mean 9.2\%) [185].

Operative Mortality/Morbidity, Postoperative Complications, Reversal/Revision LGCP has not been associated with mortality. The procedure is safe, with a rate of $4.4 \%$ major complications, $3.0 \%$ reoperation, and $0.2 \%$ conversion, as shown in a review of 521 LGCP patients [188], findings corroborated by a study by Dolezalova et al. of 212 morbidly obese LGCP patients at 5-year follow-up. Leakage occurred in this cohort in a small percentage of patients, less than in SG [185]. Talebpour et al. reported a $1.0 \%$ revision rate in their large 2012 study, and in their recent direct RCT comparison of LGCP $(n=35)$ and SG $(n=35)$, they saw comparable postoperative complication rates in short-term follow-up [184, 189]. LGCP involves risks similar to the SG, including bleeding, perforation, and portal vein thrombosis. Reversal of LGCP can be complicated after 1-6 months due to the healing of the gastric plication; however, if a patient has weight regain over the mid to long term, dilation of the lesser curvature facilitates conversion to another procedure, such as SG. Reversal vs reapplication of the plication vs conversion is determined on a case-by-case basis $[184,185]$.

\section{Banded Gastric Plication (Fig. 23)}

Origin, Advantages BGP was innovated by Huang in 2009 as a combination of the adjustable gastric banding and plication procedures designed to reduce AGB adjustment frequency and improve weight loss [190, 191].

\section{Indications/Contraindications, Weight Loss, Diabetes} Resolution BGP is indicated for patients with BMI $\geq$ $37.0 \mathrm{~kg} / \mathrm{m}^{2}$ with obesity-related comorbidities, or BMI $\geq$ $32.0 \mathrm{~kg} / \mathrm{m}^{2}$. In the Huang et al. initial study of 26 patients, at 12 -month follow-up, weight loss was $59.5 \pm 17.9 \%$ EWL with a mean of 1.1 adjustments during that period, and there were no mortality and two complications (gastrogastric intussusception and tube kinking in the subcutaneous layer) [191]. In the Huang et al. 2012 casematched comparative study of BGP and SG, 2-year EWL was similar (67.2 vs $66.9 \%, p=0.97)$ between procedures [192]. Findings of a study by Chaudhry et al. $(n=17)$ and a study by Ahluwalia et al. mirror the Huang et al. 2013 case-matched BGP vs SG weight-loss outcomes at 2-year follow-up [193, 194]. Cottam et al. in a matched study of BGP and SG found SG EWL significantly greater at 2 years (SG, $67.2 \pm 25.7 \%$ vs BGP, $45.9 \pm 25.3 \%$ ), although there was a smaller follow-up percentage in the SG group (49.0\%) than in the BGP group (70.0\%) [195].

Operative Mortality/Morbidity, Postoperative Complications, Reversal/Revision In the collective BGP studies of Huang 


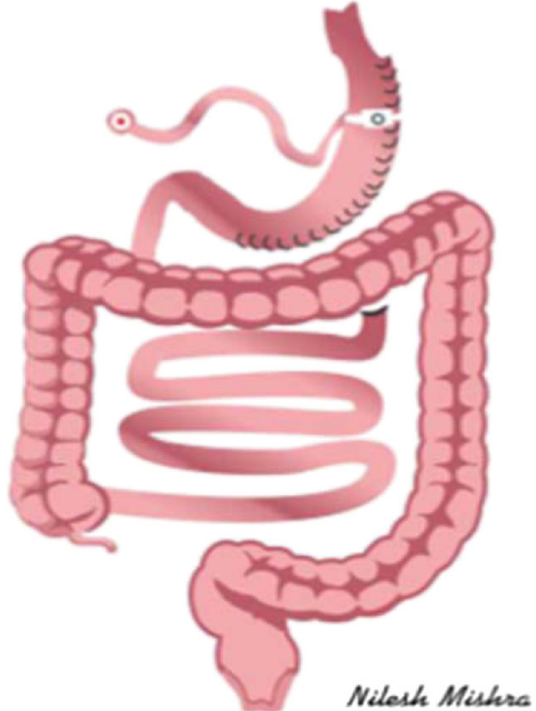

Adjustable Banded Gastric Plication (BGP)

Fig. 23 Adjustable banded gastric plication (BGP)

et al. $(n=295)$, total reoperation rate was $9.1 \%$ and no mortality. Complications included fundal herniation and band slippage (six), revised laparoscopically; two leaks, converted to normal anatomy or SG; two band failures, replaced by new bands; one injection port infection, debrided; and one case of intractable GERD, converted to RYGB. Revision to SG or RYGBP due to insufficient weight loss or regain was performed in 13 patients. BGP appears to offer weight loss between that of LAGB and SG, and is potentially reversible. It may offer a new bariatric surgical option, especially for those who will not consider nonreversible procedures and for patients who require a salvage procedure for LAGB failure.

\section{EndoBarrier (Fig. 24)}

Origin, Advantages Experimental work in nonobese diabetic rats by Rubino showed that exclusion of the duodenum has a marked effect on glucose metabolism [196], and exclusion of chyme from the duodenum by means of an endoluminal tube significantly improves glucose homeostasis [197]. The duodenojejunal bypass liner (DJBL, EndoBarrier $\left.{ }^{\circledR}\right)$, a 60 -cm long, soft, impermeable fluoropolymer sleeve, was developed for endoscopic placement and maintenance in the duodenal bulb with a nitinol anchor [198]. It entered clinical use internationally in 2006 for obese and/or diabetic patients $(\mathrm{BMI} \geq 30)$ but is not yet in the USA [199-201]. The EndoBarrier is minimally invasive and rapidly normalizes glycemic control in diabetic patients.
Indications/Contraindications, Weight Loss, Diabetes Resolution EndoBarrier is indicated for patients with BMI $\geq 30 \mathrm{~kg} / \mathrm{m}^{2}$ who have failed lifestyle modification. A 2017 meta-analysis of 17 studies by Jirapinyo et al. analyzed weight loss and $\mathrm{T} 2 \mathrm{DM}\left(\mathrm{HbA}_{1 \mathrm{C}} \geq 6.5 \%\right)$, with 14 studies of the effect of EndoBarrier on glycemic control in obese T2DM patients, and 388 patients underwent successful placement of EndoBarrier. Mean BMI was $30.0-48.9 \mathrm{~kg} /$ $\mathrm{m}^{2}$ and $\mathrm{HbA}_{1 \mathrm{C}}$ was $6.7-9.2 \%$ at the time of implantation, and the device was implanted for a mean $8.4 \pm 4.0$ months. At explantation, TBWL was $12.6 \pm 1.3 \mathrm{~kg}(p<0.0001)$, which was maintained at 6-month follow-up, significantly lower $(-7.07 \mathrm{~kg}, p<0.0001)$ than at baseline, $\mathrm{HbA}_{1 \mathrm{C}}$ decreased $1.3 \%$ (95\% CI, 1.0, 1.6; $p<0.0001)$, and FPG decreased $44.6 \mathrm{mg} / \mathrm{dL}(31.2,57.9 ; p<0.0001)$ [202]. After EndoBarrier explantation, $\mathrm{HbA}_{1 \mathrm{C}}$ and $\mathrm{BMI}$ often increase but remain significantly below baseline levels [203]. The device is associated with mean T2DM resolution of $47.0 \%$ at 1-year follow-up [199].

Operative Mortality/Morbidity, Postoperative Complications, Reversal/Revision A US pivotal double-blinded multicenter trial sham-controlled trial was terminated early with 325 of the intended 500 patients due in particular to a $3.5 \%$ incidence of hepatic abscess formation (from the spikes of the metallic anchoring stent in the duodenum), GI bleeding, device migration, and development of pancreatitis [161, 162]. Secondgeneration duodenojejunal bypass liner devices with nontraumatic anchor and retrieval systems are currently in clinical trials. EndoBarrier can be removed at any time to resolve adverse events. EndoBarrier implantation duration is 


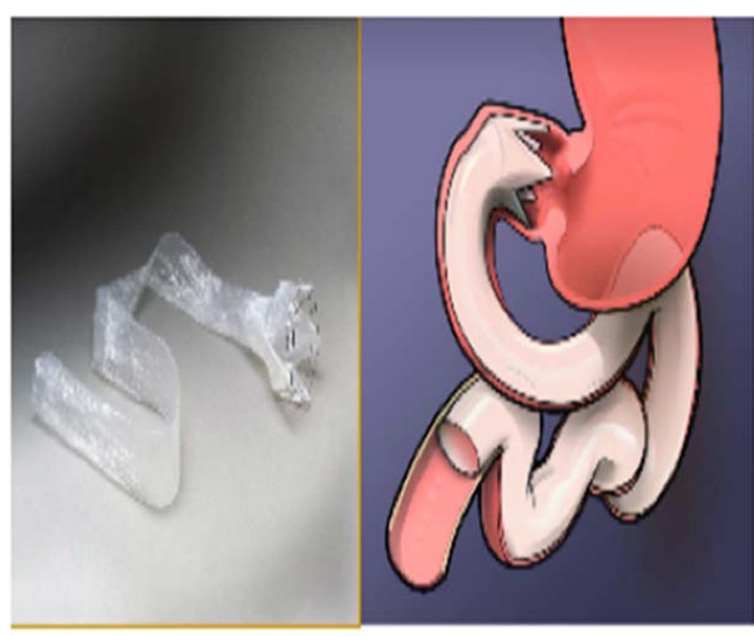

Endobarrier
Use is standardized by the manufacturer's instructions:

- Patient selection and coaching using multidisciplinary team (endocrinologist, dietician, physiotherapist, psychologist, bariatric surgeon, gastroenterologist)

- Implantation:

- General anesthesia or conscious sedation by (bariatric) endoscopist and or bariatric surgeon

○ Follow guidelines of the company

- The anchor is placed in the duodenal bulb preventing placement in or close to pylorus

- Deployment of sleeve under fluoroscopy (obligatory)

- Advised perioperative procedure prophylaxis with antibiotics, $\mathrm{H}_{2}$ receptor antagonist

- Absolute contraindication: previous upper gastrointestinal tract surgery

- Post procedure 1-2 weeks liquid diet; therafter chew food carefully according to prescribed diet, prevent use of NSAIDs

- Regular follow-up until removal at 1 year (or earlier)

- Immediate contact of patient with treating physician on unexpected complaints (pain, nausea, vomiting, fever, general, discomfort)

- Antibiotic prophylaxes on Endobarrier removal

- Removal under general anesthesia following instructions of the company, (over tube available). On difficult removal it is an option to invert the Endobarrier sleeve and anchor

Fig. 24 EndoBarrier

brief but can be successfully repeated [204]. It represents an emerging endoscopic therapy that may prove effective in resolving T2DM in many patients for whom lifestyle change is not successful.

\section{AspireAssist (Fig. 25)}

Origin, Advantages The AspireAssist ${ }^{\circledR}$ (Aspire Bariatrics, King of Prussia, PA), FDA approved in 2016, facilitates gastric aspiration therapy, in which food is removed from the stomach through an endoscopic gastrostomy aspiration tube through a skin port. The aspiration tube is endoscopically inserted; after 1-2 weeks, the external port is connected [205]. The objective of temporary or longer-term placement of the AspireAssist, beyond immediate postmeal calorie removal, is to induce long-term behavioral changes that decrease food intake and improve food choices to treat and prevent obesity.

\section{Indications/Contraindications, Weight Loss, Diabetes} Resolution The AspireAssist system is approved in the USA for patients $\geq 22$ years old with a BMI 35.0$55.0 \mathrm{~kg} / \mathrm{m}^{2}$ [206], and it is CE marked for patients with BMI $35.0-65.0 \mathrm{~kg} / \mathrm{m}^{2}$. A US pilot RCT was conducted $(n=10$, aspiration therapy group, mean BMI $42.0 \pm$ $1.4 \mathrm{~kg} / \mathrm{m}^{2} ; n=4$, lifestyle therapy-only group, mean BMI $39.3 \pm 1.1 \mathrm{~kg} / \mathrm{m}^{2}$ ) with 1-year outcomes. Weight loss was $18.6 \pm 2.3 \%$ TBWL, aspiration therapy group vs $5.9 \pm$ $5.0 \%$ TBWL, lifestyle group ( $p=0.021)$, and seven subjects in the aspiration therapy group completed 2 years of therapy with $21.2 \pm 2.8 \%$ TBWL [207]. In the multicenter US "PATHWAY" RCT $(n=111$ aspiration group, BMI $42.2 \pm 5.1 \mathrm{~kg} / \mathrm{m}^{2}$ vs lifestyle group, $n=60$, BMI $40.9 \pm$ $5.1 \mathrm{~kg} / \mathrm{m}^{2}$ ), the modified intention-to-treat analysis weight loss was $12.1 \pm 9.6$ and $3.5 \pm 6.0 \%$ TBWL, respectively $(p<0.001)$. In the completer analysis, weight loss was $14.2 \pm 9.8 \%$ (aspiration group, $n=82$ ) and $4.9 \pm 7.0 \%$ TBWL (lifestyle group, $n=31)(p<0.01)$ [208]. In a European multisite clinical registry $(n=160)$, similar TBWL was found, i.e., 1 year, $24.3 \pm 13.9 \%(n=117)$; 2 years, $26.6 \pm 17.3 \%(n=78) ; 3$ years, $30.3 \pm 15.3 \%$ $(n=23)$; and 4 years, $25.1 \pm 19.1 \%(n=12)$ [209]. In a Swedish trial by Forssell et al., T2DM patients had significant blood glucose improvement, and three out of five discontinued diabetic medications [210].

Operative Mortality/Morbidity, Postoperative Complications, Reversal/Revision In AspireAssist trials, there has been no mortality. Adverse events included abdominal pain after placement of aspiration tube, granulation tissue and irritation around the stoma, and intra-abdominal fluid collection [208, 210]. In the US pilot study, there were three infections: two were local fungal infection and one was a soft tissue infection. One of the four patients who elected to have the tube removed had a persistent fistula requiring several endoscopies to achieve closure [207]. AspireAssist therapy may become an effective tool in managing obesity when administered to carefully selected patients in the context of a multidisciplinary weight-loss program. 

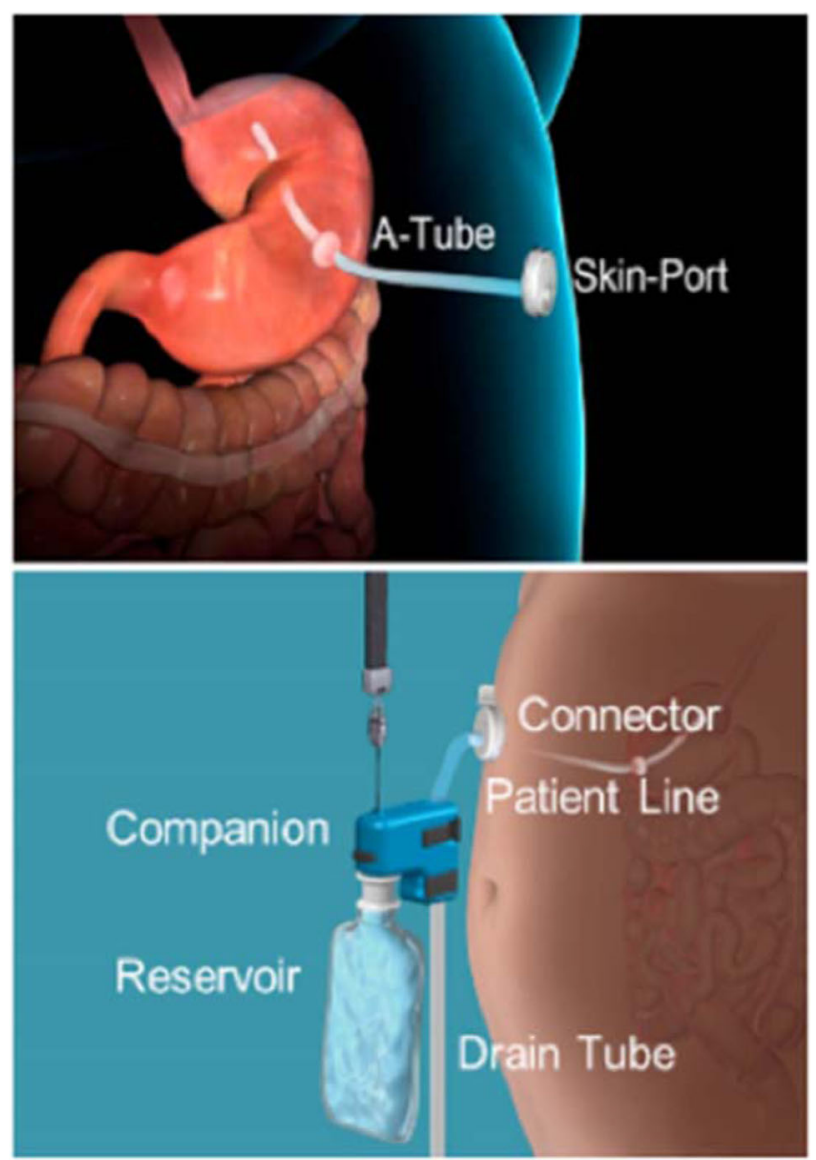

Aspire Assist

Fig. 25 AspireAssist

\section{Discussion}

\section{Standardization of Outcomes Reporting in Metabolic and Bariatric Surgery}

At the outset of the BMSS meeting, important broad concepts in bariatric metabolic surgery were reviewed. These included standards posited for weight-loss and glycemia outcome reporting, methods of measurement of the gastrointestinal tract for bariatric operations, and indications for pediatric bariatric surgery. The resulting debate suggested that consensus standardization of these multifaceted and controversial topics would be a lengthy process more fully addressed in a future meeting. Recommendations for standardized metabolic and bariatric surgery outcomes reporting (particularly the recent comprehensive review by Brethauer et al. and the ASMBS Clinical Issues Committee [211]) need to be addressed systematically.

\section{Recommendations for Procedure Standardization}

To understand the elements in each procedure that correlate with beneficial weight loss and metabolic effects, uniform
Use is standardized by manufacuturer's instructions.

measurement is a fundamental requirement. Yet, a variety of versions of bariatric metabolic procedure configurations exist, to say nothing of the range of variations in the sequence of steps involved in the complete procedure. This procedure heterogeneity was clearly established in the BMSS meeting and has been documented in prior reports [212-214]. Participants of the inaugural BMSS Consensus Meeting worked toward agreement on recommendations for procedural anatomic measurement standards. Their consensus on $22 / 25$ bariatric metabolic procedures has been presented herein (Table 1). As stated previously, inclusion and discussion of emerging procedures in this review, nor voting on their standard endprocedure anatomic configurations, does not constitute a scientific validation or approval of that procedure.

\section{Challenges of Standardization}

Two primary issues related to the process of standardization by consensus emerged and were addressed in the meeting.

In advance of the meeting, in extensive phone consultation with procedure originators and surgeons performing large series, the chairmen (MB, MF) conferred on development of the procedure standards to be proposed. At the meeting outset, the 
chairmen explained the aim of voting as affirmation that an anatomic configuration proposed was to be recognized in the field as the correct standard version of that procedure-not as the procedure configuration a surgeon voter would personally prefer to perform, or that s/he believed might be more successful, or a procedure that s/he would endorse based on available evidence. The vision for this aim was that evidence-based analysis of procedure outcomes in the future would be sharpened by establishment of a standard procedure with which new studies reporting their standardized results could be pooled. In addition, comparisons of such standardized results to variant and alternative procedures would be greatly refined.

During the first half of the meeting, misunderstanding regarding the basis for voting and some disagreement with it were evident. A voter with this ambiguity or conflict would not be able to vote with clarity of purpose to standardize certain configurations. Several arguments as to the basis for decision-making about standards were put forth: (1) the argument for use of the innovator's configuration, (2) the argument for use of the configuration with best safety and efficacy outcomes (although sufficient data comparing identically measured configurations are not available), and (3) the argument for use of the configuration performed in the largest reported series with good outcomes (although often, more than one surgeon had performed a large series, each using a somewhat different configuration of the "same procedure").

Most panelists and attendees concurred that in considering the majority of the 25 procedures, these arguments would be intertwined and additional variables would arise to conflate decision-making. A singular, uncontested basis for determining a standard was not available. The nature of this debate confirmed the importance of and need for a standardization meeting guided by a consensus of expert surgeon opinion.

During the second meeting day, the chairmen devoted a portion of a session to clarifying the voting process to ensure that the remaining votes would be undertaken with the full understanding of the group. The primary basis for defining a standard was rearticulated to orient voting toward identifying the configuration most performed with good results by most surgeons. In many instances, this procedure correlated with the configuration used by the procedure originator. Secondarily, through debate, the group agreed to revise one to two nuances of the measurements of some configurations. These changes were redrawn as the proposed anatomic standard configurations on which to vote in the remainder of phase 1 and throughout phase 2. Ten of 13 procedures (Figs. 1, 5, 6, $7,8,9,10,11,12$, and 24) that eluded consensus in the first vote met the consensus threshold, ratifying $22 / 25$ proposed standards.

A second conceptual issue raised was the challenge of selecting standards for one of the very recently introduced novel, or emerging, procedures in the absence of a body of research evidence and/or lack of personal clinical experience witnessing or performing it. Most participants had only an impression of such experimental or emerging procedures from the literature and/or solely from its description at the meeting. In this case, the majority resolved that the standardized version of an emerging procedure should be the original version as defined by its originator.

\section{Recommendation of Metabolic and Bariatric Surgery Tenets}

The following are recommended for recognition as standardized tenets on topics of central importance to bariatric metabolic surgery.

1.Obesity is a disease, and bariatric surgical treatment is a viable long-term option for the management of obesity.

2.Metabolic diabetes surgery is a viable option for longterm treatment of type 2 diabetes mellitus.

3.Bariatric surgery and diabetes surgery are subfields within metabolic surgery. Metabolic bariatric surgery, and metabolic diabetes surgery, are terms that correctly express the taxonomy of metabolic surgery.

4.Each bariatric procedure should be identified by a single set of precise anatomic measurements that characterize its final anatomic reconfiguration standard. Such identification of procedures facilitates accurate data collection and analysis of outcomes to improve targeting of treatment for specific aspects of metabolic disease.

5.To avoid creation of confounding outcomes, procedure variants, by definition, must vary from a single foundational standard procedure applied consistently by the field.

\section{Next Steps}

While no single medicine, or operation, is best for all patients, preventable heterogeneity that impedes precise and verifiable analysis exists in bariatric metabolic operative techniques. Medicines are prescribed in specifically tested dosages, so, too, standardization of key surgical procedure measurements is a prerequisite for safety and effectiveness. In addition, bariatric surgery engages a multitude of diverse metabolic effects, both weight independent and weight dependent. One of the most important questions with which the field must wrestle going forward is that these metabolic changes have not been clearly or fully correlated with clinical outcomes. Designating and consistently applying exact anatomic procedure measurements is a necessary step toward decoding these correlations.

The BMSS Working Group intends to advance discussion and revision of the consensus standards, working with the international bariatric metabolic community toward their adoption. The next step proposed is the use of a structured process of iterative consensus building, such as the Delphi technique [215, 216]. Mailed or electronically delivered 
surveys that further test the BMSS consensus outcomes can be employed. A preliminary list of open- and closed-ended questions covering the BMSS standards circulated to respondents would enable the BMSS to further refine the questions and responses that arose at the initial meeting. Participants may accept, delete, or modify these queries and add comments. A predefined percentage of agreed items, and any modifications added, would be carried forward into a second and third iteration, refining the consensus on procedure standards.

Eventual compilation of new procedure data based on refined, harmonized standards has the potential to improve outcome reporting, facilitate collaborative trial design, and provide insight into the physiology of metabolic diseases, paving the way for both surgical and nonsurgical therapies.

\section{Limitations}

A methodological limitation of the meeting and statement is that a less formal consensus process than the Delphi or Rand process was employed. Also, individual systematic reviews were not performed as the basis for each procedure background summary. Where possible, systematic reviews and meta-analyses were drawn upon as the foundation for procedure outcome summaries; however, the lack of high-quality (evidence-based medicine levels 1-2) reports cited in many of the existing published systematic reviews emphasizes the very problem of nonstandardized reporting that the BMSS consensus meeting sought to redress. The current statement is a first step toward building initial bariatric community knowledge of the included procedures.

\section{Conclusions}

In the absence of standard measurements for the key anatomic alterations of bariatric metabolic procedures, we cannot know our true outcomes, and metabolic effects cannot be finely understood and used to predict and treat disease. The inaugural 2-day BMSS meeting in New Delhi, India, and the BMSS Consensus Statement were undertaken to establish a conceptual foundation from which to move in stages toward highlevel evidence-based studies. A consensus of standards resulting from peer-reviewed evidence and expert opinion was achieved, providing a frame of reference for future research and for dialogue with fellow physicians, providers, government agencies, the media, and, most importantly, patients. To our knowledge, this Consensus Statement of the BMSS Working Group provides the first set of expert opinion-based standards to define the anatomic alterations performed in the majority of available bariatric metabolic procedures.

In this meeting, learned presentations were made by several of the originators of procedures under discussion, some of whom have performed their operations for nearly 40 years
[138]. The innovators were instrumental in validating the need for a standardization congress and the importance of the use of standard measures to ensure uniformity in comparisons. Standardization will facilitate the development of the safest and most effective procedures to treat specific diseases. Those procedures will not necessarily be the ones described by their originators or proponents, but by the authority of research performed by numerous practitioners over many years. Their precision in measurement will give rise to a consensus of the evidence.

Acknowledgments We are very grateful for the planning, preparatory work, and extensive support of the local organizing committee: Dr. Vinod Bhandari (Founding Chairman, SAIMS Medical College and Postgraduate Institution, Indore, MP, India), Dr. Manjushree Bhandari (Chairperson, SAIMS Medical College and Postgraduate Institution, Indore, MP, India), Dr. RR Wavare (Dean, SAIMS Medical College and Postgraduate Institution, Indore, MP, India), Shantanu Bhagdikar, Mahak Bhandari, Sachin Kale, Arun Mishra, Nilesh Mishra, Winnie Mathur, Manoj Reddy, Himanshu Shrivastava, and Abhishek Tiwari. We greatly appreciate the guidance and contribution in the planning of the meeting and reviewing the consensus statement by the Scientific Advisory Committee: Dr. Pradeep Chowbey, Dr. John Dixon, Dr. Kamal Mahawar, Dr. David Cummings, Dr. Abdelrahman Nimeri, Dr. Eric DeMaria, Dr. Michel Gagner, Dr. Natan Zundel, and Dr. Henry Buchwald. We thank the SAIMS Foundation for their generous sponsorship of the World Consensus Meeting on Standardization of Bariatric Metabolic Procedures and associated statement development. We also especially thank Ngwebifor Fobi for her expert meeting organization and management.

Funding This work was supported by Sri Aurobindo Institute of Medical Sciences (SAIMS), Indore, MP, India. J.N. Buchwald received a grant for manuscript development from SAIMS, Indore, MP, India.

Conflict of Interest The authors declare that they have no conflicts of interest.

Open Access This article is distributed under the terms of the Creative Commons Attribution 4.0 International License (http:// creativecommons.org/licenses/by/4.0/), which permits unrestricted use, distribution, and reproduction in any medium, provided you give appropriate credit to the original author(s) and the source, provide a link to the Creative Commons license, and indicate if changes were made.

\section{References}

1. Colquitt JL, Pickett K, Loveman E, et al. Surgery for weight loss in adults. Cochrane Database Syst Rev. 2014;8:CD003641.

2. Buchwald H, Varco R. Metabolic surgery. New York: Grune \& Stratton; 1978.

3. Buchwald H. The evolution of metabolic/bariatric surgery. Obes Surg. 2014;24:1126-35.

4. World Health Organization. Obesity and overweight key facts. Accessed July 2018. http://www.who.int/news-room/fact-sheets/ detail/obesity-and-overweight. Accessed 20 June 2018

5. Dobbs R, Sawers C, Thompson F, et al. Overcoming obesity: an initial economic analysis: McKinsey Global Institute; 2014. 
https://www.mckinsey.com/mgi/our-research/discussion-papersand-briefings. Accessed 20 June 2018

6. Global Burden of Disease Obesity Collaborators. Health effects of overweight and obesity in 195 countries over 25 years. N Engl J Med. 2017;377(1):13-27.

7. Buchwald H, Buchwald JN. Review: Metabolic (bariatric and non-bariatric) surgery for type 2 diabetes. Diabetes Care. 2019;42(2):331-40.

8. Angrisani L, Santonicola A, Iovino A, et al. Bariatric surgery and endoluminal procedures: IFSO worldwide survey 2014. Obes Surg. 2017;27(9):2279-89.

9. Reges O, Greenland P, Dicker D, et al. Association of bariatric surgery using laparoscopic banding, Roux-en-Y gastric bypass, or laparoscopic sleeve gastrectomy vs usual care obesity management with all-cause mortality. JAMA. 2018;319(3):279-90.

10. Ribaric G, Buchwald JN, McGlennon TW. Diabetes and weight in comparative studies of bariatric surgery vs conventional medical therapy: a systematic review and meta-analysis. Obes Surg. 2014;24(3):437-55.

11. Schauer PR, Bhatt DL, Kirwan JP, et al. Bariatric surgery versus intensive medical therapy for diabetes - 5-year outcomes. N Engl J Med. 2017;376(7):641-51.

12. NIH conference. Gastrointestinal surgery for severe obesity. Ann Intern Med. 1991;115:956-61.

13. WHO Consultation on Obesity (1997: Geneva, Switzerland), World Health Organization. Division of Noncommunicable Diseases \& World Health Organization. Programme of Nutrition, Family and Reproductive Health. Obesity: preventing and managing the global epidemic: report of a WHO Consultation on Obesity, Geneva, 3-5 June 1997. Geneva: World Health Organization; 1998.

14. American Medical Association. House of Delegates Resolution 420: recognition of obesity as a disease. Presented at: House of Delegates Annual Meeting, 2013. http://www.ama-assn.org/ assets/meeting/2013a/a13-addendum-refcomm-d.pdf. Accessed June 2018.

15. Mahawar KK, Himpens J, Shikora SA, et al. The First Consensus Statement on one anastomosis/mini gastric bypass (OAGB/MGB) using a modified Delphi approach. Obes Surg. 2018;28(2):303-12.

16. Rubino F, Kaplan LM, Schauer PR, et al. The Diabetes Surgery Summit consensus conference: recommendations for the evaluation and use of gastrointestinal surgery to treat type 2 diabetes mellitus. Ann Surg. 2010;251(3):399-405.

17. Coulman KD, Hopkins J, Brookes ST, et al. A core outcome set for the benefits and adverse events of bariatric and metabolic surgery: the BARIACT Project. PLoS Med. 2016;13(11):e1002187.

18. Stogryn S, Park J, Hardy K, et al. Development of consensusderived quality indicators for laparoscopic Roux-en-Y gastric bypass surgery. Surg Obes Relat Dis. 2017;13(2):198-203.

19. Gagner M, Hutchinson C, Rosenthal R. Fifth International Consensus Conference: current status of sleeve gastrectomy. Surg Obes Relat Dis. 2016;12(4):750-6.

20. Runkel N, Colombo-Benkmann M, Huttl TP, et al. Evidencebased German guidelines for surgery for obesity. Int J Colorectal Dis. 2011;26(4):397-404.

21. Misra A, Chowbey P, Makkar BM, et al. Consensus statement for diagnosis of obesity, abdominal obesity and the metabolic syndrome for Asian Indians and recommendations for physical activity, medical and surgical management. JAPI. 2009;57:163-70.

22. Galvao Neto M, Bezzera Silva L, Grecco E, et al. Brazilian intragastric balloon consensus statement (BIBC): practical guidelines based on experience of over 40,000 cases. Surg Obes Relat Dis. 2018;14:151-61.

23. Busetto L, Dixon J, de Luca M, et al. Bariatric surgery in class I obesity: a position statement from the International Federation for the Surgery of Obesity and Metabolic Disorders (IFSO). Obes Surg. 2014;24(4):487-519.

24. Kim J, American Society for Metabolic and Bariatric Surgery Clinical Issues Committee. American Society for Metabolic and Bariatric Surgery statement on single-anastomosis duodenal switch. Surg Obes Relat Dis. 2016;12(5):944-5.

25. Sauerland S, Angrisani L, Belachew M, et al. Obesity surgery: evidence-based guidelines of the European Association for Endoscopic Surgery (EAES). Surg Endosc. 2005;19(2):200-21.

26. Howick J, Chalmers I, Glasziou P, et al. Explanation of the 2011 Oxford Centre for Evidence-Based Medicine (OCEBM) levels of evidence (background document): Oxford Centre for EvidenceBased Medicine. www.cebm.net/index.aspx?o=5653. Accessed 20 June 2018

27. Chu C, Gagner M, Quinn T, et al. Two-stage laparoscopic BPD/ DS: an alternative approach to super-super morbid obesity. Surg Endosc. 2002;S187

28. Salminen P, Helmo M, Ovaska J, et al. Effect of laparoscopic sleeve gastrectomy vs laparoscopic Roux-en Y gastric bypass on weight loss at 5 years among patients with morbid obesity: the SLEEVEPASS randomized clinical trial. JAMA. 2018;319(3): 241-54.

29. Brethauer SA, Hammel J, Schauer PR. Systematic review of sleeve gastrectomy as a staging and primary bariatric operation. Surg Obes Relat Dis. 2009;5:469-75.

30. Rosenthal RJ. International Sleeve Gastrectomy Expert Panel. International Sleeve Gastrectomy Expert Panel Consensus Statement: best practice guidelines based on experience of $>12$, 000 cases. Surg Obes Relat Dis. 2012;8(1):8-19.

31. Juodeikis Z, Brimas G. Long-term results after sleeve gastrectomy: a systematic review. Surg Obes Relat Dis. 2017;13(4):693-9.

32. Switzer NJ, Prasad S, Debru E, et al. Sleeve gastrectomy and type 2 diabetes mellitus: a systematic review of long-term outcomes. Obes Surg. 2016;26(7):1616-21.

33. Birkmeyer N, Dimick J, Share D, et al. Hospital complication rates with bariatric surgery in Michigan. JAMA. 2010;304(4):435-42.

34. Alvarenga ES, Lo Menzo E, Szomstein S, et al. Safety and efficacy of 1020 consecutive laparoscopic sleeve gastrectomies performed as a primary treatment modality for morbid obesity. A single-center experience from the metabolic and bariatric surgical accreditation quality and improvement program. Surg Endosc. 2016;30:2673-8.

35. Hendricks L, Alvarenga E, Dhanabalsamy N, et al. Impact of sleeve gastrectomy on gastroesophageal reflux disease in a morbidly obese population undergoing bariatric surgery. Surg Obes Relat Dis. 2016;12(3):511-7.

36. Karcz WK, Marjanovic G, Grueneberger J, et al. Banded sleeve gastrectomy using the GaBP ring - surgical technique. Obes Facts. 2011;4(1):77-80.

37. Alexander JW, Martin Hawver LR, Goodman HR. Banded sleeve gastrectomy — initial experience. Obes Surg. 2009;19:1591-6.

38. Agrawal S, Van DE, Akin F, et al. Laparoscopic adjustable banded sleeve gastrectomy as a primary procedure for the super-super obese (body mass index $>60 \mathrm{~kg} / \mathrm{m}^{2}$ ). Obes Surg. 2010;20:1161-3.

39. Himpens J, Dobbeleir J, Peeters G. Long-term results of laparoscopic sleeve gastrectomy for obesity. Ann Surg. 2010;252:31924.

40. Lauti M, Hill AG, MacCormick AD. Weight regain following sleeve gastrectomy - a systematic review. Obes Surg. 2016;26(6):1326-34.

41. Braghetto I, Cortes C, Herquiñigo D, et al. Evaluation of the radiological gastric capacity and evolution of the BMI 2-3 years after sleeve gastrectomy. Obes Surg. 2009;19(9):1262-9.

42. Weiner RA, Theodoridou S, Weiner S. Failure of laparoscopic sleeve gastrectomy-further procedure? Obes Facts. 2011;4(Suppl 1):42-6. 
43. Campos JM, Lins DC, Silva LB, et al. Metabolic surgery, weight regain and diabetes re-emergence. Arq Bras Cir Dig. 2013;26(Suppl 1):57-62.

44. Karcz WK, Karcz-Socha I, Marjanovic G, et al. To band or not to band - early results of sleeve gastrectomy. Obes Surg. 2014;24: $660-5$.

45. Lemmens L, Van Den Bossche J, Zaveri H, et al. Banded sleeve gastrectomy: better long-term results? A long-term cohort study until 5 years follow-up in obese and superobese patients. Obes Surg. 2018;28(9):2687-95.

46. Fink JM, Hoffmann N, Kuesters S, et al. Banding the sleeve improves weight loss in midterm follow-up. Obes Surg. 2017;27(4): 1098-103.

47. Alamo M, Torres CS, Peez LZ. Vertical isolated gastroplasty with gastro-enteral bypass: Preliminary results. Obes Surg. 2006;16(3): 353-8.

48. de Menezes Ettinger JE, Azaro E, Mello CA, et al. Analysis of the vertical isolated gastroplasty: a new bariatric operation. Obes Surg. 2006;16:1261-3.

49. Huang C-K, Mahendra R, Hsin M-C, et al. Novel metabolic surgery: first Asia series and short-term results of laparoscopic proximal jejunal bypass with sleeve gasrectomy. Ann Laparosc Endosc Surg. 2016;1:37

50. Sepulveda M, Alamo M, Lynch R, et al. Comparison of long-term weight loss between sleeve gastrectomy and sleeve gastrectomy with jejunal bypass. A case-control study. Obes Surg. 2018;

51. Alamo M, Sepulveda M, Gellona J, et al. Sleeve gastrectomy with jejunal bypass for the treatment of type 2 diabetes mellitus in patients with BMI $<35 \mathrm{~kg} / \mathrm{m}^{2}$ : a cohort study. Obes Surg. 2012;22(7):1097-103.

52. Sánchez-Pernaute A, Rubio Herrera MA, Pérez-Aguirre E, et al. Proximal duodenal-ileal end-to-side bypass with sleeve gastrectomy: proposed technique. Obes Surg. 2007;17:1614-8.

53. Sanchez-Pernaute A, Rubio MA, Perez Aguirre E, et al. Singleanastomosis duodeno-ileal bypass with sleeve gastrectomy: metabolic improvement and weight loss in first 100 patients. Surg Obes Relat Dis. 2013;5:731-5.

54. Brown WA, Ooi G, Higa K, et al. Single-anastomosis duodenal ileal bypass with sleeve gastrectomy / one anastomosis duodenal switch (SADI-S/OADS) - IFSO Position Statement. Obes Surg. 2018;28(5):1207-16.

55. Sanchez-Pernaute A, Rubio MA, Conde M, et al. Singleanastomosis duodenoileal bypass with sleeve gastrectomy (SADI-S) for obese diabetic patients. Surg Obes Relat Dis. 2015b;11(5):1092-8.

56. Ramos-Levi AM, Sanchez-Pernaute A, Marcuello C, et al. Glucose variability after bariatric surgery: is prediction of diabetes remission possible? Obes Surg. 2017;27(12):3341-3.

57. Melissas J, Peppe A, Askoxilakis J, et al. Sleeve gastrectomy plus side-to-side jejunoileal anastomosis for the treatment of morbid obesity and metabolic diseases: a promising operation. Obes Surg. 2012;22(7):1104-9.

58. Kasama K, Tagaya N, Kanehira E, et al. Laparoscopic sleeve gastrectomy with duodeno-jejunal bypass: technique and preliminary results. Obes Surg. 2009;19:1341-2.

59. Seki Y, Kasama K, Umezawa A, et al. Laparoscopic sleeve gastrectomy with duodenojejunal bypass for type 2 diabetes mellitus. Obes Surg. 2016;26(9):2035-44.

60. Lee WJ, Almulaifi AM, Tsou JJ, et al. Duodenal-jejunal bypass with sleeve gastrectomy versus the sleeve gastrectomy procedure alone: the role of duodenal exclusion. Surg Obes Relat Dis. 2015;11(4):765-70.

61. Praveen Raj P, Kumaravel R, Chandramaliteeswanran C, et al. Is laparoscopic duodenojejunal bypass with sleeve an effective alternative to Roux en $\mathrm{Y}$ gastric bypass in morbidly obese patients: preliminary results of a randomized trial. Obes Surg. 2012;22: 422-6.

62. Naitoh T, Kasama K, Seki Y, et al. Efficacy of sleeve gastrectomy with duodenal-jejunal bypass for the treatment of obese severe diabetes patients in Japan: a retrospective multicenter study. Obes Surg. 2018;28(2):497-505.

63. Huang CK, Goel R, Tai CM, et al. Novel metabolic surgery for type II diabetes mellitus: loop duodenojejunal bypass with sleeve gastrectomy. Surg Laparosc Endosc Percutan Tech. 2013;23:481-5.

64. Rubino F, Forgione A, Cummings DE, et al. The mechanism of diabetes control after gastrointestinal bypass surgery reveals a role of the proximal small intestine in the pathophysiology of type 2 diabetes. Ann Surg. 2006;244:741-9.

65. Drucker DJ. The role of gut hormones in glucose homeostasis. J Clin Invest. 2007;117:24-32.

66. Huang C-K, Tai C-M, Chang P-C, et al. Loop duodenojejunal bypass with sleeve gastrectomy: comparative study with Rouxen-Y gastric bypass in type 2 diabetic patients with a BMI $<35$ $\mathrm{kg} / \mathrm{m}^{2}$, first year results. Obes Surg. 2016;26:2291-301.

67. Tsai YN, Wang HP, Huang CK, et al. Endoluminal stanting for the management of leak following duodenojejunal bypass with sleeve gastrectomy. Kaohsiung J Med Sci. 2018;34(1):43-8.

68. Santoro S, Velhote MCP, Malzoni CE, et al. Digestive adaptation with intestinal reserve: a new surgical proposal for morbid obesity. Rev Bras Videocir. 2004;2:130-8.

69. Santoro S, Castro LC, Velhote MC, et al. Sleeve gastrectomy with transit bipartition: a potent operation for metabolic syndrome and obesity. Ann Surg. 2012;256(1):104-10.

70. Azevedo FR, Santoro S, Correa-Giannella ML, et al. A prospective randomized controlled trial of the metabolic effects of sleeve gastrectomy with transit bipartition. Obes Surg. 2018;28(10): 3012-19.

71. Yan Y, Sha Y, Gao G, et al. Roux-en-Y gastric bypass vs medical treatment for type 2 diabetes mellitus in obese patients: a systematic review and meta-analysis of randomized controlled trials. Medicine (Baltimore). 2016;95(17):e3462.

72. Koopmans HS, Sclafani A, Fichtner C, et al. The effects of ileal transposition on food intake and body weight loss in VMH-obese rats. Am J Clin Nutr. 1982;35(2):284-93.

73. Gagner M. La Transposition Iléale avec ou sans gastrectomie par laparoscopie chez l'homme (TIG): La troisième génération de chirurgie bariatrique. J Coeliochirurgie. 2005;54:4-10.

74. de Paula AL, Macedo AL, Prudente AS, et al. Laparoscopic sleeve gastrectomy with ileal interposition ("neuroendocrine brake")pilot study of a new operation. Surg Obes Relat Dis. 2006;2(4): 464-7.

75. Cummings PC, Strader DS, Stanhope KI, et al. Ileal interposition surgery improves glucose and lipid metabolism and delays diabetes onset in the ucd-t2dm rat. Gastroenterology. 2010;138: 2437-46.

76. DePaula AL, Stival AR, Halpern A, et al. Surgical treatment of morbid obesity: mid-term outcomes of the laparoscopic ileal interposition associated to a sleeve gastrectomy in 120 patients. Obes Surg. 2011;21(5):668-75.

77. DePaula AL, Stival AR, de Paula CC, et al. Surgical treatment of type 2 diabetes in patients with BMI below 35: mid-term outcomes of the laparoscopic ileal interposition associated with a sleeve gastrectomy in 202 consecutive cases. J Gastrointest Surg. 2012;16(5):967-76.

78. Gagner M, Deitel M, Kalberer TL, et al. The second international summit for sleeve gastrectomy, March 19-21, 2009. Surg Obes Relat Dis. 2009;5:476-85.

79. Podnos YD, Jimenez JC, Wilson SE, et al. Complications after laparoscopic gastric bypass: a review of 3464 cases. Arch Surg. 2003;138:957-61. 
80. Mahdy T, Al Wahedi A, Schou C. Efficacy of single anastomosis sleeve ileal (SASI) bypass for type 2 diabetic morbid obese patients: gastric bipartition, a novel metaboic surgery procedure: a retrospective cohort study. Int J Surg. 2016;34:28-34.

81. Salama TMS, Sabry K, Ghamrini YE. Single anastomosis sleeve ileal bypass: new step in the evolution of bariatric surgeries. J Invest Surg. 2017;30(5):291-6.

82. Thompson CC, Carr-Locke DL, Saltzman J. Peroral endoscopic repair of staple line dehiscence in Roux-en-Y gastric bypass: a less invasive approach [Abstract]. Gastroenterology. 2004;126(4, Suppl 2):A-810.

83. Brethauer SA, Chand B, Schauer PR, et al. Transoral gastric volume reduction as intervention for weight management: 12-month follow-up of TRIM trial. Surg Obes Relat Dis. 2012;8(3):296303.

84. Kumar N, Abu Dayyeh BK, Lopez-Nava Breviere G, et al. Endoscopic sutured gastroplasty: procedure evolution from firstin-man cases through current technique. Surg Endosc. 2018;32(4): 2159-64.

85. Lopez-Nava G, Galvao MP, Bautista-Castaño I. Endoscopic sleeve gastroplasty for obesity treatment: two years of experience. Arq Bras Cir Dig. 2017;30(1):18-20.

86. Sharaiha RZ, Kumta NA, Saumoy M. Endoscopic sleeve gastroplasty significantly reduces body mass index and metabolic complications in obese patients. Clin Gastroenterol Hepatol. 2017;15(4):504-10.

87. Lopez-Nava G, Sharaiha RZ, Vargas EJ, et al. Endoscopic sleeve gastroplasty for obesity: a multicenter study of 248 patients with 24 months follow-up. Obes Surg. 2017;27(10):2649-55.

88. Garcia A, Coll E, Lopez-Nava G, et al. First comparative study between sleeve gastrectomy, laparoscopic greater curvature plication and endoscopic plicated gastroplasty. Surg Obes Relat Dis. 2016;12(7):S59-60.

89. Mason EE, Ito C. Gastric bypass in obesity. Surg Clin North Am. 1967;47:1345-52.

90. Wittgrove AC, Clark GW, Tremblay LJ. Laparoscopic gastric bypass, Roux-en-Y: preliminary report of five cases. Obes Surg. 1994:4:353-7.

91. Griffen WO, Young VL, Stevenson CC. A prospective comparison of gastric and jejunoileal bypass operation for morbid obesity. Ann Surg. 1977;186:500-7.

92. Buckwalter JA. Clinical trial of jejunoileal and gastric bypass for the treatment of obesity: four-year progress report. Am Surg. 1980;46:377-81.

93. Rubino F, Nathan DM, Eckel RH, et al. Delegates of the 2nd Diabetes Surgery Summit. Metabolic surgery in the treatment algorithm for type 2 diabetes: a joint statement by international diabetes organizations. Obes Surg. 2017;27(1):2-21.

94. Kang J, Le QA. Effectiveness of bariatric surgical procedures: a systematic review and network meta-analysis of randomized controlled trials. Medicine. 2017;96(46):e8632.

95. Buchwald H, Avidor Y, Braunwald E, et al. Bariatric surgery: a systematic review and meta-analysis. JAMA. 2004;292:1724-37.

96. Mehaffey J, Hunter MD, LaPar DJ, et al. 10-year outcomes after Roux-en-Y gastric bypass. Ann Surg. 2016;264(1):121-6.

97. Awad W, Garay A, Martinez C. Ten years experience of banded gastric bypass: does it make a difference? Obes Surg. 2012;22: 271-8.

98. Adams TD, Gress RE, Smith SC, et al. Long-term mortality after gastric bypass surgery. N Engl J Med. 2007;357(8):753-61.

99. Riccioppo D, Santo MA, Rocha S. Small-volume, fast-emptying gastric pouch leads to better long-term weight loss and food tolerance after Roux-en-Y gastric bypass. Obes Surg. 2018;28(3):693701.

100. Linner JH, Drew RL. New modification of Roux-en-Y gastric bypass procedure. Clin Nutr. 1986;5:33-7.
101. Drew RL, Linner JH. Revisional surgery for severe obesity with fascia banded stoma Roux-en-Y gastric bypass. Obes Surg. 1992;2(4):349-54

102. Fobi MAL. Banded gastric bypass: combining two principles. Surg Obes Relat Dis. 2005;1:304-9.

103. Capella JF, Capella RF. An assessment of vertical banded gastroplasty-Roux-en-Y gastric bypass for the treatment of morbid obesity. Am J Surg. 2002;183:117-23.

104. Buchwald H, Buchwald JN, McGlennon TW. Systematic review and meta analysis of medium-term outcomes after banded Rouxen-Y gastric bypass. Obes Surg. 2014;29(9):1536-51.

105. Lemmens L. Banded gastric bypass: better long-term results? A cohort study with minimum 5-year follow-up. Obes Surg. 2017;27:864-72.

106. Magro DO, Ueno M, Coelho-Neto J, et al. Long-term weight loss outcomes after banded Roux-en-Y gastric bypass: a prospective 10-year follow-up study. Surg Obes Relat Dis. 2018;14(2018): $910-7$.

107. Arasaki CH, Del Grande JC, Yanagita ET, et al. Incidence of regurgitation after banded gastric bypass. Obes Surg. 2005;15: 1408-17.

108. Fobi M, Lee H, Igwe D, et al. Band erosion: incidence, etiology, management and outcome after banded vertical gastric bypass. Obes Surg. 2001;11(6):699-707.

109. Arceo-Olaiz R, Espana-Gomez MN, Montalvo-Hernandez J, et al. Maximal weight loss after banded and unbanded laparoscopic Roux-en-Y gastric bypass: a randomised controlled trial. Surg Obes Relat Dis. 2008;4:507-11.

110. Rutledge R. The mini-gastric bypass: experience with the first 1272 cases. Obes Surg. 2001;11:276-80.

111. Tacchino RM, Greco F, Matera D, et al. Single-incision laparoscopic gastric bypass for morbid obesity. Obes Surg. 2010;20(8): 1154-60.

112. Kular KS, Manchanda N, Rutledge R. A 6-year experience with 1, 054 mini-gastric bypasses-first study from Indian subcontinent. Obes Surg. 2014;24(9):1430-5.

113. Chevallier JM, Arman GA, Guenzi M, et al. One thousand single anastomosis (omega loop) gastric bypasses to treat morbid obesity in a 7-year period: outcomes show few complications and good efficacy. Obes Surg. 2015;25(6):951-8.

114. Parmar CD, Mahawar KK. One anastomosis (mini) gastric bypass is now an established bariatric procedure: a systematic review of 12,807 patients. Obes Surg. 2018; published online July11

115. Fisher BL, Buchwald H, Clark W, et al. Mini-gastric bypass controversy [Letter]. Obes Surg. 2001;11:773-7.

116. Motamedi MAK, Barzin M, Ebrahimi M, et al. Severe fatal protein malnutrition and liver failure in a morbidly obese patient after mini-gastric bypass surgery: case report. Int J Surg Case Report. 2017:33:71-4.

117. De Luca M, Tie T, Oi G, et al. Obes Surg. 2018;

118. Rutledge R, Walsh W. Continued excellent results with the minigastric bypass: six-year study in 2,410 patients. Obes Surg. 2005;15(9):1304-8.

119. Lee WJ, Ser K-H, Lee Y-C, et al. Laparoscopic Roux-en-Y vs. minigastric bypass for the treatment of morbid obesity: a 10-year experience. Obes Surg. 2012;22:1827-34.

120. Lee WJ, Yu PJ, Wang W, et al. Laparoscopic Roux-en-Y versus minigastric bypass for the treatment of morbid obesity. Ann Surg. 2005;242:20-8.

121. Wang W, Wei PL, Lee YC, et al. Short-term results of laparoscopic mini-gastric bypass. Obes Surg. 2005;15:648-54.

122. Noun R, Skaff J, Riachi E, et al. One thousand consecutive minigastric bypass: short and long-term outcome. Obes Surg. 2012;22(5):697-703.

123. Jammu GS. Sharma R2. A 7-year clinical audit of 1107 cases comparing sleeve gastrectomy, Roux-en-Y gastric bypass, and 
mini-gastric bypass, to determine an effective and safe bariatric and metabolic procedure. Obes Surg. 2016;26:926-32.

124. Lee WJ, Wang W, Lee YC, et al. Laparoscopic mini-gastric bypass: experience with tailored bypass limb according to body weight. Obes Surg. 2008;18:294-9.

125. Ribeiro R, Guerra A, Viveiros O. (Chapter) Diverted MGB: a new procedure. In: Deitel M, editor. Essentials of mini - one anastomosis gastric bypass. New York: Springer; 2018. p. 327-42.

126. De Luca M, Himpens J, Angrisani L, et al. A new concept in bariatric surgery. Single anastomosis gastro-ileal (SAGI): technical details and preliminary results. Obes Surg. 2017;27(1):143-7.

127. Brown W, O'Brien PE. The band must not be abandoned. Obes Surg. 2017;27:1911-3.

128. O'Brien PE, MacDonald L, Anderson M, et al. Long-term outcomes after bariatric surgery: fifteen-year follow-up of adjustable gastric banding and a systematic review of the bariatric surgical literature. Ann Surg. 2013;257:87-94.

129. Dixon JB, O'Brien PE. Bariatric surgery provides unparalleled metabolic benefits. Obes Surg. 2007;17:193-4.

130. Ibrahim AM, Thumma JR, Dimick JB. Reoperation and medicare expenditures after laparoscopic gastric band surgery. JAMA Surg. 2017;152(9):835-42.

131. Wentworth JM, Cheng C, Laurie C, et al. Diabetes outcomes more than a decade following sustained weight loss after laparoscopic adjustable gastric band surgery. Obes Surg. 2018;28:982-9.

132. Dumont PN, Blanchet MC, Gignoux B, et al. Medium- to longterm outcomes of gastric banding in adolescents: a single-center study of 97 consecutive patients. Obes Surg. 2018;28(1):285-9.

133. Giet L, Baker J, Favretti F, et al. Medium and long-term results of gastric banding: outcomes from a large private clinic in UK. BMC Obes. 2018;5:12-7.

134. Ooi GJ, Doyle L, Tie T, et al. Weight loss after laparoscopic adjustable gastric band and resolution of the metabolic syndrome and its components. Int J Obes. 2017;41(6):902-8.

135. Mistry P, Currie V, Super P, et al. Changes in glycaemic control, blood pressure and lipids 5 years following laparoscopic adjustable gastric banding combined with medical care in patients with type 2 diabetes: a longitudinal analysis. Clin Obes. 2018;8(3): $151-8$.

136. Sartori A, de Luca M, Clemente M, et al. Complications of laparoscopic gastric banding: detection and treatment. Ann Ital Chir. 2017;88:206-14.

137. Vinzens F, Kilchenmann A, Zumstein V, et al. Long-term outcome of laparoscopic adjustable gastric banding (LAGB): results of a Swiss single-center study of 405 patients with up to 18 years' follow-up. Surg Obes Relat Dis. 2017;13(8):1313-9.

138. Scopinaro N, Gianetta E, Civalleri D, et al. Biliopancreatic bypass for obesity: II. Initial experience in man. Br J Surg. 1979;66: 618-20.

139. Scopinaro N, Gianetta E, Civalleri D, et al. Long-term clinical and functional impact of biliopancreatic diversion on type 2 diabetes in morbidly and non-morbidly obese patients. Surg Obes Relat Dis. 2016;12(4):822-7.

140. Sethi M, Chau E, Youn A, et al. Long-term outcomes after biliopancreatic diversion with and without duodenal switch: 2-, 5-, and 10-year data. Surg Obes Relat Dis. 2016;12:1697-705.

141. Anderson B, Gill RS, de Gara CJ, et al. Biliopancreatic divesion: the effectiveness of duodenal switch and its limitations. Gastroenterol Res Pract. 2013:974762. 8 pages

142. Scopinaro N, Marinari GM, Camerini GB, et al. Specific effects of biliopancreatic diversion on the major components of metabolic syndrome: a long-term follow-up study. Diabetes Care. 2005;28(10):2406-11.

143. Cossu ML, Meloni GB, Alagna S, et al. Emergency surgical conditions after biliopancreatic diversion. Obes Surg. 2007;17(5): $637-41$
144. Topart PA, Becouam G. Revision and reversal after biliopancreatic diversion for excessive side effects or ineffective weight loss: a review of the current literature on indications and procedures. Surg Obes Relat Dis. 2015;11(4):965-72.

145. DeMeester TR, Fuchs KH, Ball CS, et al. Experimental and clinical results with proximal end-to-end duodenjejunostomy for pathologic duodenogastric reflux. Ann Surg. 1987;206:414-24.

146. Hess DS, Hess DW. Biliopancreatic diversion with a duodenal switch. Obes Surg. 1998;8:267-82.

147. Marceau P, Biron S, St-Georges R, et al. Biliopancreatic diversion with gastrectomy as surgical treatment of morbid obesity. Obes Surg. 1991;1:381-7.

148. Marceau P, Hould FS, Simard S, et al. Biliopancreatic diversion with duodenal switch. World J Surg. 1998;22(9):947-54.

149. Ren CJ, PAtterson E, Gagner M. Early results of laparoscopic biliopancreatic diversion with duodenal switch: a case series of 40 consecutive patients. Obes Surg. 2000;10(6):514-23. discussion 524

150. Buchwald H, Estok R, Fahrbach K, et al. Weight and type 2 diabetes after bariatric surgery: systematic review and meta-analysis. Am J Med. 2009;122(3):248-56.

151. Ballesteros-Pomar M, González de Francisco T, Urioste-Fondo A, et al. Biliopancreatic diversion for severe obesity: long-term effectiveness and nutritional complications. Obes Surg. 2016;26: $38-44$.

152. Marceau P, Biron S, Marceau S, et al. Long-term metabolic outcomes 5 to 20 years after biliopancreatic diversion. ObesSurg. 2015;25(9):1584-93.

153. Yu J, Zhou X, Li L, et al. The long-term effects of gariatric surgery for type 2 diabetes: systematic review and meta-analysis of randomized and non-randomized evidence. Obes Surg. 2015;25:14358.

154. Buchwald H, Estok R, Fahrbach K, et al. Trends in mortality in bariatric surgery: a systematic review and meta-analysis. Surgery. 2007;142(4):621-35.

155. Biertho L, Lebel S, Marceau S, et al. Perioperative complications in a consecutive series of 1000 duodenal switches. Surg Obes Relat Dis. 2013;9(1):63-8.

156. Hamoui N, Chock B, Anthone GJ, et al. Revision of the duodenal switch: indications, technique, and outcomes. J Am Coll Surg. 2007;204(4):603-8.

157. Garcia-Granero E, Navarro F, Cerdan Santacruz C, et al. Individual surgeon is an independent risk factor for leak after double-stapled colorectal anastomosis: an institutional analysis of 800 patients. Surgery. 2017;162(5):1006-16.

158. Meshkinpour H, Hsu D, Farivar S. Effect of gastric bubble as a weight reduction device: a controlled, crossover study. Gastroenterology. 1988;95:589-92.

159. Tsesmeli N, Coumaros D. Review of endoscopic devices for weight reduction: old and new balloons and implantable prostheses. Endoscopy. 2009;41(12):1082-9.

160. Nguyen N, Champion JK, Ponce J, et al. A review of unmet needs in obesity management. Obes Surg. 2012;22(6):956-66.

161. Abu Dayyeh BK, Kumar N, Edmundowicz SA, et al. ASGE Bariatric Endoscopy Task Force systematic review and metaanalysis assessing the ASGE PIVI thresholds for adopting endoscopic bariatric therapies. Gastroint Endosc. 2015;82:425-38 e5.

162. Vargas EJ, Rizk M, Bazerbachi F, et al. Medical devices for obesity treatment: endoscopic bariatric therapies. Med Clin North Am. 2018;102(1):149-63.

163. Al-Sabah S, Al-Marri F, Vaz JD. Intragastric balloon as a bridge procedure in patients with high body mass index. Surg Obes Relat Dis. 2016;12:1900-1.

164. Abu Dayyeh BK, Edmundowicz S, Thompson CC. Clinical practice update: expert review on endoscopic bariatric therapies. Gastroenterology. 2017;152:716-29. 
165. Melissas J, Mouzas J, Filis D, et al. The intragastric balloonsmoothing the path to bariatric surgery. Obes Surg. 2006;16: 897-902.

166. Keren D, Rainis T. Intragastric balloons for overweight populations-1 year post removal. Obes Surg. 2018;28(8): 2368-73.

167. Courcoulas A, Abu Dayyeh BK, Eaton L, et al. Intragastric balloon as an adjunct to lifestyle intervention: a randomized controlled trial. Int J Obes (Lond). 2017;41:427-33.

168. Ponce J, Woodman G, Swain J, et al. The REDUCE pivotal trial: a prospective, randomized controlled pivotal trial of a dual intragastric balloon for the treatment of obesity. Surg Obes Relat Dis. 2015;11:874-81.

169. Popov VB, Ou A, Schulman AR, et al. The impact of intragastric balloons on obesity-related co-morbidities: a systematic review and meta-analysis. Am J Gastroenterol. 2017;112:429-39.

170. Tate CM, Geliebter A. Intragastric balloon treatment for obesity: review of recent studies. Adv Ther. 2017;34(8):1859-75.

171. Genco A, Maselli R, Frangella F, et al. Intragastric balloon for obesity treatment: results of a multicentric evaluation for balloons left in place for more than 6 months. Surg Endosc. 2015;29(8): 2339-43.

172. Cigaina VV, Saggioro A, Rigo VV, et al. Long-term effects of gastric pacing to reduce feed intake in swine. Obes Surg. 1996:6:250-3.

173. Shikora SA. What are the Yanks doing? The U.S. experience with implantable gastric stimulation (IGS®) for the treatment of obesity. Update on the ongoing clinical trials. Obes Surg. 2004;14:S40-8.

174. Kral JG, Gortz L. Truncal vagotomy in morbid obesity. Int J Obes. 1981;5(4):431-5.

175. Camilleri M, Toouli J, Herrera MF, et al. Intra-abdominal vagal blocking (VBLOC therapy): clinical results with a new implantable medical device. Surgery. 2008;143(6):723-31.

176. Sarr MG, Billington CJ, Brancatisano R, et al. The EMPOWER study: randomized, prospective, double-blind, multicenter trail of vagal blockade to induce weight loss in morbid obesity. Obes Surg. 2012;(11):1771-82.

177. Ikramuddin S, Blackstone RP, Brancatisano A, et al. Effect of reversible intermittent intra-abdominal vagal nerve blockade on morbid obesity: the ReCharge randomized, clinical trial. JAMA. 2014;312:915-22.

178. Shikora SA, Wolfe BM, Apovian CM, et al. Sustained weight loss with vagal nerve blockade but not with sham: 18-month results of the ReCharge trial. J Obesity. 2015; https://doi.org/10.1155/2015/ 365604

179. Shikora SA, Toouli J, Herrera MF, et al. Intermittent vagal nerve block for improvements in obesity, cardiovascular risk factors, and glycemic control in patients with type 2 diabetes mellitus: two-year results of the vBLOC DM2 study. Obes Surg. 2016;26: $1021-8$

180. Morton JM, Shah SN, Wolfe BM, et al. Effect of vagal nerve blockade on moderate obesity with an obesity related co-morbid condition: the ReCharge Study. Obes Surg. 2016;26(5):983-9.

181. Apovian CM, Shah SN, Wolfe BM, et al. Two-year outcomes of vagal nerve blocking (vBloc) for the treatment of obesity in the ReCharge trial. Obes Surg. 2017;27(1):169-76.

182. Timossi G, Madonia G. Gigantic gastric plication simulating a neoplasm of the stomach. Ann Radiol Diagn (Bologna). 1960;33:486-93.

183. Fried M, Doležalová K, Buchwald JN, et al. Laparoscopic greater curvature plication (LGCP) for treatment of morbid obesity in a series of 244 patients. Obes Surg. 2012;22:1298-307.

184. Talebpour M, Motamedi SM, Talebpour A, et al. Twelve year experience of laparoscopic gastric plication in morbid obesity: development of the technique and patient outcomes. Ann Surg Innov Res. 2012;6:7.

185. Doležalová-Kormanová K, Buchwald JN, et al. Five-year outcomes: laparoscopic greater curvature plication for treatment of morbid obesity. Obes Surg. 2017;27(11):2818-28.

186. Ji W, Wang Y, Zhu J, et al. A systematic review of gastric plication for the treatment of obesity. Surg Obes Relat Dis. 2014;10(6):122-32.

187. Talebpour M, Talebpour A, Barzin G, et al. Effects of laparoscopic gastric plication (LGP) in patients with type 2 diabetes, one year follow-up. J Diabetes Metab Disord. 2015;14:60.

188. Kourkoulos M, Giorgakis E, Kokkinos C, et al. Laparoscopic gastric plication for the treatment of morbid obesity: a review. Minim Invasive Surg. 2012;2012:696348.

189. Talebpour M, Sadid D, Talebpour A, et al. Comparison of shortterm effectiveness and postoperative complications: laparoscopic gastric plication vs laparoscopic sleeve gastrectomy. Obes Surg. 2018;28(4):996-1001.

190. Huang CK, Asim S, Lo CH. Augmenting weight loss after laparoscopic adjustable gastric banding by laparoscopic gastric plication. Surg Obes Relat Dis. 2011;7:235-6.

191. Huang CK, Lo CH, Shabbir A, et al. Novel bariatric technology: laparoscopic adjustable gastric banded plication: technique and preliminary results. Surg Obes Relat Dis. 2012;8:41-7.

192. Huang CK, Chhabra N, Goel R, et al. Laparoscopic adjustable gastric banded plication: a case-matched comparative study with laparoscopic sleeve gastrectomy. Obes Surg. 2013;23(8):1319-23.

193. Chaudhry UI, Osayi SN, Suzo AJ, et al. Laparoscopic adjustable gastric banded plication: case-matched study from a single U.S. center. Surg Obes Relat Dis. 2015;11:119-24.

194. Ahluwalia JS, Chang PC, Tai CM, et al. Comparative study between laparoscopic adjustable gastric banded plication and sleeve gastrectomy in moderate obesity -2 year results. Obes Surg. 2016;26:552-7.

195. Cottam A, Cottam D, Zaveri H, et al. Adjustable gastric banded plication versus sleeve gastrectomy: the role of gastrectomy in weight loss. Surg Obes Relat Dis. 2018;14:780-4.

196. Rubino F, Marescaux J. Effect of duodenal-jejunal exclusion in a non-obese animal model of type 2 diabetes: a new perspective for an old disease. Ann Surg. 2004;239(1):1-11.

197. Aguirre V, Stylopoulos N, Grinbaum R, et al. An endoluminal sleeve induces substantial weight loss and normalizes glucose homeostasis in rats with diet-induced obesity. Obesity (Silver Spring). 2008;16(12):2585-92.

198. Rodriguez L, Reyes E, Fagalde P, et al. Pilot clinical study of an endoscopic, removable duodenal-jejunal bypass liner for the treatment of type 2 diabetes. Diabetes Technol Ther. 2009;11(11):725-32.

199. Patel SR, Hakim D, Mason J, et al. The duodenal-jejunal bypass sleeve (EndoBarrier Gastrointestinal Liner) for weight loss and treatment of type 2 diabetes. Surg Obes Relat Dis. 2013;9(3): $482-4$.

200. Escalona A, Pimentel F, Sharp A, et al. Weight loss and metabolic improvement in morbidly obese subjects implanted for 1 year with an endoscopic duodenal-jejunal bypass liner. Ann Surg. 2012;255(6):1080-5.

201. Rhode U, Hedback N, Gluud LL, et al. Effects of the EndoBarrier Gastrointestinal Liner on obesity and type 2 diabetes: a systematic review and meta-analysis. Diabetes Obes Metab. 2016;18(3):300-5.

202. Jirapinyo P, Haas AV, Thompson CC. Effect of the duodenaljejunal bypass liner on glycemic control in type- 2 diabetic patients with obesity: a meta-analysis with secondary analysis on weight loss and hormonal changes. Diabetes Care. 2018;41(5):1106-15.

203. Riedel N, Laubner K, Lautenbach A, et al. Trends in BMI, glycemic control and obesity-associated comorbidities after 
explantation of the duodenal-jejunal bypass liner (DJBL). Obes Surg. 2018;28(8):2187-96.

204. Koehestanie P et al. Is reimplantation of the duodenal-jejunal bypass liner feasible? Surg Obes Relat Dis. 2015;11(5):1099-104.

205. Kumar K, Sullivan S, Thompson CC. The role of endoscopic therapy in obesity management: intragastric balloons and aspiration therapy. Diabet Met Syn Obes Targets Ther. 2017;10:311-6.

206. FDA. Summary of safety and effectiveness data AspireAssist. In: Health CfDaR; 2016. Accessible at: https://www.accessdata.fda. gov/scripts/cdrh/cfdocs/cfPMA/pma.cfm?id=P150024

207. Sullivan S, Stein R, Jonnalagadda S, et al. Aspiration therapy leads to weight loss in obese subjects: a pilot study. Gastroenterology. 2013;145(6): 1245-52 e1-5.

208. Thompson CC, Abu Dayyeh BK, Kushner K, et al. The AspireAssist is an effective tool in the treatment of class II and class III obesity: results of a one-year clinical trial. Gastroenterology. 2016;4(Suppl 1):S86.

209. Machytka E, Forssell H, Alberto Testoni P, et al. Aspiration therapy as a tool to treat obesity: one to four year results in a 160 patient multi-center post-market registry study. Surg Obes Relat Dis. 2017;13(10):S57-S.

210. Forssell H, Norén E. A novel endoscopic weight loss therapy using gastric aspiration: results after 6 months. Endoscopy. 2015;47(1):68-71.
211. Brethauer S, Kim J, el Chaar M, et al. ASMBS Clinical Issues Committee. Standardized outcomes reportin in metabolic and bariatric surgery. Obes Surg. 2015;25:587-606.

212. Madan AK, Harper JL, Tichansky DS. Techniques of laparoscopic gastric bypass: on-line survey of American Society for Bariatric Surgery practicing surgeons. Surg Obes Relat Dis. 2008;4:16673.

213. Abdel-Galil E, Sabry AA. Laparoscopic Roux-en-Y gastric bypass - evaluation of three different techniques. Obes Surg. 2002;12:639-42.

214. Lauti M, Lemanu D, Zeng ISK, et al. Definition determines weight regain outcomes after sleeve gastrectomy. Surg Obes Relat Dis. 2017;13(7):1123-9.

215. Hasson F, Keeney S, McKenna H. Research guidelines for the Delphi survey technique. J Adv Nurs. 2000;32:1008-15.

216. Kaijser MA, van Ramshorst GH, Emous M, et al. A Delphi consensus of the crucial steps in gastric bypass and sleeve gastrectomy procedures in the Netherlands. Obes Surg. 2018;28(9):2634-43.

Publisher's Note Springer Nature remains neutral with regard to jurisdictional claims in published maps and institutional affiliations. 